Tesis doctoral:

\title{
Traumatismo \\ craneoencefálico leve \\ pediátrico en Europa
}

Presentada por Marta Arribas Arceredillo

Dirigida por el Dr. Roberto Velasco Zúñiga

\section{Universidad de Valladolid}

Facultad de Medicina

Departamento de pediatría e inmunología, ginecología y obstetricia, nutrición y bromatología, psiquiatría e historia de la ciencia 



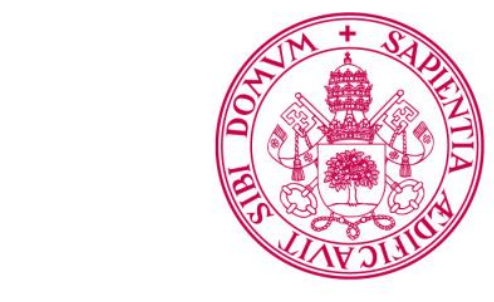

Universidad deValladolid

CIENCIAS DE LA SALUD

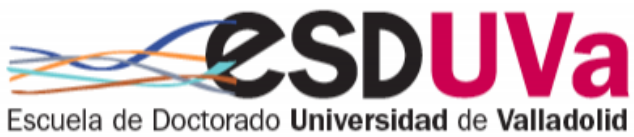

Escuela de Doctorado Universidad de Valladolid

PROGRAMA DE DOCTORADO EN INVESTIGACIÓN EN

TESIS DOCTORAL:

\section{TRAUMATISMO CRANEOENCEFÁLICO LEVE PEDIÁTRICO EN EUROPA}

Presentada por Marta Arribas Arceredillo para optar al grado de doctora por la Universidad de Valladolid

Dirigida por:

Dr. Roberto Velasco Zúñiga

Año 2018 



\section{AUTORIZACIÓN DEL DIRECTOR DE TESIS}

(Art. 2.1. c de la Normativa para la presentación y defensa de la Tesis Doctoral en la $U V a$ )

D. Roberto Velasco Zúñiga, con D.N.I. n¹2408069Y, profesor asociado del departamento de Pediatría de la Universidad de Valladolid; con dirección a efecto de notificaciones en C/Pisuerga $73^{\circ}$ B (47140- Laguna de Duero) y e-mail robertovelascozuniga@gmail.com, como Director de la Tesis Doctoral titulada “Traumatismo craneoencefálico leve pediátrico en Europa”, presentada por D Marta Arribas Arceredillo alumna del programa de doctorado: Investigación en Ciencias de la Salud, autoriza la presentación de la misma, considerando que el presente trabajo reúne, las condiciones de originalidad y rigor metodológico necesarios para que pueda ser leído y defendido públicamente ante el Tribunal correspondiente.

Valladolid, 29 de Enero de 2018

El Director de la Tesis,

Fdo.: Roberto Velasco Zúñiga 



\section{AUTORIZACIÓN DEL TUTOR DE TESIS}

(Art. 2.1. c de la Normativa para la presentación y defensa de la Tesis Doctoral en la $U V a$ )

D. Jose Schneider Fontan, con D.N.I. n⿳13780864T, profesor del departamento de Neurociencias y Farmacología de la Universidad de Valladolid; con dirección a efecto de notificaciones en c/Estambul, 7, portal4, bajoC (28922 Alcorcón) y e-mail jose.schneider@uva.es, como Tutor de la Tesis Doctoral titulada "Traumatismo craneoencefálico leve pediátrico en Europa", presentada por $D^{\mathbf{a}}$ Marta Arribas Arceredillo, alumna del programa de doctorado: Investigación en Ciencias de la Salud autoriza la presentación de la misma, considerando que el presente trabajo reúne, las condiciones de originalidad y rigor metodológico necesarios para que pueda ser leído y defendido públicamente ante el Tribunal correspondiente.

Valladolid, 29 de Enero de 2018

El Tutor de la Tesis,

Fdo.: Dr. Schneider Fontan 



\section{AGRADECIMIENTOS}

Deseo expresar mi más sincero agradecimiento a Rober quien, además de transmitirme su vocación investigadora, me ha orientado, ayudado y estimulado constante y directamente en todos los aspectos de la tesis durante estos años. Agradecerle la plena confianza que siempre me ha demostrado así como la dedicación y la atención que en todo momento me ha ofrecido.

Igualmente a todos los profesionales que han trabajado en la recogida de datos y que han hecho factible este trabajo doctoral.

Mi inmensa gratitud a mi familia y a Joseba, cuyo apoyo incondicional a lo largo de este trayecto ha sido fundamental para llegar a buen puerto.

Por último, dar las gracias a tantas personas amigas y compañeras de trabajo que de un modo u otro han respaldado este esfuerzo. 
"Nunca te entregues ni te apartes junto al camino, nunca digas no puedo más, aquí me quedo.

Otros esperan que resistas, que les ayude tu alegría, tu canción entre sus canciones.

Entonces siempre acuérdate de lo que un día yo escribí pensando en ti como ahora pienso”.

Palabras para Julia (José Agustín Goytisolo) 


\section{RESUMEN}

El traumatismo craneal leve (TCEL) pediátrico es un motivo de consulta habitual en los servicios de urgencias. Aunque generalmente la evolución es satisfactoria, es causa de numerosas hospitalizaciones y de una mortalidad importante y genera un coste económico y social considerable.

Pese a lo frecuente de la enfermedad hay multitud de protocolos, diagnósticos y guías de manejo distintos.

Estas diferencias en el manejo se acentúan según aumenta la complejidad del caso y vienen determinadas por las costumbres locales, las prácticas institucionales habituales, la accesibilidad a las pruebas diagnósticas, la experiencia de los facultativos y la presión parental.

Estudios previos realizados en EEUU y Canadá han mostrado una gran variabilidad en el uso de las pruebas de imagen en pacientes con TCEL, con evidencia de una menor proporción de las mismas realizadas en las Urgencias Pediátricas frente a los Servicios de Urgencias Generales (1-4). Hasta este momento no se ha publicado ningún trabajo que evalúe esta variabilidad en Europa.

El objetivo del presente trabajo ha sido estudiar las características de los pacientes pediátricos con TCEL así como el manejo que se realiza en distintos centros hospitalarios de diversos países europeos. 


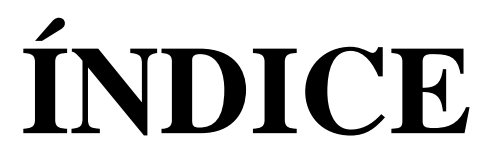




\section{INTRODUCCIÓN}

1.1. Definición 21

1.2. Epidemiología 24

1.3. Anatomía 30

1.3.1. Anatomía craneal en niños 33

1.4. Fisiopatología 35

1.4.1. Daño cerebral primario 38

1.4.2. Daño cerebral secundario 41

14.3. Daño cerebral terciario $\quad 42$

1.5. Aspectos clínicos 43

1.6. Clasificación 50

1.6.1. Compromiso neurológico 50

1.6.2. Tipo de lesión encefálica 51

1.6.3. Integridad sobre las cubiertas meníngeas $\quad 52$

1.6.4. Tipo de fractura 53

1.7. Escalas de valoración 55

1.8. Manejo del traumatismo craneoencefálico leve 59

1.8.1. Evaluación inicial $\quad 60$

1.8.2. Evaluación secundaria 68

1.9. Aproximación diagnóstica 71

1.9.1. Pruebas de imagen 72

1.9.2. Pruebas de laboratorio 90

1.10. Guías de práctica clínica 95

1.10.1. PECARN 97

1.10.2. CHALICE 104

1.10.3. CATCH 106

1.10.4. AEP 108

1.11. Variabilidad del manejo 117

2. JUSTIFICACIÓN 121 
4. MATERIAL Y MÉTODOS 131

4.1. Diseño del estudio 133

4.2. Desarrollo del estudio 137

4.3. Análisis estadístico 138

4.4. Tamaño muestral 138

4.5. Declaración de intereses 139

4.6. Aprobación institucional 139

5. RESULTADOS 141

5.1. Datos generales 144

5.2. Anamnesis 151

5.3. Exploración física 154

5.4. Pruebas complementarias 157

5.5. Manejo y destino 163

5.6 Análisis de la variabilidad 167

6. DISCUSIÓN 173

7. CONCLUSIONES 181

8. BIBLIOGRAFÍA 185

9. ANEXOS 207

9.1. Glosario de términos 209

9.2. Niveles de evidencia 211

9.3. Encuesta de inclusión en cada hospital 212

9.4. Hoja de recogida de datos 214

9.5. Aprobación del Comité Ético de Investigación 216

Científica 


\section{INTRODUCCIÓN}




\section{INTRODUCCIÓN}

\subsection{DEFINICIÓN}

\section{Definición de traumatismo craneoencefálico (TCE)}

El traumatismo craneoencefálico se define como cualquier lesión directa producida por fuerzas mecánicas que actúan sobre el encéfalo o alguna de sus cubiertas, que se presenta como consecuencia del efecto mecánico provocado por un agente físico externo y que puede originar un deterioro funcional del contenido craneal. Esta definición incorpora el código S06 (traumatismo craneal) del CIE 10 (5).

Otra definición aceptada de TCE es cualquier lesión del conjunto craneoencefálico no congénita ni degenerativa producida por una fuerza mecánica. En ocasiones se asocia a síntomas o signos atribuibles al traumatismo tales como alteraciones del nivel de consciencia, amnesia, cualquier otra alteración neurológica o neuropsicológica, fractura craneal, lesión intracraneal o la muerte del paciente (6).

Según la Brain Injury Association of America (2011) un TCE se define como una fuerza externa que altera la función del cerebro o existe evidencia de patología cerebral (7).

En definitiva, existen múltiples definiciones posibles de TCE, siendo todas ellas válidas. 


\section{Definición de traumatismo craneoencefálico leve (TCEL)}

A pesar de la frecuencia del trauma craneal, no existe una definición universalmente aceptada para el traumatismo craneoencefálico leve (TCEL) y continúa existiendo controversia en cuanto a lo que constituye un TCEL, siendo muestra de ello la variabilidad existente entre diversos autores a la hora de definir el TCEL.

Glasgow y McGovern determinan que el TCEL es debido a un mecanismo no violento en un paciente consciente, sin hallazgos neurológicos en la exploración, vómitos ni fractura craneal (8). Davis y Quayle catalogan el TCE como leve cuando la puntuación en la Escala de Coma de Glasgow (GCS) es entre 13 y 15 puntos sin déficit neurológico en la exploración $(9,10)$. Lavelle y Shaw puntualizan que el TCEL es cuando la GCS es mayor de 12 puntos con pérdida de consciencia o amnesia y el TCE es mínimo cuando la GCS es de 15 puntos sin pérdida de consciencia, amnesia, crisis convulsiva, focalidad neurológica ni otros síntomas persistentes (11).

La definición de TCEL propuesta por la Organización Mundial de la Salud (OMS) en la sección de la World Health Organization Collaborating Center Task Force on Mild Traumatic Brain Injury, muy similar a la desarrollada por el Mild Traumatic Brain Injury Committee of the Head Injury Interdisciplinary Special Interest Group of the American Congress of Rehabilitation Medicine en el año 1993, es la siguiente: «el TCEL es una lesión cerebral aguda resultado de la energía mecánica ejercida a la cabeza por fuerzas físicas externas».

Los criterios para la identificación clínica incluyen uno o más de los siguientes:

a) confusión o desorientación, pérdida de consciencia menor de 30 minutos, amnesia postraumática menor de 24 horas y/o otras alteraciones neurológicas transitorias como la focalidad neurológica, convulsiones o lesión intracraneal.

b) GCS de 13-15 puntos a los 30 minutos del traumatismo o en el momento de la atención sanitaria, si es más tardía.

A su vez, estas manifestaciones clínicas de TCEL no deben ser producidas por efectos del alcohol, drogas, medicación, por lesiones o tratamiento de otras lesiones (faciales, sistémicas o intubación), ni por patología de índole psicológica $(12,13)$. 
Esta definición que propone el grupo de trabajo de trauma craneal de la OMS, similar a la definición de TCEL ofrecida por el Centro de Control y Prevención de Enfermedades de Estados Unidos (CDC), es hoy en día aceptada y utilizada por la comunidad científica tanto para el uso clínico como en investigación (14).

A la hora de valorar a un niño que ha sufrido un TCE conviene tener en cuenta la edad del paciente. Por ello, en la práctica clínica es más oportuno proponer una definición del concepto de TCEL según la edad, debido a las diferencias en mecanismos y formas de presentación.

Esencialmente se define de manera separada en menores y mayores de dos años por varios motivos: la valoración clínica es más dificultosa; los lactantes con lesión intracraneal (LIC) están con frecuencia asintomáticos en el momento de ser atendidos; las fracturas o las lesiones intracraneales clínicamente importantes (LICci) en ocasiones ocurren a pesar de traumatismos menores y las lesiones infligidas son más frecuentes $(15,16)$. Los expertos definen el TCEL en este grupo de pacientes como una historia o signos físicos de traumatismo en cráneo, encéfalo o cuero cabelludo en lactante o niño consciente que responde a estímulos verbales o al tacto ligero (17).

Se ha tomado como definición de TCEL la propuesta por la Pediatric Emergency Care American Research Network (PECARN), que define el TCEL como «historia o signos físicos de traumatismo en cráneo, encéfalo o cuero cabelludo en lactante o niño consciente que responde a estímulos verbales o al tacto con una CGS $\geq 14$ » (17).

La diferencia entre TCEL y TCE trivial o mínimo presenta dudas para muchos profesionales y autores, constituyendo un aspecto relevante al tratarse de supuestos que precisan manejos diferentes.

En el TCE trivial, la GCS es de 15 puntos, el paciente se encuentra asintomático y el mecanismo de lesión es de poco impacto como caídas desde bipedestación o corriendo o traumatismos contra objetos estacionarios $(10,18)$.

Por otra parte, la LICci se define como aquellos casos con LIC constatada en una prueba de imagen en los que además se produce al menos una de las siguientes circunstancias: fallecimiento por el TCE, intervención neuroquirúrgica, intubación durante más de 24 horas o ingreso hospitalario durante más de 48 horas. 


\subsection{EPIDEMIOLOGÍA}

El traumatismo craneoencefálico es un problema sanitario de primer orden y el TCE infantil es un motivo muy frecuente de consulta en urgencias. Como señalan Lacerda-Gallardo y Abreu-Pérez, cualquier problema de salud puede considerarse como prioritario si ocurre con frecuencia o si es muy grave (8). Por lo tanto, actualmente, el TCEL infantil puede considerarse un importante problema de Salud Pública. A la vez que se investiga y mejora el manejo del traumatismo, es primordial un conocimiento epidemiológico profundo obtenido mediante la elaboración de registros que permitan establecer políticas de prevención adecuadas.

El TCE es el traumatismo más frecuente en la edad pediátrica ya sea de forma aislada o como parte de un politraumatismo. Representa un porcentaje considerable de los accidentes infantiles, supone un problema habitual en los servicios de urgencias pediátricos y aunque generalmente es leve, es la primera causa de mortalidad entre los niños de uno a catorce años (16). Además, la morbilidad asociada es significativa, ya que también pueden producirse secuelas graves, todavía no bien conocidas, en el aspecto neuropsicológico que generan un gran coste social y económico (19).

Se estima que uno de cada diez niños sufrirá un TCE no banal a lo largo de la infancia. Por otra parte, se considera que la mortalidad de los traumatismos es dos veces mayor en niños menores de doce meses que en el resto de edades pediátricas (20).

$\mathrm{Su}$ incidencia varía según las distintas zonas del mundo. En los países desarrollados, en concreto en los Estados Unidos (EEUU) y en Europa actualmente constituye la primera causa de muerte e incapacidad en la población pediátrica en mayores de un año (21).

La ausencia de consenso a la hora de definir y clasificar el TCE, acompañada de las discrepancias en los datos recogidos, dificulta hablar de epidemiología del TCE de forma precisa. Los problemas en recopilación de datos incluyen, entre otros, el número considerable pacientes con TCEL que bien no consultan en los servicios de 
urgencias, o en los que no se dispone de la correspondiente documentación clínica (22).

Luego veremos la clasificación de TCE con las definiciones de TCE leve, moderado y grave, pero se calcula que la incidencia de TCE leve es de 131 casos por 100000 habitantes, de TCE moderado 15 casos por 100000 habitantes y de TCE grave de 14 casos por 100000 habitantes (22).

En EEUU la prevalencia de TCE no está estrictamente documentada ya que la mayoría de TCE no precisan hospitalización.

Los datos publicados por los Centros para el Control y la Prevención de Enfermedades o Centers for Disease Control and Prevention National Center for Injury Prevention and Control estiman que en EEUU en el año 2010 se produjeron aproximadamente 2,5 millones de atenciones médicas por TCE aislado o asociado a otras lesiones, incluyendo 2,2 millones de visitas a urgencias, más de 50000 fallecimientos y más de 280000 hospitalizaciones (23). En los últimos años, las visitas a los servicios de urgencias de Pediatría (SUP) por TCE se han incrementado en un $70 \%$, los ingresos hospitalarios han aumentado un $11 \%$ mientras que la mortalidad ha descendido un $7 \%$.

Se producen al año aproximadamente 300000 TCEL relacionados con el deporte con un incremento del $57 \%$ los últimos 10 años, siendo el fútbol americano la causa del $63 \%$ de los casos. En cuanto a los menores de 18 años con TCE, cada año en EEUU suponen más de 500000 atenciones en servicios de urgencias, con más de 40 000 ingresos hospitalarios y 7400 fallecimientos (24).

En España no existe un registro oficial sobre su prevalencia, si bien se estima que se producen entre 80000 y 100000 TCEs anualmente (incidencia de 150 a 250 por cada 100000 habitantes al año) y que un 50\% acontecen en menores de 15 años. Según un estudio multicéntrico elaborado por la Sociedad Española de Urgencias de Pediatría (SEUP) en 2009 se observó una mayor prevalencia en los menores de dos años, que suponían casi el 50\% de los casos, con un claro predominio entre el sexo masculino. Las caídas fueron la causa principal de TCE leves en niños pequeños y el domicilio familiar el entorno más frecuentemente implicado. De los 1071 pacientes incluidos en el estudio precisó ingreso el 25,3\%, y el 0,37\% requirió neurocirugía, sin que se registrara ningún fallecimiento (25). 
En Europa los datos epidemiológicos sobre el TCEL pediátrico son desconocidos y los estudios que han intentado su análisis concluyen que la interpretación de los datos de distintos estudios sobre TCE a nivel europeo es compleja debido a diferencias metodológicas sustanciales entre ellos (26).

En cuanto a la LICci, la verdadera incidencia en el TCEL es desconocida. La mayoría de estudios facilitan información de poblaciones seleccionadas con TCE moderados o graves (9). Así, el riesgo de LICci en estas series probablemente se encuentra sobreestimado. En menores de dos años que han sufrido un TCEL con exploración neurológica normal, entre el 3-10\% tiene una LIC en la TAC, de ellos el $1 \%$ tienen LICci y $0,2 \%$ requiere intervención neuroquirúrgica. La mayoría de estos pacientes no presentan síntomas de lesión cerebral aunque muchos de ellos presentan cefalohematomas (9-11).

Los datos de que disponemos en la población europea sugieren que la incidencia de LICci es menor, del 0,6 al 1,2\%. No obstante, en estos estudios únicamente a dos de cada tres pacientes se les realizó un escáner $(12,13)$.

En niños con comorbilidades como portadores de derivaciones ventrículoperitoneales o alteraciones de la coagulación, no está claro que las LICci sean más frecuentes tras un TCE que en niños previamente sanos. En un estudio observacional multicéntrico, de los 98 niños que portaban shunt ventricular y los 230 niños con alteraciones de la coagulación sólo el $1 \%$ tenía una LICci en la TAC comparado con el $0,9 \%$ de los demás niños tras un TCEL. Aun así, las LICci en niños con coagulopatías ocurrieron tras mecanismos menos graves comparando con niños previamente sanos $(14,15)$.

En cuanto a la distribución por edad, los TCE se distribuyen bimodalmente en la edad pediátrica: los menores de dos años y los adolescentes. El grupo con más frecuencia atendido es el de menores de dos años; en la pubertad existe otro pico de gran incidencia por la participación de los jóvenes en actividades de riesgo. En lo referente a las diferencias por sexos, los TCE son más frecuentes en varones en todos los grupos de edad, siendo más marcadas las diferencias a partir de los cuatro años (16).

Se han descrito otros factores que se relacionan con mayor riesgo de sufrir un TCE como son familias con bajos recursos, miembros de grupos étnicos minoritarios, residentes en grandes ciudades y antecedentes de TCE previos (17). 
Las causas de los traumatismos están ligadas a la edad de los sujetos que los sufren, difiriendo los mecanismos del impacto claramente entre niños y adultos. Entre los niños se relacionan además con el grado de desarrollo psicomotor.

En general, el mecanismo etiológico más frecuente lo constituyen las caídas, seguido en segundo lugar por los traumatismos contra objetos y, en tercer lugar, por los accidentes de circulación que, sin embargo, ocupan el primer lugar en lesiones graves y fallecimientos.

El maltrato es una causa de TCE poco frecuente, pero grave, que afecta con mayor frecuencia a los menores de dos años, siendo la primera causa de hemorragia intracraneal en los menores de un año $(10,16)$. Aunque su incidencia es incierta, se ha estimado que la mitad de los TCE que producen la muerte o secuelas irreversibles en lactantes son secundarios a daño intencional. Los traumatismos producidos por estos mecanismos suelen asociar otras lesiones que conviene siempre descartar.

También se debe tener en cuenta, que el trauma craneal puede ser secundario a la pérdida de consciencia por una intoxicación o convulsión (27).

Es necesario considerar que ante un niño que presente una hemorragia intracraneal aparentemente inexplicada con o sin la evidencia externa de lesión, además de una lesión accidental a partir de una caída aparentemente inofensiva se debe considerar una lesión intencional $(19,28)$.

Estratificado por edad, los niños menores de dos años sufren TCE fundamentalmente por caídas y maltrato; los niños entre dos y diez años por accidentes de circulación, caídas (durante el segundo año la mayor parte son caídas desde su propia altura, los niños adquieren la deambulación estable y al presentar gran necesidad de explorar sin sensación de peligro se producen caídas desde mayores alturas), accidentes escolares y de bicicleta; y los mayores de diez años por accidentes deportivos, de circulación y de bicicleta $(24,29)$.

Existen estudios sobre los mecanismos causales y la severidad de los traumatismos que los producen, que resultan ser de vital importancia para informar sobre prevención. Por ejemplo las caídas de lactantes desde los brazos de sus cuidadores parecen ser de las que mayor riesgo de LIC o fractura craneal comprenden $(30,31)$. 


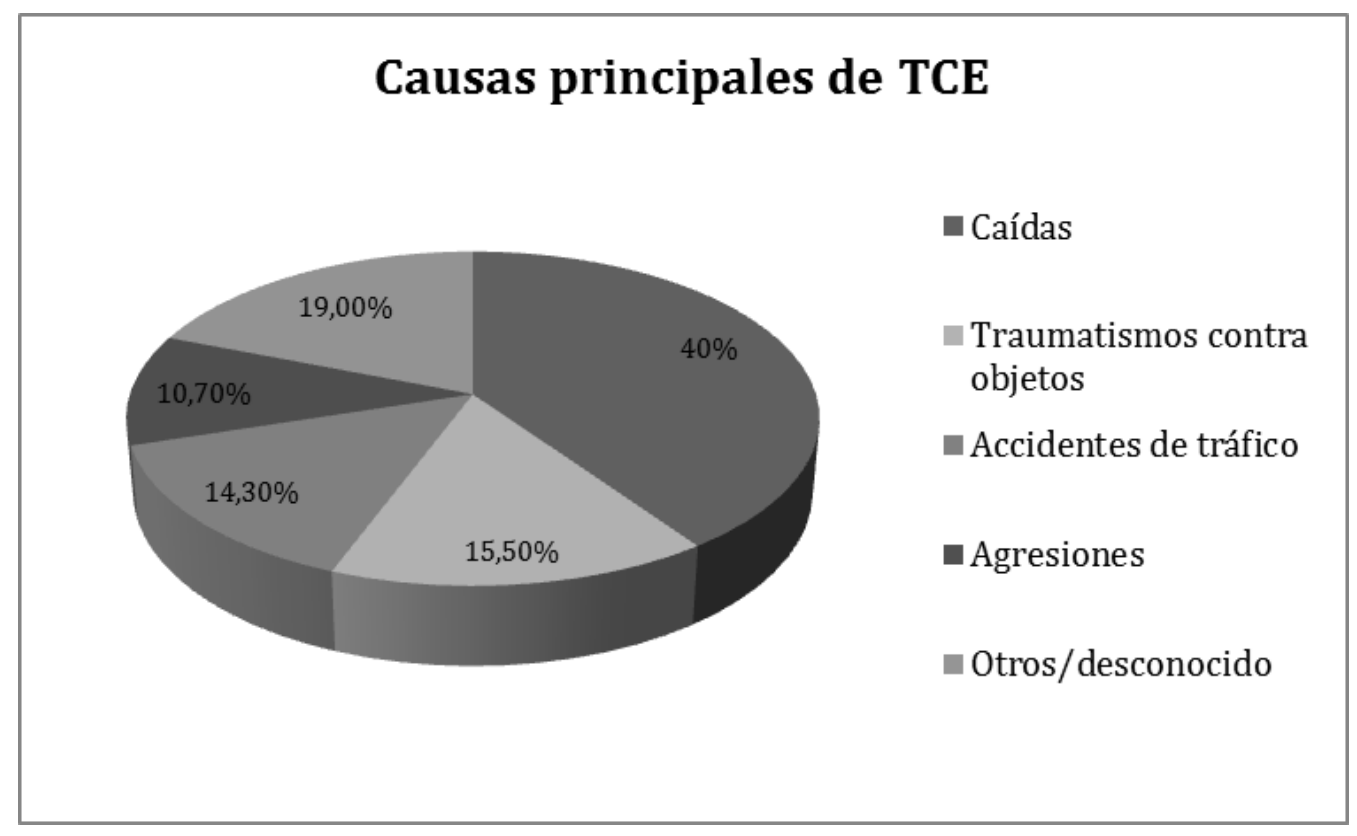

Figura 1. Causas principales de TCE en la población pediátrica.

El coste económico de los traumatismos en población pediátrica es de gran magnitud al igual que la repercusión social de la incapacidad infantil post-traumática, hasta el punto de que el gasto económico en recursos y personal producido por la misma es mucho mayor que el derivado del trauma en personas adultas (32).

El mejor tratamiento del traumatismo craneal es su prevención. El uso de las medidas de prevención, como los cascos o los sistemas de sujeción en los automóviles, ha conllevado un descenso de la morbilidad y mortalidad por los TCE. A pesar de ello, la mortalidad por TCE supone 52000 casos al año en EEUU, siendo 17 por cada 100000 habitantes a nivel extrahospitalario y 6 por cada 100000 habitantes en los pacientes hospitalizados (22).

En el ámbito de la prevención, deben desarrollarse programas de prevención de los traumatismos infantiles, en los que deben participar los pediatras de manera activa informando tanto a padres como a educadores de la importancia de cuestiones tales como educación vial y seguridad en el automóvil, fomentando el uso de dispositivos adecuados para el transporte del niño, así como el uso del casco en las prácticas lúdicas o deportivas (bicicleta, monopatín, esquí, etc.), de protecciones de caída de las camas, etc. (33). En España, el Comité de Seguridad y Prevención de 
Accidentes Infantiles ha elaborado una guía para padres con el fin de ayudar a los padres a que protejan a sus hijos (34). 


\subsection{ANATOMÍA}

Un breve repaso anatómico de las estructuras craneales y encefálicas principales con repercusión en los TCE, nos permitirá la interpretación fisiopatológica de los mismos $(6,35)$.

- Piel y tejido conjuntivo. Es la parte más externa que rodea el cráneo y sirven como primer amortiguador ante un TCE. Es una gran red de tejido vascularizado, lo que lo convierte en una zona con alto riesgo de sangrado. Limita en su parte interna con la galea aponeurótica, una vaina tendinosa que conecta los músculos frontal y occipital. Un hematoma a este nivel se denomina caput succedaneum. Por debajo de la galea se encuentra el compartimiento subgaleal.

- Bóveda craneal. Su porción más externa es el periostio externo. Las tablas externas e internas del cráneo están separadas por el hueso diplóico con un interior irrigado por venas diplóicas y emisarias que, al igual que la piel de la cabeza, es una de las zonas óseas más vascularizadas. En la cara inferior se encuentra la base de cráneo por la cual entran y salen nervios craneanos, la médula espinal, senos venosos, venas y arterias con alto flujo sanguíneo (que contienen entre $20 \%$ y $25 \%$ del gasto cardíaco total).

- Meninges. El encéfalo y médula espinal están rodeados tejido conjuntivo denominadas meninges, siendo su papel principal el protector. Las meninges están constituidas por tres capas que separan el parénquima cerebral del cráneo y, por ende, de la contaminación al exterior ante la posibilidad de que haya exposición a agentes infecciosos por heridas en la piel con fracturas abiertas de cráneo. Las tres capas desde el exterior al interior son:

- La duramadre es la capa más externa y la más fuerte. Está formada por tejido conjuntivo denso irregular y está adherida al periostio del hueso, entre los cuales se forma un espacio virtual llamado epidural que puede llenarse de sangre tras un TCE.

- La aracnoides por debajo de la duramadre. Está formada por tejido conjuntivo avascular rico en fibras de colágeno y elásticas que 
forman como una malla. Entre esta meninge y la duramadre está el espacio subdural que en condiciones fisiológicas no aparece, pero tras un TCE puede dar lugar al hematoma subdural.

- La piamadre es una capa muy fina y transparente de tejido conectivo que está íntimamente adherida al sistema nervioso central al cual recubre. Está constituida por tejido conectivo muy vascularizado, donde abundan las fibras colágenas y elásticas. Entre la aracnoides y la piamadre se halla un espacio real, el espacio subaracnoideo, por donde pasan los vasos y el líquido cefalorraquídeo.

La aracnoides y la piamadre constituyen las leptomeninges. La duramadre contiene pocos vasos sanguíneos en contraste con las leptomeninges, muy vascularizadas, que están en contacto íntimo con el encéfalo.

- Líquido cefalorraquídeo (LCR). El encéfalo está recubierto y protegido por el LCR ubicado en los espacios subaracnoideos, las cisternas de la base del encéfalo, las cavidades ventriculares y los canales de interconexión. El LCR contiene nutrientes y sirve como amortiguador para evitar que el parénquima choque o roce directamente con las estructuras óseas ante las aceleraciones, desaceleraciones y rotaciones. El LCR se produce en unas estructuras vasculares situadas en las paredes de los ventrículos llamadas plexos coroideos. Son redes de capilares cubiertas de células ependimarias que forman el LCR a partir de la filtración del plasma sanguíneo. 
- Parénquima cerebral. Está compuesto por estructuras vitales tales como el cerebro, cerebelo, tronco cerebral y los pares craneales. El cerebro pesa entre 1300 y 1500 g. (2\% del peso corporal), y está compuesto en un $40 \%$ de su masa por sustancia gris.

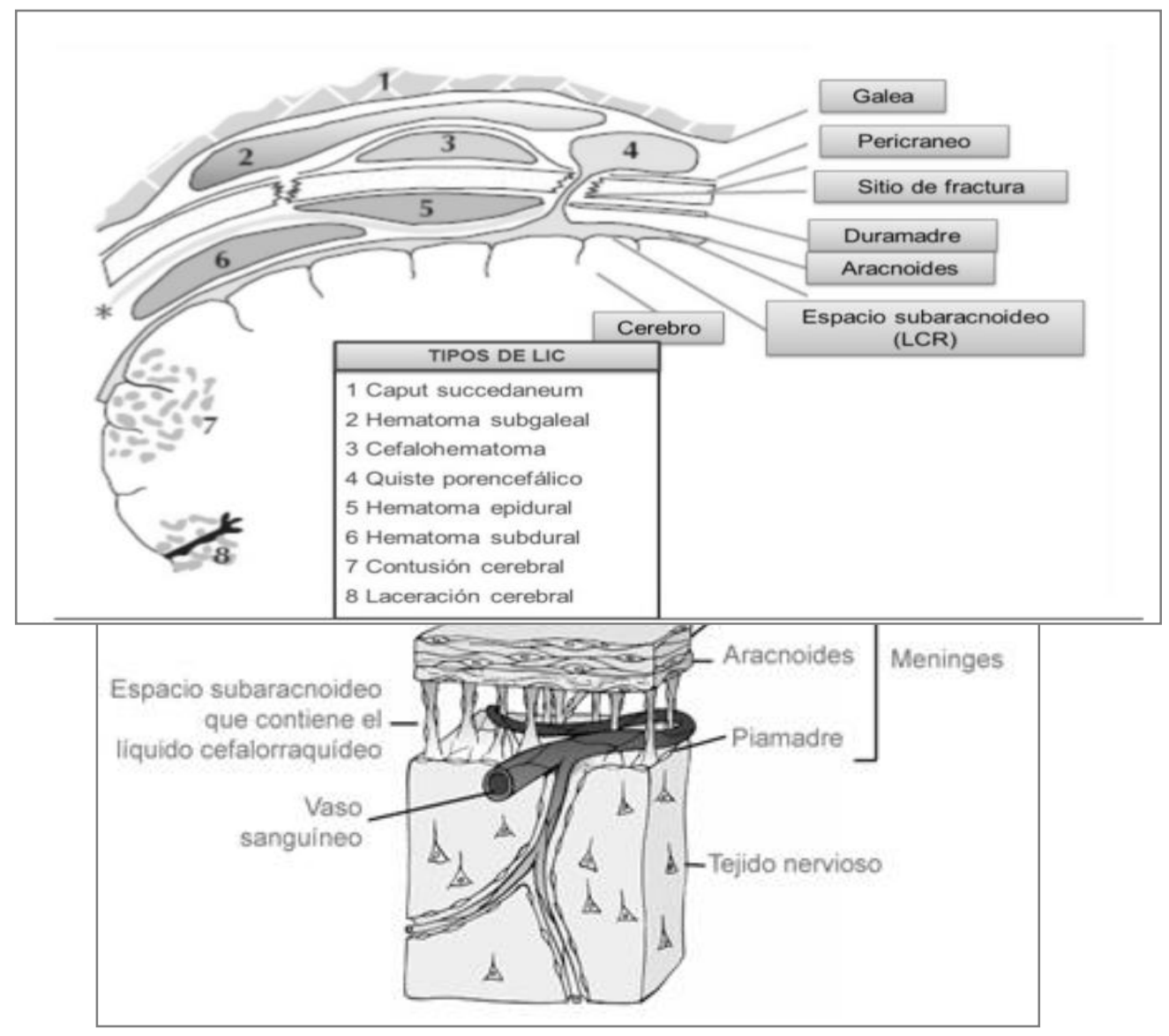

Figura 2. Anatomía de las cubiertas encefálicas y tipos de lesión intra y extracraneal 


\subsubsection{ANATOMÍA CRANEAL EN NIÑOS}

Existen variaciones anatómicas significativas entre los niños y adultos que conllevan diferencias importantes en la fisiopatología y patogenia tras un TCE (6). A continuación, comentaremos algunas.

Por un lado, durante la fase de crecimiento cerebral, se producen una serie de cambios anatómicos craneales como son el cierre paulatino de las suturas y fontanelas, que condicionarán las manifestaciones tras un TCE. Las fontanelas son las membranas fibrosas que cubren las cavidades que se encuentran entre la unión de dos huesos, mientras que las suturas son estructuras estrechas de tejido conectivo, que se encuentran separando los huesos planos del cráneo (36).

En recién nacidos y lactantes, las manifestaciones difieren a las del niño mayor y adulto debido a la presencia de fontanelas y al no cierre de las suturas. Éstos son los mecanismos de compensación más importantes que tienden a disipar los efectos del aumento de presión intracraneal (PIC) causando una demora en la aparición de los síntomas y signos. Las manifestaciones más importantes a estas edades serán el abombamiento de las fontanelas, el incremento acelerado del perímetro cefálico, dehiscencia de las suturas craneales, ingurgitación de las venas craneales, somnolencia que alterna con irritabilidad, vómitos y signo del sol poniente, sobre todo en caso de hidrocefalia. El papiledema, por ejemplo, casi nunca aparece en el niño menor de dos años (37).

Por otro lado, en la infancia el cráneo es más flexible y más elástico, lo que predispone a un mayor grado de deformaciones y desplazamientos, por lo que el daño cerebral postraumático suele ser más difuso.

La bóveda craneal de los niños es más grande y pesada en proporción con la masa corporal total; la relación entre cabeza y cuerpo es de 1:3 en niños pequeños frente a 1:9 en adultos lo que facilita las lesiones craneales en los niños, fundamentalmente en los lactantes, en los que a mayor grado de torsión generado por fuerzas a lo largo del eje de la médula espinal se producen más lesiones cervicales.

El cerebro tiene un gran contenido en agua, es frágil y sus cubiertas son fácilmente desgarrables. El lactante tiene las fontanelas abiertas, el cráneo es flexible 
y con gran vascularización de la duramadre, aumentando el riesgo de hematomas epidurales. En el niño las fracturas craneales cursan gran parte de veces sin alteraciones parenquimatosas.

Los niños, en comparación con los adultos, presentan menor mielinización con mayor contenido de agua, lo que conlleva a fuerzas de cizallamiento notables con una lesión nerviosa mayor.

La combinación de estos factores, acompañada de la presencia de unos huesos craneales más finos en los niños, deriva en lesiones cerebrales más graves. 


\subsection{FISIOPATOLOGÍA}

En los TCEs, las células cerebrales y sus prolongaciones sufren un daño que dará como resultado un comportamiento irregular del funcionamiento normal del cerebro. Se entiende que se produce una funcionalidad del contenido craneal inapropiada debida a un intercambio mecánico de energía (38).

Es primordial conocer la fisiología cerebral normal en población pediátrica para comprender la serie de cambios que subyacen en el cerebro después de un TCE.

El mecanismo sustancial de este tipo de lesiones permite establecer los escenarios posteriores que determinan el daño cerebral adquirido. Se observa una relación directa entre los siguientes tres elementos (39-41):

El cerebro ocupa el 70\% del volumen craneal y está compuesto en un 75-80\% de agua. Se divide en componentes intracelular y extracelular. El componente intracelular se subdivide a la vez en sustancia gris, poco distensible, y la sustancia blanca, que es menos densa que la gris, pudiendo almacenar incrementos de un diez por ciento o más de agua. El componente extracelular consiste de una capa líquida fina similar al LCR, la cual representa hasta el 20\% del volumen cerebral.

El LCR, que ocupa el $20 \%$ del volumen de la bóveda craneana, es producido principalmente por los plexos coroideos de los ventrículos cerebrales, circulando hacia el espacio subaracnoideo a través de los forámenes de Luschka y de Magendie. De allí el LCR fluye hacia las estructuras craneales y la médula espinal.

El volumen sanguíneo cerebral (VSC) es el espacio que ocupa el contenido sanguíneo dentro de la vasculatura cerebral y está determinado por el diámetro de las arteriolas y vénulas. En condiciones ideales ocupa el diez por ciento del volumen craneal.

En función del mecanismo de producción y del momento de aparición, se han descrito tres tipos de lesiones desde el punto de vista patogénico:

- Mecanismo lesional primario, responsable de las lesiones nerviosas vasculares. 
- Mecanismo secundario, responsable de las lesiones cerebrales producidas por alteraciones sistémicas.

- Mecanismo terciario o neuroquímico, que se inicia inmediatamente tras el trauma (42).

Las lesiones primarias, por el impacto, producen una desestructuración tisular irreversible. Por el contrario, las lesiones secundarias son el objetivo del tratamiento intensivo neurológico.

Algunos de los daños finales observados en el cerebro lesionado evolucionan a lo largo de horas o días, siendo las dianas terapéuticas los mecanismos implicados subyacentes en el TCE (edema, apoptosis y axotomía secundaria). Por otra parte, el cerebro lesionado es vulnerable a agresiones adicionales, ya que la lesión desorganiza los mecanismos de defensa autorreguladores normales, y la desestructuración de la autorregulación del flujo sanguíneo cerebral (FSC) puede dar lugar a isquemia por hipotensión, que de otro modo sería bien tolerada por un cerebro sano (24).

Casi la mitad de las muertes por TCE ocurren a los pocos minutos de la lesión primaria, siendo el único tratamiento su la prevención a través de la educación de niños y padres. Por el contrario, la lesión cerebral secundaria se puede evitar mediante intervención médica siendo el objetivo principal del tratamiento del TCE. Un manejo satisfactorio de un niño que ha sufrido un TCE supone una evaluación clínica adecuada de la lesión primaria y una estimación del riesgo potencial de lesiones intracraneales y anticiparse y tratar activamente el desarrollo de hipertensión intracraneal (HTIC) (43).

Los niños son más susceptibles de padecer una lesión intracraneal tras un TCE por sus características anatómicas: superficie craneal proporcionalmente mayor, plano óseo más fino y deformable, musculatura cervical relativamente débil y un mayor contenido de agua y menor de mielina, que favorece el daño axonal difuso ante fuerzas de aceleración y desaceleración (6).

Desde el punto de vista fisiopatológico es interesante conocer los fundamentos de los mecanismos de control del FSC y, para eso, desarrollaremos brevemente los conceptos de vasorreactividad y autorregulación.

La autorregulación cerebral se basa en la modificación de la resistencia vascular cerebral (RVC) mediante vasodilatación o vasoconstricción con el fin de mantener 
un FSC acorde a las necesidades metabólicas cerebrales de oxígeno $\left(\mathrm{O}_{2}\right)$ de cada momento. La autorregulación está determinada en gran parte por la la presión parcial de dióxido de carbono $\left(\mathrm{PCO}_{2}\right)$, por la presión arterial media (PAM) y, en menor medida, por la presión arterial de $\mathrm{O}_{2}\left(\mathrm{PaO}_{2}\right)$, la adenosina y el $\mathrm{pH}$.

La presión de perfusión cerebral (PPC) se define como la presión necesaria para perfundir el tejido nervioso, garantizando un buen funcionamiento metabólico. Una PPC menor de $50 \mathrm{mmHg}$ implica una disminución severa del FSC, con el riesgo de isquemia cerebral. En este tipo de accidentes que lesionan el encéfalo, hay una importante relación estrecha entre el metabolismo, el flujo sanguíneo cerebral, el gasto energético, la presión intracraneal, el volumen intracraneal y el volumen sanguíneo que involucran la fisiología de un cerebro en la infancia. Comprenderla proporciona elementos para advertir los cambios que se producen ante un evento de traumatismo craneoencefálico y su impacto en el desarrollo. Hay que tener en cuenta que el flujo sanguíneo cerebral y el consumo de oxígeno son casi de doble en los niños en comparación con los adultos (44).

En condiciones fisiológicas el FSC permanece constante ante cambios en la PPC para satisfacer de una forma continua las necesidades metabólicas cerebrales; este fenómeno se denomina autorregulación. El límite superior normal de autorregulación de la PPC se sitúa en $130 \mathrm{mmHg}$ y el inferior en $50 \mathrm{mmHg}$. Rebasados en exceso, se producirá edema, y por debajo del límite inferior se producirá isquemia. Los cambios de la $\mathrm{PCO}_{2}$ también dan lugar a variaciones en el flujo cerebral sanguíneo. Así, cuando la $\mathrm{PCO}_{2}$ cerebral es alta con mayor trabajo metabólico, la RVC cae, aumentando el FSC y lo contrario ocurre cuando la $\mathrm{PCO}_{2}$ disminuye con menor trabajo metabólico. Esta forma de respuesta se denomina vasorreactividad al dióxido de carbono $\left(\mathrm{CO}_{2}\right)$ y es completamente independiente de la autorregulación.

En situaciones patológicas estas respuestas pueden encontrarse disminuidas o abolidas. Podría decirse que cuando hay pérdida de autorregulación ante aumentos de la PAM se produce un aumento de PIC en lugar de una disminución, que sería la respuesta adecuada, y viceversa. 


\subsubsection{DAÑO CEREBRAL PRIMARIO}

Se refiere al daño neuronal producido por el impacto directo del propio traumatismo y/o por las fuerzas de aceleración y desaceleración. Dichas lesiones son escasamente modificables por la intervención terapéutica, siendo la prevención un aspecto fundamental.

Las lesiones vendrán determinadas por el lugar del impacto, la dirección de la fuerza, la intensidad y la resistencia tisular.

Tipos de fuerzas o mecanismos físicos en el TCE:

- Aceleración lineal laterolateral. Predominan lesiones extraaxiales (hematoma epidural y subdural y hemorragia subaracnoidea) y lesiones golpe/contragolpe.

- Aceleración lineal fronto-occipital u occipito-frontal. Produce principalmente lesiones de estructuras profundas, el denominado daño axonal difuso.

- Síndrome del niño agitado o Shaken baby síndrome (SBS). Es una forma de maltrato físico caracterizada por la presencia de hemorragias retinianas, subdurales y/o subaracnoideas, en ausencia de otras muestras de lesión traumática externa. Las sacudidas por aceleración pueden potencialmente causar lesiones cervicales severas de la médula espinal o del tronco del encéfalo en el niño y la ruptura de los vasos entre el cráneo y el encéfalo. El SBS puede provocar encefalopatía severa, con importantes secuelas y trastornos de la visión, al producir hematomas subdurales y/o epidurales voluminosos, que conducen a una pérdida neuronal severa, gliosis y pueden dar a lugar a coma y muerte $(19,28)$.

Tipos de lesión primaria (pueden combinarse y presentarse simultáneamente):

- Contusión y laceración del cuero cabelludo. Lesión únicamente externa en la piel o cuero cabelludo, sin afectación ósea ni intracraneal.

- Fractura de cráneo. Es una ruptura en el hueso del cráneo. Pueden ser fracturas cerradas o simples ( (involucra una rotura o pérdida de piel y astillamiento del hueso), con 
hundimiento (depresión del hueso hacia el cerebro) y de la base del cráneo. Además, se pueden clasificar en: lineales (rotura delgada, sin astillamiento, depresión ni distorsión del hueso), incompletas (sin rotura de todo el hueso) y cominutas (rotura en varios fragmentos). La mayoría son lineales, sin hundimiento y sin trascendencia en un niño asintomático. Si cruzan la línea media o si cruzan el seno sagital pueden producir hemorragia. El cráneo es particularmente susceptible de romperse en ciertas localizaciones como son: los huesos temporal y parietal, el seno esfenoidal y la base del cráneo (45). Se debe sospechar fractura de la base en caso de hemotímpano u otorragia, rinorrea u otorrea de LCR, equimosis periorbitaria (ojos de mapache, fractura del piso de la fosa anterior) o retroauricular (signo de Battle, fractura en la porción petrosa del esfenoides) (43).

- Contusión y laceración cerebral, por golpe directo o por contragolpe. La sintomatología clínica depende de la localización y del alcance de la lesión. Con frecuencia sólo existe disminución del nivel de consciencia, vómitos y cefalea transitoria (43). Más frecuente en áreas subyacentes a zonas óseas prominentes (hueso frontal inferior, cresta petrosa, etc.). En la tomografía axial computerizada (TAC) aparecen en la zona lesionada múltiples lesiones puntiformes hiperdensas (sangre) con edema perilesional (hipodensidad) y necrosis tisular, si bien inicialmente puede que no se evidencien grandes alteraciones.

- Hemorragia cerebral, que se clasifica según la localización en:

- Epidural. Se origina por rotura de una arteria de la duramadre, generalmente la arteria meníngea media. Frecuentemente está asociada a fractura craneal en el área parietotemporal, donde cruzan los surcos de la arteria meníngea media. Es poco frecuente, produciéndose en el 0,5-3\% de todos los TCE de la infancia pero tiene una elevada mortalidad (46). Habitualmente se producen por traumatismos de alto impacto pero se ha visto que pueden aparecer tras traumatismos leves (47). Puede cursar con un intervalo libre sin alteración de la consciencia seguido de un rápido deterioro neurológico (disminución de la conciencia, midriasis ipsilateral con ptosis y desviación medial del globo 
ocular, hemiparesia contralateral). El hematoma epidural se observa en la TAC con morfología de lente biconvexa con límites bien definidos y habitualmente adyacentes a la línea de fractura. El tratamiento es quirúrgico inmediato, con muy buen pronóstico si se interviene de forma precoz. De todos modos, el pronóstico variará dependiendo de la situación del paciente antes de ser operado y de la precocidad de la evacuación quirúrgica. A mayor gravedad y mayor retraso en la cirugía, menos posibilidades de supervivencia (46).

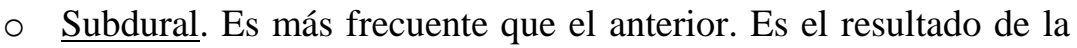
ruptura de venas comunicantes entre la corteza cerebral y la duramadre, aunque también puede relacionarse con laceraciones cerebrales o lesiones de arterias corticales. Se localiza con más frecuencia en regiones de contragolpe, observándose en la TAC como lesiones hiperdensas yuxtaóseas con forma de semiluna y bordes menos nítidos que el anterior. Su localización más frecuente es en la zona parietal, respetando habitualmente los polos frontal y occipital (46). Se produce especialmente en niños menores de dos años, raramente asociada a fractura. Sugiere malos tratos (SBS), especialmente si se acompaña de hemorragias retinianas o si cruzan la línea media. La clínica típica es de instauración brusca con pérdida de consciencia y focalidad.

- Subaracnoidea. Constituye un síndrome más que una entidad patológica aislada, que tiene lugar como consecuencia de la ruptura de uno o más vasos sanguíneos con extravasación de sangre hacia los espacios subaracnoideos (un espacio continuo entre los compartimientos supratentorial e infratentorial). Al ocurrir la hemorragia se eleva la PIC y, como consecuencia, disminuye de forma aguda la PPC. La hipoperfusión produce isquemia cerebral aguda (48). Generalmente, se manifiesta clínicamente como una cefalea de gran intensidad que puede acompañarse o no de disminución del nivel de consciencia (49). Además, suele asociar otra sintomatología como: rigidez de nuca, 
fotofobia, náuseas y vómitos, entre otros. Puede haber intervalo libre de síntomas.

- Intraparenquimatosa. Se produce tras la ruptura de vasos sanguíneos intracerebrales con extravasación de sangre hacia el parénquima cerebral. Las manifestaciones clínicas dependen de la localización y de la extensión, puede producir HTIC y deterioro de la consciencia.

\subsubsection{DAÑO CEREBRAL SECUNDARIO}

Se refiere a la lesión subsiguiente de las células cerebrales no lesionadas por el evento traumático inicial.

Consiste en las lesiones producidas por distintos factores: la isquemia (hipoperfusión, hipotensión, hipoxia, alteración del flujo cerebral...), el daño citotóxico, el daño por radicales libres, las alteraciones de la función celular (afectación de la permeabilidad de la membrana celular) y las alteraciones de las cascadas del metabolismo. En algunos casos, el efecto de la lesión cerebral secundaria es más devastador que la lesión cerebral primaria. El daño primario hace referencia a lo que ocurre en el momento del impacto y el daño secundario a los efectos de los procesos fisiológicos derivados del daño primario. El conocimiento del efecto de estas condiciones ha permitido una mejor monitorización de éstas, así como el adecuado tratamiento farmacológico y de rehabilitación (50). El factor más importante es la reducción de la perfusión cerebral, ya sea por disminución de la PAM o por aumento de la presión intracerebral, contribuyendo para su aparición alteraciones sistémicas, como hipoxemia, hipercapnia, fiebre, alteraciones en la homeostasis del sodio, hipo- o hiperglucemia, acidosis o alteraciones intracraneales como hematomas, hemorragia parenquimatosa u obstrucción del flujo de LCR.

Este daño cerebral secundario se desarrolla en las horas siguientes al traumatismo $\mathrm{y}$, a diferencia del daño cerebral primario, puede ser reversible con un correcto manejo terapéutico. En algunas ocasiones, el trauma de cráneo grave está asociado con disección, laceración, compresión o trombosis de vasos cerebrales mayores, produciendo un infarto tisular. Un adecuado FSC depende de la presencia de la 
integridad de los vasos sanguíneos cerebrales para perfundir adecuadamente el cerebro. El vasoespasmo de la vasculatura cerebral contribuye también a la lesión cerebral secundaria. Esto no es raro en el trauma de cráneo grave, especialmente en los casos asociados con hemorragia subaracnoidea $(35,46)$.

El pronóstico dependerá de la gravedad en cada fase de la lesión. Excepto la prevención nada puede hacerse para modificar el daño inicial sobre el cerebro producido por el traumatismo.

Todos los esfuerzos irán, pues, encaminados a combatir los factores etiológicos causantes de la lesión secundaria.

\subsubsection{DAÑO CEREBRAL TERCIARIO}

Algunos autores engloban en el concepto de lesión terciaria la muerte neuronal derivada de las alteraciones producidas por la liberación de aminoácidos excitadores, el estrés oxidativo, los fenómenos inflamatorios y la liberación de diversos neurotransmisores. Todo ello es consecuencia de la puesta en marcha de cascadas neuroquímicas anómalas y alteraciones metabólicas tanto en el momento del impacto como posteriormente a la lesión inicial que tienen como punto de partida la liberación de neurotransmisores, como el glutámico o el aspártico $(35,43)$.

La lesión cerebral secundaria postraumática puede atribuirse también a la isquemia cerebral. En realidad, el consumo metabólico de oxígeno asociado al mantenimiento del flujo cerebral es el parámetro más relacionable con las secuelas que puede producir este daño secundario. A su vez, el flujo cerebral depende de la PPC que será menor si aumenta la PIC, tal como queda reflejado en la ecuación: PPC $=$ PAM - PIC . La capacidad de autorregulación se pierde en un $50-60 \%$ de los traumatismos craneales graves, y esto implica un peor pronóstico. La vasorreactividad al $\mathrm{CO}_{2}$ puede conservarse; esta situación se denomina vasoparálisis disociada. No obstante, la pérdida de la vasorreactividad se produce en torno a un $12 \%$ de los casos (e implica una mayor gravedad que la pérdida de la autorregulación) al igual que en el adulto (33). 


\subsection{ASPECTOS CLÍNICOS}

La mayoría de los TCEL no producen daño cerebral y cursan con ausencia de síntomas o signos exploratorios. Los distintos tipos de daño cerebral pueden correlacionarse con una serie de manifestaciones clínicas. Las manifestaciones clínicas del TCEL pueden ir desde la ausencia de síntomas o signos, que es lo más frecuente, hasta la aparición de manifestaciones guía que orientan hacia la posible existencia de lesión intracraneal.

Entre las manifestaciones que pueden aparecer, destacan las siguientes $(24,29,41)$ :

Alteración del nivel de consciencia. La presencia o ausencia de este síntoma y su duración son factores pronósticos de la gravedad del TCE. Una pérdida de consciencia supone, per se, un traumatismo de intensidad moderada/alta. La duración de la pérdida de consciencia es directamente proporcional a la gravedad de la lesión intracraneal; de forma que cuando es superior a un minuto hay alta probabilidad de lesión intracraneal (41). La pérdida de consciencia tras un TCEL ocurre en aproximadamente el 5\% de los menores de dos años y hasta en un 13\% en mayores de dos años. Se trata de un aspecto importante para decidir la necesidad de neuroimagen, ya que según la duración y la presencia de otros hallazgos clínicos se asocia a LICci. A pesar de ello, el riesgo de LIC en los casos con pérdida de consciencia breve, aislada y sin otros signos de alarma es baja. Como ejemplo, en un subanálisis de la PECARN, de los 6286 niños con pérdida de consciencia aislada, el $0,5 \%$ presentó una LICci (51). Por otro lado, en otro estudio, objetivaron un mayor riesgo de LICci en los niños con un intervalo de tiempo de pérdida de consciencia mayor a cinco minutos con un valor predictivo positivo (VPP) de 0,45 (12).

Amnesia postraumática. Es un síntoma relativamente frecuente que la mayor parte de las veces no se asocia a la existencia de lesión intracraneal. Sin embargo, hay lesiones cerebrales que afectan a la región temporal y pueden manifestarse con este síntoma (41). 
Convulsiones. Es un signo infrecuente tras un TCEL. Las convulsiones postraumáticas inmediatas en series pequeñas, oscilan entre el 3\% y el 19\% en los casos de TCE grave $(52,53)$. En una cohorte grande, la frecuencia de convulsiones tras un TCEL fue del $4 \%$ y la mitad ocurrieron en el momento del impacto (54). Las crisis postraumáticas contribuyen al daño secundario después del TCE y se han observado con frecuencia en niños con lesión cerebral moderada o grave $(55,56)$.

Según el momento de aparición se clasifican en (41):

- Crisis inmediatas. Ocurren en segundos o minutos tras el traumatismo y se manifiestan con atonía o hipertonía generalizada. No tienen valor pronóstico en la aparición de epilepsia postraumática.

- Crisis precoces. Aparecen entre la primera hora y los siete días posteriores al traumatismo, y pueden manifestarse como crisis parciales simples o crisis parciales con generalización secundaria. Suelen significar la presencia de daño cerebral (hematomas intracraneales, contusión cerebral, trastornos vasculares...).

- Crisis tardías. Ocurren después de la primera semana postraumatismo, siendo más frecuentes durante el primer mes y rara su aparición a partir de un año. Suelen ser crisis parciales simples durante la infancia, y aumenta la posibilidad de crisis generalizadas en la adolescencia. El diagnóstico de epilepsia postraumática viene determinado por la presencia de crisis tardías repetidas y suele tratarse de pacientes que han presentado previamente hematomas intracraneales, contusiones cerebrales, fracturas de la base de cráneo o fracturas con hundimiento y coma postraumático. La presencia de crisis febriles en la infancia o historia familiar de epilepsia predispone al desarrollo de epilepsia postraumática. El uso del electroencefalograma (EEG) en los pacientes que no han recibido tratamiento antiepiléptico parece tener un buen valor predictivo negativo (53).

Vómitos. Es un síntoma bastante frecuente, casi el 13\% de los niños presentan al menos un episodio de vómitos tras el TCEL. De ellos, muy pocos presentan una LICci. Sin embargo, la LICci es más probable en niños con vómitos que asocian otra sintomatología $(10,11,57)$. Ocurre sobre todo formando parte de la reacción 
vagal que puede acontecer después de un TCE, sin que esto suponga la presencia de lesión intracraneal. Sin embargo, los vómitos pueden ser un síntoma guía de HTIC cuando son repetitivos, no se preceden de náuseas (vómitos en escopetazo), o si se acompañan de síntomas neurológicos (58). Dayan evaluó 5557 pacientes con vómitos tras un TCEL y objetivó una prevalencia de LICci del 0,2\% en los que presentaban vómitos aislados y del 2,5\% en el grupo de los pacientes con vómitos asociados a otra sintomatología. No identificó mayor riesgo de LICci en pacientes con aparición tardía de vómitos o con mayor frecuencia de vómitos (57). No está claro si el número de vómitos o el tiempo de duración son indicativos de LICci. Según un estudio observacional multicéntrico, la presencia de dos o más vómitos tras un TCE se asoció a un riesgo de LIC unas 1,3 veces mayor, aproximadamente (11).

Cefalea. Es un síntoma difícil de valorar en niños y especialmente en los de corta edad. La cefalea es un síntoma frecuente, que ocurre hasta en el $46 \%$ de los niños tras TCEL (59). En niños pequeños, la irritabilidad suele ser indicador de disconfort, incluyendo cefalea. La presencia de este síntoma de manera aislada es poco indicativa de lesión intracraneal, pero sí que aumenta el riesgo de LICci si hay un empeoramiento progresivo y se acompaña de otras alteraciones neurológicas $(41,59,60)$. No obstante, en los pacientes que únicamente presentan cefalea de manera aislada, la incidencia de LICci es baja. Según Dayan, en un estudio multicéntrico de 28000 niños de 2 a 18 años con TCEL, ninguno de los que sufrían cefalea de forma aislada presentó LICci comparado con el 1,6\% en el grupo de pacientes con cefalea y otros síntomas (10).

Cefalohematoma. La mayoría de niños con cefalohematomas aislados sin otros síntomas no tienen una LICci. Pero en lactantes pequeños los cefalohematomas sí pueden ser indicadores potenciales de LICci si son grandes y se localizan en las regiones parietal, occipital o temporal $(61,62)$. En un estudio observacional multicéntrico de 2998 menores de 2 años con cefalohematoma aislado, el 8,8\% de aquellos en que se realizó una TAC craneal tenía LIC (hematoma epidural o subdural, hemorragia cerebral o subaracnoidea o contusión cerebral). De los 111 menores de 3 meses con cefalohematoma con TAC craneal realizado, el 21\% tenía LIC; lo que sugiere que en neonatos y lactantes pequeños el cefalohematoma es un importante indicador potencial de LIC. Sin embargo, sólo doce pacientes presentaron una LICci $(0,4 \%)$ y ninguno precisó neurocirugía ni 
falleció. En el análisis multivariante, las características asociadas de manera independiente a LIC incluyeron: el tamaño del cefalohematoma, la edad, la localización no frontal y el mecanismo traumático severo (61).

Un score clínico validado publicado por Bin, Schutzman y Greenes ayuda a estratificar el riesgo de LIC en menores de un año (63). Incluye las variables: edad, localización y características del hematoma. Una puntuación mayor o igual a tres puntos se asocia a mayor riesgo LICci en niños con cefalohematomas. No se tiene en cuenta el mecanismo de lesión en este score.

\begin{tabular}{|c|c|c|c|}
\hline Puntuación & $\begin{array}{c}\text { Edad } \\
\text { (meses) }\end{array}$ & $\begin{array}{c}\text { Tamaño del } \\
\text { hematoma }\end{array}$ & $\begin{array}{c}\text { Localización del } \\
\text { hematoma }\end{array}$ \\
\hline $\mathbf{0}$ & $\geq 12$ & Ninguno & Frontal \\
\hline $\mathbf{1}$ & 6 a 11 & $\begin{array}{c}\text { Pequeño (a penas } \\
\text { palpable) }\end{array}$ & Occipital \\
\hline $\mathbf{2}$ & 3 a 5 & $\begin{array}{c}\text { Medio (fácilmente } \\
\text { palpable) }\end{array}$ & Temporal/parietal \\
\hline 3 & 0 a 2 & Grande (muy & \\
\hline
\end{tabular}

Tabla 1. Score clínico para niños con cefalohematomas (63)

Fractura craneal. Aparecen hasta en el $10 \%$ de los menores de dos años con TCEL. La mayoría en este grupo de edad son lineales. Entre los niños con fractura craneal lineal, un 15-30\% presentan LIC asociada (64-67). Casi la totalidad de niños con fractura presenta, además, cefalohematoma subyacente. No obstante, una proporción pequeña de los niños con cefalohematoma presenta fractura craneal asociada. En los menores de dos años, la presencia de cefalohematoma grande, la edad menor de tres meses y la localización distinta del hueso frontal, sugieren mayor incidencia de fractura craneal. Greenes mostró que los niños con cefalohematoma frontal presentan un riesgo mínimo de LIC (68). Otros hallazgos de fractura craneal incluyen la palpación de hundimiento craneal, 
rinolicuorrea u otolicuorrea, el signo de Battle, los ojos de mapache y el hemotímpano.

Síndrome conmocional. Es una secuela importante de un TCEL agudo. Suele consistir en quejas subjetivas relacionadas con síntomas somáticos, cognitivos o emocionales, como cansancio, cefaleas, pérdida de memoria, mareos, irritabilidad, defectos de atención, depresión, dificultad de concentración, problemas de sueño y cambios de personalidad. Los síntomas conmocionales son más frecuentes después de complicaciones de alto riesgo de un TCEL. Este síndrome suele resolverse habitualmente en dos o tres meses, aunque algunos síntomas sutiles pueden durar más tiempo. El tratamiento consiste en evitar una «actividad cerebral» excesiva (televisión, juegos de ordenador, tareas del hogar o escolares) y permitir que el niño descanse o duerma bien. En algunos niños los síntomas pueden persistir más de un año después de la lesión aguda. En ocasiones, es posible que necesiten apoyo escolar con programas de aprendizaje individualizados (69).

Otros hallazgos clínicos. Defectos transitorios corticales como pérdida de visión o el estado confusional agudo, tienen una baja asociación con el TCEL. Estos déficits se piensa que son secundarios a hiperreactividad vascular inducida por el trauma, producidos por un mecanismo fisiopatológico similar al de la migraña $(70,71)$. Por otro lado, aunque son casos aislados, se han descrito ictus isquémicos tras TCEL en niños $(72,73)$.

Los niños que sufren un TCEL sin lesión intracraneal tienen en general un pronóstico excelente y se recuperan completamente en 24-48 h. La gran mayoría de los niños con TCE cerrados, con objetos romos, no experimenta complicaciones graves que pongan en peligro el cerebro o incluso la vida (24). No obstante, algunos pueden presentar alguna alteración cognitiva. En el contexto de traumatismos más graves se ha considerado clásicamente que el pronóstico en el niño era mejor que en el adulto tanto por lo que se refiere a la mortalidad como a las secuelas.

En algunas ocasiones, como en el caso del hematoma epidural, el niño puede estar inicialmente alerta y deteriorarse al cabo de unas horas. Un cuadro similar puede verse en los niños con tumefacción difusa, donde se ha descrito un escenario conocido como periodo lúcido seguido del fallecimiento. 
No debe infravalorarse el potencial de deterioro de un niño con un TCE con una contusión significativa, ya que el edema progresivo puede dar lugar a complicaciones devastadoras. En el niño comatoso con un TCE grave, la segunda manifestación clave es el desarrollo de HTIC.

Este desarrollo, con una herniación inminente, puede presagiarse por la aparición de una cefalea nueva o que se agrava, disminución del nivel de consciencia, cambios en las constantes vitales (hipertensión, bradicardia, respiraciones irregulares) y signos de compresión del sexto par craneal (parálisis del recto externo) o del tercer par craneal (anisocoria, ptosis, globo ocular hacia abajo y hacia afuera por parálisis de músculo recto).

El desarrollo del edema cerebral es progresivo. Una PIC notablemente elevada (>20 mmHg) puede aparecer después de un TCE, pero el valor máximo de la PIC suele verse, por lo general, en 48-72 horas. La necesidad de una terapia encaminada a disminuir la PIC puede mantenerse más de una semana. Unos pocos niños padecen coma sin aumento de la PIC, secundario a lesión axonal o del tronco del encéfalo (24).

Las tasas de mortalidad de los niños con TCE graves que ingresan en la Unidad de Cuidados Intensivos Pediátricos (UCIP) oscilan entre el $10 \%$ y el $30 \%$. La capacidad para controlar la PIC guarda relación con la supervivencia, y la magnitud de las lesiones craneales y sistémicas se relaciona con la calidad de vida. Las secuelas motoras y cognitivas derivadas de los TCE graves suelen beneficiarse de modalidades de rehabilitación para minimizar las discapacidades a largo plazo. La recuperación de un TCE puede tardar meses en lograrse pudiendo la terapia física facilitar la recuperación motora en mayor o menor medida (24).

Cuando abordamos los accidentes en vehículos de motor en los que existe un mecanismo de aceleración-desaceleración-impacto, no hay diferencias entre un grupo de edad de tres a dieciocho años y adultos menores de cuarenta años. En relación con las secuelas, se ha postulado que el pronóstico en el niño es mucho mejor que en el adulto por los fenómenos de plasticidad y capacidad de reorganización del cerebro inmaduro.

No obstante, aunque la recuperación motora y sensorial suele ser rápida y favorable, parece ser que las consecuencias de la lesión cerebral difusa se compensan peor que en el adulto, siendo más graves cuanto más pequeño es el niño y con 
repercusión en el aprendizaje y desarrollo de nuevas habilidades y conductas que pueden valorarse mejor en la edad adulta, por lo que pueden minimizarse en edades más tempranas.

Es preciso en el proceso de rehabilitación de los niños con lesión cerebral traumática un especial seguimiento neuropsicológico que contribuya a una completa inserción en el mundo laboral al llegar a la edad adulta (33). 


\subsection{CLASIFICACIÓN}

Hay múltiples formas de clasificar los traumatismos craneoencefálicos y existen controversias entre las distintas sociedades científicas a la hora de hacer la clasificación (74).

Para el estudio del TCE, se requiere un enfoque que comprenda la relación entre los distintos tipos de lesiones. Es importante, considerar los mecanismos estructurales, metabólicos y neurofisiológicos del cerebro infantil, ya que el compromiso de las distintas estructuras y cambios en la fisiología son distintos en un cerebro en desarrollo.

La clasificación del TCE puede analizarse desde varias perspectivas (40):

A) En base al compromiso neurológico de evaluación inicial mediante la GCS

Leve. Como se ha expuesto, no hay unanimidad a la hora de definir el TCEL. Según las guías clínicas publicadas por PECARN, se clasifican en esta categoría los niños con GCS de $\geq \mathbf{1 4}$ puntos. Se trata del lactante o del niño con historia o signos físicos de traumatismo en cráneo, encéfalo o cuero cabelludo, consciente y que responde a estímulos verbales o al tacto (10).

Moderado. GCS entre 9-13 puntos. Puede haber deterioro progresivo después de una pérdida inicial de la consciencia y producirse algún déficit neurológico focal transitorio.

Grave. La situación de coma se define por un valor en la GCS de $\leq \mathbf{8}$ puntos. Debe valorarse una vez que se han corregido los factores extracraneales que pueden incidir negativamente sobre el nivel de consciencia como la hipotensión arterial, la hipoxemia o la hipercapnia. Así mismo, se debe tener en cuenta la posibilidad de consumo o administración terapéutica de sustancias con acción depresora sobre el nivel de consciencia que pueden alterar la valoración de la escala de modo que se obtenga una puntuación inferior a la debida únicamente por 
el traumatismo (40). Lo desarrollaremos posteriormente en el apartado "escalas de valoración" por su gran relevancia en el presente trabajo $(29,33,74)$.

B) En función del tipo de lesión encefálica, se clasifican en:

Focal. Involucra las siguientes manifestaciones:

Contusión: lesión localizada, necrótica o hemorrágica, causada por transmisión directa de la energía de un trauma craneal a la región cortical y a la sustancia blanca subcortical. Característicamente, se ve en las regiones temporal o frontal por contacto directo del encéfalo con protuberancias óseas.

\section{Hematomas:}

Epidural. Colección de sangre entre la duramadre y el cráneo. Puede ser de origen venoso o arterial y generalmente no sobrepasa las líneas de las suturas, a menos que coexista con fractura. En la TAC aparece como una imagen localizada, lenticular, de alta densidad, con evidente efecto de masa.

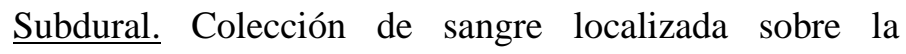
superficie de la corteza, bajo la duramadre. Generalmente está asociado a daño cortical por vasos lacerados o contusión cortical directa. En la TAC se observa una imagen crescéntica, hiperdensa, localizada a lo largo de las convexidades cerebrales.

Intracerebral. Coágulo sólido de sangre dentro del parénquima cerebral.

\section{Hemorragias:}

Intraventricular. Sangre dentro de los ventrículos.

Subaracnoidea. Sangre en el espacio subaracnoideo. Es la hemorragia más frecuente en el TCE. 
Daño axonal difuso (DAD). Se caracteriza por lesiones multifocales, consecuencia de daño primario y secundario. El componente mecánico del traumatismo produce estiramiento, torsión y rupturas de los axones y de capilares cerebrales provocando microhemorragias.

Se produce una degeneración de los axones, con presencia de retracción de la masa axonal, proliferación microglial, y desmielinización. Esto usualmente se acompaña de daño endotelial de los capilares, con áreas de microhemorragia, y edema focal o difuso.

Las tres áreas cerebrales más frecuentemente afectadas por el DAD son la sustancia blanca subcortical, el cuerpo calloso y el mesencéfalo. Histológicamente, el DAD se ha asociado con alteraciones citoesqueléticas y con cambios en la permeabilidad de la membrana del axón, dependiendo de la gravedad de la lesión $(75,76)$.

\section{C) Según la integridad de las cubiertas meníngeas}

TCE abierto o penetrante. Lesión con solución de continuidad de las envolturas meníngeas y comunicación del encéfalo con el medio externo. Se produce por un golpe u objeto perforante, que golpea con fuerza en la cabeza con dirección hacia el objeto lesionante. Hay una herida perforante, abierta, que lleva a una exposición de masa encefálica y dispersión de fragmentos de hueso.

TCE cerrado. Lesión sin comunicación del encéfalo con el exterior. Resulta de un golpe o impacto sobre la cavidad craneal con o sin herida del cuero cabelludo o fractura de cráneo, sin exhibir masa encefálica. Produce efectos de golpe y contragolpe, así como movimientos de aceleración y desaceleración por el desplazamiento del encéfalo.

En estos casos, al no existir fractura craneal se produce un aumento de la PIC debido al edema cerebral, produciendo compresión del tejido cerebral. 


\section{D) En función del tipo de fractura}

TCE con fractura de la base del cráneo. De manera característica en la fractura de la base del cráneo se produce daño de los nervios y vasos sanguíneos que pasan a través de los agujeros de la base craneal, dando lugar a dos signos típicos: signo de Battle (fractura en el hueso petroso, produciendo una mancha azulada-negruzca retroauricular, cervical y mandibular) y los ojos de mapache (fractura en la fosa craneal anterior, con hematoma periorbitario), pudiendo conjuntamente aparecer otolicuorrea con lesión del nervio acústico y rinolicuorrea con posible daño de los nervios olfatorio o visual.

TCE con fractura de la bóveda craneal. Puede ser lineal, cominuta, deprimida o con hundimiento o diastática.

Al mismo tiempo, se puede utilizar la clasificación de Marshall (tabla 2) propuesta por el Traumatic Coma Data Bank (TCDB) para clasificar las lesiones cerebrales, basada en los hallazgos neurorradiológicos de la TAC cerebral y que diferencia cuatro tipos de lesiones difusas y dos tipos de lesiones focales.

Cada uno de los tipos de lesiones de esta clasificación presenta un riesgo de HTIC y un carácter pronóstico específico.

Esta clasificación define mejor a grupos de pacientes que tienen en común el curso clínico, la incidencia de HTIC, el pronóstico y los esfuerzos terapéuticos requeridos. Por ello, posibilita estudios comparativos sobre pronóstico vital y funcional del TCE.

El porcentaje de HTIC y de resultados fatales (muerte y secuelas invalidantes) es más elevado conforme aumenta el grado de lesión difusa, así como en las masas no evacuadas frente a las evacuadas. 
I. Lesión difusa tipo I: ausencia de patología intracraneal visible en TAC cerebral (TAC normal).

II. Lesión difusa tipo II: cisternas perimesencefálicas presentes y $\sin$ alteraciones sin desplazamiento de la línea media o si lo hay, es de 0 $5 \mathrm{~mm}$. En esta categoría pueden existir lesiones focales cuyo volumen es igual o inferior a $25 \mathrm{cc}$.

III. Lesión difusa tipo III ("swelling"): se incluyen aquellos pacientes en los cuales las cisternas perimesencefálicas están comprimidas o ausentes, con desplazamiento de la línea media de $0-5 \mathrm{~mm}$. No deben existir lesiones hiperdensas o de densidad mixta con volumen superior a los 25 cC.

IV. Lesión difusa tipo IV ("shift" o desplazamiento): se incluyen aquellos pacientes en los cuales la desviación de la línea media es superior a 5 $\mathrm{mm}$ y presentan lesiones focales menores de $25 \mathrm{cc}$.

V. Lesión focal evacuada: cualquier lesión evacuada quirúrgicamente.

VI. Lesión focal de densidad alta o mixta y mayor de 25 cc no evacuada quirúrgicamente.

Tabla 2. Clasificación del Traumatic Coma Data Bank para el TCE (clasificación de las lesiones en la TAC craneal) (46) 


\subsection{ESCALAS DE VALORACIÓN}

Es fundamental catalogar la gravedad del TCE, ya que, además de tener implicaciones pronósticas, en función de ella se pondrán en marcha diversas actuaciones diagnósticas y terapéuticas.

Puede valorarse mediante diversas escalas, de las cuales la de mayor aceptación, en la que nos centraremos en el presente trabajo, es la GCS que en ocasiones precisa ser adaptada a la edad pediátrica para solventar la dificultad en el intercambio de información (74).

\begin{tabular}{|c|c|c|c|c|c|}
\hline $\begin{array}{c}\text { Respuesta } \\
\text { motora }\end{array}$ & & Respuesta verbal & & Apertura ocular & \\
\hline Obedece órdenes & 6 & Orientada & 5 & Espontánea & 4 \\
\hline Localiza el dolor & 5 & Confusa & 4 & A la voz & 3 \\
\hline Retirada al dolor & 4 & $\begin{array}{c}\text { Palabras } \\
\text { inapropiadas }\end{array}$ & 3 & Al dolor & 2 \\
\hline Decorticación & 3 & $\begin{array}{c}\text { Sonidos } \\
\text { incomprensibles }\end{array}$ & 2 & Ausencia & 1 \\
\hline Descerebración & 2 & Ausencia & 1 & & \\
\hline Ausencia & 1 & & & & \\
\hline
\end{tabular}

Tabla 3. Escala de coma de Glasgow para población general (77) 


\begin{tabular}{|c|c|c|c|c|c|}
\hline Respuesta motora & & Respuesta verbal & & $\begin{array}{c}\text { Apertura } \\
\text { ocular }\end{array}$ \\
\hline $\begin{array}{c}\text { Movimientos } \\
\text { espontáneos }\end{array}$ & 6 & Sonríe, llora, balbuceos & 5 & Espontánea & 4 \\
\hline Localiza el dolor & 5 & Irritable, llanto continuo & 4 & A la voz & 3 \\
\hline Retira al dolor & 4 & Llanto exagerado & 3 & Al dolor & 2 \\
\hline Decorticación & 3 & Quejido, gruñido & 2 & Ausencia & 1 \\
\hline Descerebración & 2 & Ausencia & 1 & \\
\hline Ausencia & 1 & & & \\
\hline
\end{tabular}

Tabla 4. Escala de coma de Glasgow modificada para lactantes (78)

Ésta última evalúa la respuesta ocular y las mejores respuestas verbales y motoras. El componente de mayor valor pronóstico es el motor, que debería referirse a las cuatro extremidades, aunque en la práctica se analiza con más frecuencia la respuesta de las extremidades superiores (33). La puntuación máxima es de quince puntos y la mínima de tres puntos. Un niño normal desde el punto de vista neurológico tiene una puntuación de quince puntos, mientras que un niño en coma profundo tendrá una puntuación de tres. Factores como la hipotensión, hipoxia, hipoglucemia, hipotermia, administración de sedantes, analgésicos o relajantes musculares alteran la puntuación disminuyéndola significativamente.

Por ello, para que esta escala sea fiable debe medirse tras la estabilización respiratoria y hemodinámica del niño y sin administración de sedantes o analgésicos. La intubación endotraqueal anula la GCS, ya que no permite valorar la escala verbal y exige tener al paciente sedado (79).

La GCS es una escala utilizada ampliamente en la evaluación inicial de pacientes con un TCE, tanto a nivel extrahospitalario como a su llegada al hospital y muchos estudios apoyan su validez y reproducibilidad. Existen datos que apoyan la GCS como un indicador fiable de la severidad del TCE en relación al riesgo de complicaciones intracraneales y a la necesidad de cirugía, no como medida única, 
sino en relación a la disminución de la puntuación en el tiempo, tras medidas repetidas $(80,81)$.

En ocasiones, se utiliza lo que se llama la escala motora simplificada o Simplified Motor Score, que se trata de una escala de 2 puntos como máxima puntuación y valora únicamente los tres siguientes supuestos: obedece órdenes ( 2 puntos), localiza el dolor (1 punto) y retira al dolor (0 puntos).

Según un estudio de Thompson et al, la utilización de la escala simplificada obtuvo resultado similares a la GCS en un ambiente extrahospitalario a la hora de evaluar pacientes que habían sufrido un TCE (82). Un metaanálisis posterior concluía que la escala simplificada en la evaluación del paciente politraumatizado era igual de útil y más sencilla de llevar a cabo, fundamentalmente a la hora de la atención a nivel extrahospitalario $(83,84)$.

Como se ha desarrollado, la puntuación de la GCS debería medirse después de que la vía aérea se haya asegurado y después de cualquier maniobra de resucitación respiratoria o circulatoria y previamente a la administración de agentes sedantes o paralizantes, o tras la metabolización de dichas drogas, ya que éstas pueden modificar el resultado de la valoración. La evaluación inicial de pacientes con TCE debería estar basada en medidas repetidas de la GCS.

En niños por debajo de los cinco años la GCS es difícil de aplicar, por lo que se debe tener mucho cuidado en su interpretación y debería ser realizado por personal con experiencia en su manejo.

En menores de dos años utilizaremos para la evaluación inicial del TCE la GCS modificada para lactantes, la cual incluye una alternativa para la valoración verbal. Las dificultades a la hora de evaluar al paciente con este método serían el edema de párpados, afasia, intubación, sedación, etc.

Otro sistema de evaluación que ha caído en desuso es la regla AVPU (alert, verbal, pain, unresponsiveness), que clasifica al paciente en 4 categorías:

\section{A. Alerta}

V. Responde a estímulos verbales

P. Responde a estímulos dolorosos

U. No responde 
En algunos centros se continúa utilizando, básicamente en la asistencia prehospitalaria.

En varios estudios se demostró una buena correlación entre las escalas AVPU y la GCS sobre todo en las categorías "A" y "U" pero resulta imprecisa en fases precoces de alteración de consciencia.

Ninguna escala simplificada debería reemplazar el uso de la GCS para una evaluación formal en el paciente crítico tras un TCE (85-87). 


\subsection{MANEJO DEL TCE LEVE}

Cuando se realiza correctamente la valoración del enfermo con TCEL, nos encontramos con que la gran mayoría de los niños no requiere más que unos cuidados sencillos y estandarizados en lugar de unas medidas terapéuticas activas, y que sólo en aisladas ocasiones se necesitará un tratamiento quirúrgico (29).

A pesar de lo frecuente de la enfermedad, hay multitud de protocolos diagnósticos y de actuación distintos. Estas diferencias en el manejo se acentúan conforme aumenta la complejidad del caso y vienen determinadas por las costumbres locales, las prácticas institucionales habituales, la accesibilidad a las pruebas diagnósticas, la opinión del facultativo y la presión familiar.

La evaluación y tratamiento inicial de pacientes con traumatismos, requiere un acercamiento sistemático al mismo con el fin de identificar y tratar en primer lugar el problema de mayor compromiso vital, evitar provocar daños mayores y proporcionar un sistema de transporte seguro a un centro hospitalario con los recursos necesarios para optimizar los resultados. Los servicios sanitarios encargados de la atención a pacientes con traumatismos, deberían estar plenamente entrenados en el uso de la GCS.

El sistema de soporte vital avanzado en traumatismos y el sistema de soporte vital avanzado pediátrico (Advanced Trauma Life Support y Advanced Paediatric Life Support Systems) sustentan la práctica estándar en la evaluación y cuidado inicial de los pacientes con un traumatismo. La prioridad en el cuidado inmediato de pacientes con traumatismos es tratar la situación de mayor riesgo vital y evitar daños mayores (88-90).

Teniendo en cuenta que no existe evidencia suficiente para apoyar estándares de tratamiento para muchas de las intervenciones prehospitalarias, las guías revisadas recomiendan potenciar la investigación sobre la efectividad de estas intervenciones.

La prioridad en la evaluación a los niños con TCE es la identificación de aquellos que presenten una LIC y puedan requerir intervención inmediata, observación o ingreso para monitorización o seguimiento estrecho, mientras que limitamos la realización de pruebas de imagen de manera innecesaria. 


\subsubsection{EVALUACIÓN PRIMARIA}

La evaluación inicial engloba dos herramientas imprescindibles: la impresión general que se obtiene por medio del Triángulo de Evaluación Pediátrica (TEP) y la evaluación $\mathrm{ABCDE}$ que nos permite identificar alteraciones funcionales $\mathrm{y}$ anatómicas y actuar en consecuencia.

\subsubsection{Triángulo de Evaluación Pediátrica}

El TEP es una herramienta especialmente adaptada para la edad pediátrica que nos permite, de una forma rápida, evaluar el estado fisiológico global del niño; es decir, su oxigenación, ventilación, perfusión y función cerebral. El TEP facilita la evaluación funcional inmediata y la toma de decisiones rápidas con respecto al apoyo vital. Incluye tres componentes a valorar: la apariencia, la respiración y la circulación. Con ellos, el TEP no nos proporciona un diagnóstico del paciente, pero sí una valoración del estado fisiológico y de sus necesidades urgentes para mantener una adecuada homeostasis (91).

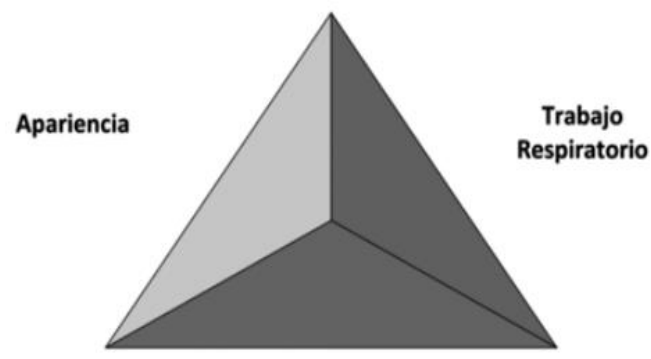

Circulación de la piel

Figura 3. Triángulo de evaluación pediátrica. 
Aspecto general: es el apartado que aporta más información sobre el estado de oxigenación, ventilación, perfusión cerebral y función del sistema nervioso central (SNC). Las características que se deben tener en cuenta son el tono, la interacción con el entorno, el consuelo, la mirada, el llanto y el lenguaje. La apariencia puede estar alterada por una mala oxigenación o perfusión cerebrales, por causas sistémicas, como hipoglucemia o intoxicación, por una infección del SNC, por una lesión cerebral, como un TCE.

Respiración: aporta información rápida sobre la oxigenación y ventilación. Se evaluarán los ruidos respiratorios (gruñido, ronquera, disfonía, estridor, quejido, sibilancias), la postura anormal y los signos visuales (tiraje, aleteo nasal, taquipnea, cabeceo).

Circulación: ayuda a determinar si el gasto cardiaco y la perfusión de los órganos vitales son adecuados. Los principales indicadores a valorar son la palidez, la cianosis y el cutis reticular.

La combinación de estos tres lados nos proporcionará una evaluación rápida y precisa del estado fisiológico del paciente y de cuáles son sus necesidades prioritarias hacia las cuales debemos dirigir nuestras actuaciones siguientes.

En la tabla 5 vemos los estados fisiológicos en función de la alteración de ninguno, uno, dos o los tres lados del triángulo, y las causas más frecuentes de estas alteraciones (92). 


\begin{tabular}{|c|c|c|c|c|}
\hline Apariencia & $\begin{array}{c}\text { Trabajo } \\
\text { respiratorio }\end{array}$ & $\begin{array}{c}\text { Circulación } \\
\text { cutánea }\end{array}$ & Estado fisiológico & Causas \\
\hline NORM & NORM & NORM & Normal & \\
\hline ALT & NORM & NORM & Disfunción SNC & $\begin{array}{l}\text { Hipoglucemia } \\
\text { Lesión cerebral } \\
\text { Intoxicación } \\
\text { Sepsis }\end{array}$ \\
\hline NORM & ALT & NORM & Dificultad respiratoria & $\begin{array}{c}\text { Broncoespasmo } \\
\text { Laringitis } \\
\text { Neumonía } \\
\text { Aspiración de cuerpo extraño }\end{array}$ \\
\hline ALT & ALT & NORM & Fallo respiratorio & $\begin{array}{l}\text { Broncoespasmo severo } \\
\text { Laringitis severa } \\
\text { Trauma tórax penetrante }\end{array}$ \\
\hline NORM & NORM & ALT & Shock compensado & $\begin{array}{c}\text { Hemorragia } \\
\text { Deshidratación leve }\end{array}$ \\
\hline ALT & NORM & ALT & Shock descompensado & $\begin{array}{c}\text { Hemorragia grave } \\
\text { Deshidratación grave } \\
\text { Sepsis } \\
\text { Quemadura grave } \\
\text { Trauma abdominal penetrante }\end{array}$ \\
\hline ALT & ALT & ALT & Fallo cardiopulmonar & Parada cardiorrespiratoria \\
\hline
\end{tabular}

Tabla 5. Estados fisiológicos según la alteración de los lados del TEP y sus causas más comunes.

\subsubsection{Evaluación ABCDE}

\section{A. Control cervical y vía aérea}

Inmovilización cervical, se recomienda realizar inmovilización de la columna cervical en pacientes con TCE y alguno de los siguientes factores de riesgo: GCS < 15 en cualquier momento tras el traumatismo, dolor de cuello o rigidez, parestesias en extremidades, déficit focal neurológico, mecanismo traumático de alta energía y sospecha clínica de daño cervical.

La inmovilización de columna cervical debería mantenerse hasta que se realice una evaluación completa del riesgo, incluidas pruebas de imagen si se considera necesario y se determine que puede retirarse con seguridad $(65,85)$.

Vía aérea, la permeabilización de la vía aérea se debe asegurar de rutina. Se debe intubar cuando la hipoxemia no se corrija con oxígeno suplementario o ventilación 
no invasiva, exista incapacidad de mantener la vía aérea permeable, hipoventilación $y$ en TCE graves $(\mathrm{GSC}<9)$.

La intubación debe realizarse de forma inmediata en los siguientes supuestos: coma, pérdida de reflejos laríngeos, insuficiencia respiratoria (hipoxemia o hipercapnia), hiperventilación espontánea y arritmia respiratoria. Se puede valorar intubación previa al traslado en casos de fractura bilateral de la mandíbula, sangrado abundante a través de la boca (fractura de la base del cráneo) o convulsiones. Tanto la intubación como el mantenimiento del paciente intubado deben realizarse con el paciente bien sedado y relajado, administrando sedantes antes de la intubación para evitar aumentos innecesarios de la PIC (79).

\section{B. Ventilación}

Se debe controlar la ventilación midiendo frecuencia y patrón respiratorios, así como mediante la saturación arterial de oxígeno $\left(\mathrm{SatO}_{2}\right)$ y la auscultación pulmonar. Es muy importante evitar la hipoxemia, por lo que se administrará oxígeno con fracción inspirada de oxígeno $\left(\mathrm{FiO}_{2}\right)$ al $100 \%$ y se mantendrá la $\mathrm{SatO}_{2}$ superior al 95\%. Para reconocer la hipoxemia usaremos la exploración física (apnea, cianosis) o la $\mathrm{SatO}_{2}$ (pulsioxímetro). La hipoxemia debe ser corregida mediante la administración de oxígeno suplementario. Se identificará y corregirá inmediatamente cualquier lesión en el aparato respiratorio que comprometa gravemente el intercambio gaseoso. No se recomienda hiperventilar de forma rutinaria, solamente si hay datos de sufrimiento cerebral y con control capnográfico (42).

\section{Circulación}

Ejecutar la valoración de la circulación mediante la toma de pulso (intensidad, frecuencia cardiaca y ritmo), medición de la tensión arterial (TA), relleno capilar para valorar el estado de perfusión y control del sangrado, si lo hubiera. Es fundamental evitar la hipotensión que supondrá una disminución de la perfusión cerebral mediante monitorización frecuente de la TA y la frecuencia cardiaca (FC).

Estos valores varían en función de la edad y se entiende por hipotensión el estado en que la presión arterial sistólica (TAS): entre 15-16 años TAS < 90 mmHg; entre 512 años TAS < 80 mmHg; entre 1-5 años PAS < 75 mmHg; menores de 1 año TAS < 
$65 \mathrm{mmHg}$. La medición de la TA se debe realizar con el método más exacto que tengamos y, a ser posible, de forma continua. La fluidoterapia es la medida más importante para mantener la TA, de esta forma nos aseguramos una buena perfusión cerebral y limitamos el daño cerebral secundario.

Se utilizarán soluciones cristaloides isotónicas (suero salino fisiológico (SSF) o Ringer) o soluciones coloides (albúmina al 5\%) evitando los sueros glucosados y soluciones hipotónicas. Se deben evitar sobrecargas de líquidos, ya que aumentan la precarga.

Previo al ingreso hospitalario y a la neuromonitorización, solamente se administrarán soluciones hiperosmolares (manitol, salino hipertónico) cuando se observen signos evidentes de enclavamiento.

\section{Evaluación neurológica}

Una vez estabilizado respiratoria y hemodinámicamente, se procede a la exploración neurológica básica, con valoración pupilar y valoración de la GCS. Resulta esencial que esta evaluación se realice de forma repetida y frecuente valorando la aparición de cambios debido a que el estado neurológico del paciente es cambiante.

El personal asistencial debería evaluar completamente al paciente cada cinco minutos y tratar o modificar el tratamiento en la medida que se requiera en cada momento. La puntuación de la GCS es un indicador fiable de la gravedad del TCE, en especial si se repite su medición varias veces (observando variaciones en la puntuación). La GCS debe obtenerse explorando al paciente (dar órdenes, aplicar estímulos dolorosos, etc.) y debe medirse en la valoración inicial del paciente, una vez que la vía aérea se haya asegurado, y después de cualquier maniobra de resucitación respiratoria o circulatoria.

Como se ha explicado, la GCS debe obtenerse previamente a la administración de agentes sedantes o paralizantes, o tras la metabolización de dichas drogas. En la exploración pupilar, de manera resumida debemos observar: la asimetría, la ausencia de respuesta a un estímulo luminoso, los posibles traumas orbitarios y el tiempo que permanecen fijas o dilatadas. 
Es conveniente examinar las pupilas una vez que el paciente haya sido estabilizado. En un paciente que no se haya monitorizado la PIC ni la saturación de oxígeno en el bulbo de la yugular $\left(\mathrm{SjO}_{2}\right)$ y presente signos indirectos de HTIC (alteraciones pupilares, descenso brusco de la FC o aparición de focalidad neurológica) puede hiperventilarse de forma transitoria (frecuencia respiratoria cinco respiraciones por minuto mayor que la normal para su edad, objetivo gasométrico de $\mathrm{PaCO}_{2}$ entre 35 y $40 \mathrm{mmHg}$ y $\mathrm{PaO}_{2}$ alrededor de $100 \mathrm{mmHg}$ ) y, si persiste la PIC elevada estaría indicada la terapia hiperosmolar, intentando alcanzar una osmolaridad sérica entre 320 y $360 \mathrm{mOsm} / \mathrm{kg}$ mediante la administración de suero salino hipertónico al 3\% o al 6\% o manitol (79).

Por todo lo anterior, la GCS adaptada a la edad del niño, ha demostrado ser una herramienta eficaz en la valoración inicial del TCE, tanto en el ámbito extra como intrahospitalario. Esta escala permite la clasificación del TCE según su gravedad y es un método simple y fiable de registro y monitorización del nivel de consciencia.

\section{E. Exposición}

Es el último paso de la evaluación primaria, consiste en la exposición con examen físico y control ambiental. En este apartado se desviste completamente al niño para observarle detenidamente por si presenta indicios de traumatismo, hemorragias no visualizadas anteriormente, quemaduras o lesiones en piel como púrpuras o lesiones habonosas. Además, en esta fase se toma la temperatura al niño y se toman medidas para evitar la hipotermia. (46).

Tras la evaluación y estabilización inicial y una vez que el paciente se encuentra estable, es el momento de realizar una historia clínica dirigida y una exploración física detallada.

\section{Historia clínica}

Lo primero que debemos hacer es recabar información mediante la anamnesis. Para poder realizar un correcto diagnóstico del TCE, se debe comenzar realizando una buena historia clínica en la que se recojan, al menos, los siguientes datos $(11,18,21)$ : 
- Edad: los menores de un año son pacientes de mayor riesgo.

- Mecanismo del traumatismo: caída desde altura, accidente de tráfico, impacto directo... Con ello, podemos sospechar el tipo de lesión que puede presentar el paciente y determinar si el mecanismo causal ha sido de alta o baja energía. Una historia incongruente debe hacer sospechar la posibilidad de que las lesiones sean intencionales.

- Síntomas asociados: interrogar sobre los referidos en el apartado "aspectos clínicos" (vómitos, pérdida de consciencia y su duración, cefalea, convulsiones, etc.).

- Localización del traumatismo y tiempo transcurrido desde el mismo.

Las características que sugieren mayor riesgo de LICci son: preocupación por parte de los cuidadores en un menor de dos años con comportamiento extraño, convulsiones, confusión o pérdida de consciencia, cefalea intensa o en aumento, vómitos, mecanismo de alta energía (accidente de vehículo a motor, agresión, caídas de altura considerable...) y antecedentes personales patológicos como malformación arteriovenosa a nivel del SNC o coagulopatías (67-70).

\section{Exploración física}

El facultativo debe llevar a cabo una exploración neurológica completa además de valorar los signos vitales y posibles lesiones extracraneales. Las presencia de los siguientes signos es significativa $(12,13,94-96,99)$ : alteración del cuero cabelludo como el cefalohematoma, fontanela anterior abombada, alteración del estado de consciencia $(\mathrm{GCS} \leq 14)$, focalidad neurológica, signos de fractura de la base del cráneo (signo de Battle, equimosis periorbitaria, otorinolicuorrea), etc.

La historia clínica y la exploración física, junto con la neuroimagen apropiada, generalmente identifican a los niños con lesión cerebral que precisan manejo agudo. En niños con TCEL, no existe una combinación de síntomas y signos con sensibilidad o especificidad del $100 \%$ para detectar LICci. No obstante, los hallazgos físicos ayudan a estratificar la gravedad de los pacientes de sufrir una LICci y así determinar la necesidad de neuroimagen $(80,81,84)$.

Es frecuente que un TCE se encuentre en el contexto de un politraumatismo; por tanto, la secuencia de actuación más aceptada sería iniciar la exploración física por el 
ABCDE, que forma parte de la evaluación primaria, para descartar la existencia de riesgo vital. En el abordaje inicial al TCE debe considerarse como prioritario la óptima estabilización del $\mathrm{ABCDE}$, para conseguir una adecuada ventilación y estabilización hemodinámica (79).

El TCE es uno de los grupos más beneficiados por la prioridad del sistema cardiorespiratorio sobre el sistema nervioso durante la asistencia urgente, ya que esta secuencia asistencial permite identificar y corregir los factores etiológicos sistémicos que provocan la lesión cerebral secundaria, como son hipoxemia y la hipotensión arterial que se asocian a mayor morbimortalidad, así como valorar la posible influencia de éstos en el sensorio $(41,100)$. 


\subsubsection{EVALUACIÓN SECUNDARIA}

Tras finalizar la evaluación primaria y una vez estabilizado el paciente, iniciaremos la evaluación secundaria realizando una exploración física y neurológica exhaustiva para descartar lesiones concretas.

En esta exploración es importante buscar focalidad neurológica, valorar la presencia de signos de fractura de base de cráneo, la exploración del cuero cabelludo en busca de posibles heridas que hayan pasado desapercibidas, cuerpos extraños penetrantes, hematomas en zonas de riesgo (temporal y parietal) y presencia de fracturas con hundimiento, entre otros. Los lactantes presentan líneas de sutura craneales móviles y las fontanelas abiertas, lo que supone una mayor tolerancia a lesiones expansivas intracraneales. Esta circunstancia produce que la clínica pueda aparecer de forma tardía, cuando la lesión ya es extensa (41).

Una vez realizadas la evaluación primaria y secundaria, en la mayoría de lactantes y niños con TCEL el manejo se basa en los hallazgos clínicos más que en los resultados de neuroimagen. Además, en los pacientes con LICci, el manejo específico puede venir determinado por el tipo de lesión.

Los pacientes con una LICci ser valorados de manera urgente por un neurocirujano cuando: se detecta una lesión intracraneal en la TAC, existe fractura deprimida, diastática o de la base del cráneo o se deteriora el estado clínico (GCS $<12$ o en descenso rápido) independientemente de los resultados de las pruebas de imagen. Estos pacientes precisan ingreso hospitalario con monitorización intensiva o intervención neuroquirúrgica en función del estado clínico y del tipo de lesión detectada (79).

La posible aparición de un empeoramiento clínico motiva en ocasiones la observación del paciente en el medio sanitario; ya que el intervalo en el que suele aparecer el deterioro asociado a daño cerebral secundario es de 4-6 horas. Algunos autores sugieren que el periodo de observación no debe ser inferior a ese tiempo (29). Durante su estancia se deben realizar controles periódicos de constantes hemodinámicas, y del estado neurológico, con la determinación del valor de la GCS, desglosada en cada uno de sus componentes. 
El ambiente ha de ser tranquilo, y el paciente debe estar colocado en posición semiincorporada con la cabeza unos $30^{\circ}$ sobre el plano horizontal. De esta forma se reduce la PIC al mejorar el retorno venoso. También hay que evitar la lateralización de la cabeza. La dieta absoluta no es imprescindible, excepto que se prevea la necesidad de una sedación para la realización de TAC (29).

La mayoría de los lactantes y niños con TCEL pueden ser dados de alta tras la evaluación por parte de los facultativos.

La observación sigue siendo importante incluso después del alta, porque los signos y síntomas del trauma craneal pueden surgir con posterioridad. Por ello se deben dar instrucciones claras de los signos y síntomas que se deben vigilar en el domicilio y se debe asegurar la presencia de cuidadores que estarán pendientes y acudirán de nuevo al hospital para reevaluación en caso necesario. El facultativo debe también determinar, en función del escenario clínico (edad, síntomas, tiempo desde el traumatismo, momento del día, distancia al hospital desde el domicilio y la calidad de la observación de los cuidadores), si puede ser necesaria observación hospitalaria del paciente y cuánto debería durar la misma.

En los pacientes con TCEL que han sido evaluados y tienen bajo riesgo de LICci pueden ser dados de alta sin neuroimagen ni necesidad de ingreso hospitalario.

La evidencia indica que la probabilidad de una LICci no detectada que necesita intervención es extremadamente baja en estos pacientes. Por ejemplo, el riesgo de LICci en los pacientes que cumplen los criterios de bajo riesgo de LICci según las guías clínicas de PECARN es menor de cinco por cada diez mil, por lo que no está indicada la realización de neuroimagen, dado el riesgo de exposición a la radiación que supone (10).

Los pacientes que han permanecido en observación sin realizar neuroimagen durante un periodo entre cuatro y seis horas, pueden ser dados de alta si muestran mejoría de la clínica inicial durante la observación y cumplen los criterios de un alta segura. Un diagnóstico tardío de LICci es muy infrecuente. Por ejemplo, en un estudio observacional de 17962 niños evaluados en servicios de urgencias por TCE no complicado, con o sin TAC craneal, la incidencia de diagnóstico tardío (considerado como después de 6 horas) de LIC en un paciente sin deterioro del nivel de consciencia fue del 0,14-0,6 casos por cada 100000 niños al año (101). 
Por el contrario, aquellos pacientes que muestran un empeoramiento de los síntomas con el tiempo precisan neuroimagen y manejo según los hallazgos radiológicos.

Los pacientes que inicialmente no cumplen los criterios de bajo riesgo o que presenta una fractura craneal y se les realiza una TAC con resultado normal, con nivel de consciencia normal y cumplen los criterios de alta hospitalaria pueden ser dados de alta. Blackwood et al. demostraron que de los 71 pacientes con fractura craneal aislada que ingresaron para observación, ninguno requirió intervención quirúrgica. Concluyeron que pacientes con fractura de cráneo sin sangrado intracraneal en la TAC y con exploración neurológica normal podrían ser dados de alta sin necesidad de ingreso hospitalario para observación, lo que conllevaría un ahorro importante del gasto sanitario (102).

El alta hospitalaria de pacientes vigilados en observación o ingresados por un TCE debe hacerse tras una cuidada planificación, con un protocolo de seguridad, y distribuyendo a los cuidadores una serie de recomendaciones al alta para una adecuada observación domiciliaria y un seguimiento extrahospitalario sistemático dada la posibilidad de complicaciones tardías y discapacidades a largo plazo.

Previo al alta el facultativo debe valorar al paciente y asegurarse de que: ha recuperado totalmente y de forma sostenida el nivel de conciencia; presenta buena tolerancia oral sin presentar vómitos; los síntomas y signos neurológicos se han resuelto, o son menores y en resolución, y son susceptibles de recomendaciones sencillas o tratamientos (como analgésicos para la cefalea); no existe sospecha de abuso; que los resultados de las imágenes y de otras investigaciones han sido revisados y no requieren nuevas pruebas complementarias y que se ha excluido o tratado cualquier otra lesión extracraneal. Asimismo, hay que asegurar que tiene un soporte social adecuado y que los cuidadores o familiares pueden llevar a cabo una vigilancia adecuada y reconsultarán en caso de aparición de signos de alarma explicados. Es recomendable adjuntar una hoja de recomendaciones al informe de alta, que debe ser explicada verbalmente al paciente y a la persona cuidadora o familiar (103). 


\subsection{APROXIMACIÓN DIAGNÓSTICA}

Los avances tecnológicos en radiología en los últimos 30 años han mejorado mucho la capacidad para diagnosticar enfermedades neurológicas. Antes de la introducción de la TAC en 1974 las exploraciones neurorradiológicas del cerebro consistían fundamentalmente en radiografías simples de cráneo, arteriografía cerebral, neumoencefalografía y estudios convencionales de medicina nuclear.

La mayor parte de dichas técnicas sólo daban información indirecta sobre las afecciones intracraneales sospechadas, pero no eran sensibles para detectar lesiones cerebrales sutiles o precoces o eran potencialmente peligrosas para el paciente.

La TAC revolucionó el manejo de las alteraciones del SNC debido a que, por primera vez, se pudieron ver directamente las estructuras neurales normales y alteradas (104).

La realización de pruebas complementarias en pacientes con TCEL tiene como principal finalidad identificar, de forma rápida, lesiones que requieran una actuación médica o quirúrgica urgente, con el objetivo de disminuir la morbimortalidad (41).

Las técnicas radiológicas que se utilizan para evaluar el cerebro y sus cubiertas pueden dividirse en dos grupos principales: modalidades anatómicas y modalidades funcionales.

Por un lado, las técnicas anatómicas proporcionan principalmente información de naturaleza estructural o morfológica, que incluyen la radiografía simple de cráneo, la $\mathrm{TAC}$, la resonancia magnética (RM), la arteriografía cerebral y la ultrasonografía.

Por otro, la tomografía computerizada por emisión de fotón simple (SPECT) y la tomografía por emisión de positrones (PET), la TAC-perfusión, las imágenes de RM potenciadas en difusión y perfusión, la RM funcional y la espectroscopia por RM son modalidades principalmente funcionales que proporcionan información sobre el metabolismo o la perfusión cerebral.

Algunas de estas técnicas como la RM proporcionan tanto información anatómica como funcional $(104,105)$. 


\subsubsection{Pruebas de imagen}

El primer objetivo de las pruebas de imagen es facilitar un diagnóstico rápido y preciso de las lesiones cerebrales. Este propósito resulta crucial en aquellos sujetos que se beneficien de una actuación médica o quirúrgica urgente para minimizar la morbilidad y mortalidad derivadas del daño cerebral secundario.

Son pruebas complementarias útiles aquellas cuyo resultado contribuye a modificar la conducta diagnóstico-terapéutica del médico o a confirmar su diagnóstico. Las pruebas radiológicas que no cumplen estos cometidos suponen un coste innecesario de recursos, y en ocasiones, una exposición innecesaria del paciente a radiación ionizante. Es importante recordar, además, que la realización de pruebas complementarias no puede anteponerse a la estabilización de las funciones vitales del paciente (104). 


\subsubsection{TOMOGRAFÍA AXIAL COMPUTERIZADA}

La TAC es la técnica de imagen de elección para el estudio de prácticamente todas las lesiones traumáticas agudas de la cabeza. El tiempo de estudio es corto, y tanto las hemorragias intracraneales como las fracturas craneales se evidencian fácilmente. Los pacientes en situación inestable pueden monitorizarse fácilmente y la administración de contraste intravenoso no suele ser necesaria en esta situación clínica.

No obstante, esta técnica no siempre está disponible, requiere una interpretación especializada, representa un coste económico considerable y posee unos potenciales efectos iatrogénicos.

La dosis de radiación de una exploración (de 2,3 $\mathrm{mSv}$ ) es superior a la radioexposición ambiental recibida en un año de vida, y para su realización en los lactantes y niños no colaboradores se ha de recurrir a la sedación. Esto hace que su utilización quede restringida a una serie de situaciones clínicas con sospecha de lesión intracraneal $(10,106)$.

Un estudio de TAC consiste en imágenes tomográficas generadas en un ordenador y que se obtienen mediante un haz de rayos $\mathrm{X}$ rotatorio y un sistema de detectores. Los avances recientes en la tecnología de la TAC permiten actualmente la adquisición simultánea de múltiples imágenes en cada rotación del tubo de rayos X.

Las imágenes resultantes, muestran de forma clara los tejidos blandos y permiten diferenciar unos de otros. Por tanto, proporcionan una visualización directa de los contenidos intracraneales y de las alteraciones que se asocian a las enfermedades neurológicas (104).

Las principales ventajas de la TAC son: es una técnica económica, fácilmente disponible, puede utilizarse en pacientes con implantes no compatibles con la RM y permite una valoración bastante rápida de los contenidos intracraneales. Las imágenes de la TAC son muy sensibles para detectar hemorragia aguda y calcificación, y pueden adquirirse imágenes con un magnífico detalle óseo del cráneo o de la base del cráneo. 
Sin embargo, también existen algunas desventajas: expone a los pacientes a radiaciones ionizantes y en ocasiones se utilizan medios de contraste yodados. A veces hay artefactos en la imagen que pueden dificultar una interpretación adecuada. En especial, la evaluación del tronco cerebral y de la fosa posterior con frecuencia es difícil debido a "artefactos en bandas" originados por el hueso denso de los peñascos. Las imágenes pueden ser de muy baja calidad si el paciente se mueve lo que conlleva la necesidad de someter a los pacientes pediátricos a sedaciones para poder llevar a cabo la prueba (104).

El uso de la TAC en la población pediátrica se ha duplicado en las últimas dos décadas; de forma global, de 10,6 por cada 1000 niños en 1996 a 21,5 por cada 1000 en 2010, dato que preocupa a los profesionales sanitarios (107,108). El uso incrementado de la TAC añade a la asistencia sanitaria un coste importante así como la exposición de un gran número de niños a los efectos dañinos de la radiación ionizante (109). Actualmente, en torno al $10 \%$ de todas las TAC se llevan a cabo en pacientes pediátricos y constituyen alrededor del $67 \%$ de la radiación derivada de pruebas médicas en dicho colectivo (110). En los servicios de urgencias pediátricos de Canadá aumentó el porcentaje de realización de TAC en TCEL del 15\% en 1995 al 53\% en 2005 (111).

En la mayoría de niños con TCEL puede descartarse una LICci sin necesidad de una TAC. La decisión de realizar una TAC debe realizarse utilizando indicadores clínicos para determinar el riesgo de LICci.

Calcular la probabilidad individual de LICci de los pacientes mediante los indicadores clínicos es un factor clave para el correcto manejo de los pacientes. Por ejemplo, en un estudio Hennely et al. observaron que ninguna prueba de imagen era útil en pacientes menores de dos años con TCEL, en términos de riesgo-beneficio, cuando la probabilidad de LICci era del $0,9 \%$ o inferior (112).

No obstante, en los niños con TCEL de alto riesgo de LICci y que puedan necesitar neurocirugía o cuidados intensivos deben realizarse una TAC craneal de manera precoz. La TAC identifica todas las LICci siendo las imágenes que inicialmente son más patentes las fracturas y las hemorragias (113). Las lesiones isquémicas pueden tardar varios días en aparecer. En niños pueden producirse lesiones parenquimatosas con escasa o nula repercusión clínica. 
Asimismo, la práctica habitual que se lleva a cabo en algunos centros de repetir la TAC en pacientes con LIC no parece ser más beneficiosa que la vigilancia clínica por parte de los facultativos durante la observación hospitalaria salvo en algunos casos concretos (114-117).

El National Research Council Committee on the Biological Effects of Ionizing Radiation estima que los niños menores de diez años son mucho más sensibles a la radiación que los adultos. Pero el riesgo individual asociado a la TAC puede ser pequeño comparado con los beneficios que proporciona un diagnóstico preciso a través de la prueba siempre que esté bien indicada. La exposición a la radiación de manera innecesaria debe evitarse, sobre todo en niños (118).

La dosis de radiación es particularmente importante en la población pediátrica ya que la exposición a la TAC se asocia a un aumento de riesgo de cáncer en la edad adulta $(119,120)$. El riesgo por cáncer estimado por una TAC craneal es substancialmente mayor en niños, cuadruplicándolo frente a los adultos, debido a una esperanza de vida más larga y mayor sensibilidad de los órganos en desarrollo (como la médula ósea o el SNC) a la radiación. Aun así, el periodo de latencia para desarrollar el cáncer puede ser de varias décadas $(121,122)$.

La literatura científica proclama que la radiación cerebral temprana perjudica la función cognitiva a largo plazo $(106,123)$. Se estima que el riesgo de muerte causado por la radiación de una TAC craneal es de 1 en 1500 en lactantes de un año y de 1 en 5000 en niños de 10 años (119).

La mayoría de estudios hasta la fecha sobre la TAC se han llevado a cabo en adultos, utilizándose las mismas dosis que en adultos con los niños. Muchas TAC tienen un software que automáticamente utiliza los parámetros para obtener la calidad óptima de las imágenes calculadas para adultos.

Se debe hacer todo el esfuerzo posible para minimizar la dosis de radiación en los niños sometidos a TAC según la política de "lo razonablemente menos posible" o as low as reasonably achievable (ALARA) o least radiation dose necessary (124). Estos conceptos se basan en los siguientes métodos: utilizar protocolos basados en el peso y mejorar la protección, considerar técnicas alternativas no radiantes como la RM, utilizar el mínimo número de cortes posibles y evitar repetir los estudios de TAC (125). 
La corriente del tubo es un parámetro que puede ajustarse para reducir la exposición a radiación en los niños durante la TAC. Se trata del número de electrones utilizados para generar la fuente de rayos X; si se disminuye la corriente de tubo, disminuye la exposición a la radiación, aunque aumenta el ruido. Muchos autores recomiendan la disminución de este parámetro a la hora de realizar la prueba en niños $(126,127)$.
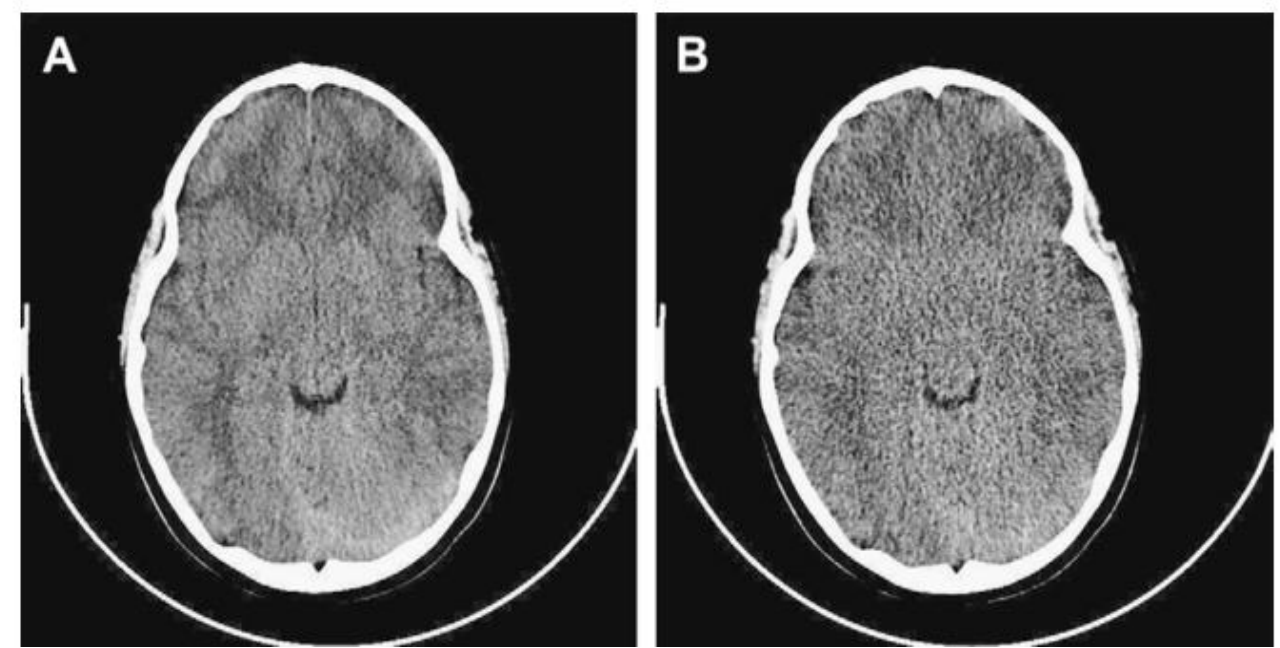

Los estudios de escáner que utilizaron bajas dosis de radiación resultaron en una dosis efectiva para la prueba de $0,58 \mathrm{mSv}$, que sería comparable a los niveles de radiación de una $\mathrm{Rx}$ antero-posterior $(0,54 \mathrm{mSv})$. Udayasankar et al. demostraron la utilidad de un protocolo de TAC con bajas dosis al evaluar a pacientes tras colocación de una derivación ventriculoperitoneal (128). La limitación de los estudios con bajas dosis es el aumento del ruido, pero existen filtros para reducir el mismo. Además, la calidad diagnóstica de la imagen se mantiene aceptable.

En un estudio prospectivo de dos años de Donnelly se evaluó la utilización de menores dosis de radiación en niños sometidos a TAC y también se concluyó que no comprometía la capacidad diagnóstica de la técnica y que no fueron necesarios más estudios ni repetirlos por pobre calidad técnica (129).

Figura 4. Imágenes de TAC craneal (105): (A) TAC craneal con dosis estándar (220 mA) (B) TAC craneal con dosis bajas (80mA) 
La campaña Image Gently (www.imagegently.org) es una iniciativa de la Society for Pediatric Radiology que se creó en el año 2006 de la que es miembro la Sociedad Europea de Radiología Pediátrica, entre otras sociedades científicas. Tiene como objetivo concienciar a los profesionales en la reducción de dosis cuando se realizan estudios radiológicos en niños y ofrece información a clínicos, pacientes y radiólogos para utilizar dosis menores de radiación en niños (130). 


\subsubsection{RADIOGRAFÍA SIMPLE DE CRÁNEO}

Las radiografías (RX) simples de cráneo se obtienen colocando la cabeza del paciente entre una fuente de rayos X y un sistema receptor. Los huesos del cráneo bloquean el paso de un gran número de rayos $\mathrm{X}$ y, por tanto, proyectan una "sombra" blanca en la película radiográfica. Por el contrario, los tejidos blandos como el cuero cabelludo o el cerebro casi no bloquean el paso de los rayos $\mathrm{X}$ y no se aprecian en la película. Como el cráneo tiene una forma esférica, los huesos van a aparecer superpuestos. Por tanto, pueden ser necesarias múltiples proyecciones radiográficas del cráneo que incluyen frontal, lateral y axial para valorar adecuadamente la calota y localizar con precisión una lesión. Incluso así, estos estudios a veces son difíciles de interpretar debido al gran número de estructuras superpuestas.

Las radiografías simples ofrecen información, fundamentalmente, de los huesos del cráneo, pero no la dan de los contenidos intracraneales. En ocasiones puede obtenerse información indirecta de lesiones intracraneales en una RX simple de cráneo, aunque los datos suelen ser bastante sutiles incluso en casos muy avanzados (104).

El papel de la RX simple de cráneo en el TCE es aún un tema controvertido a pesar de las múltiples publicaciones sobre el tema. Ha sido reemplazada casi por completo por técnicas más sensibles como la TAC o la RM. Incluso ante la sospecha de una fractura craneal raras veces están indicadas las RX, debido a que las imágenes de la TAC pueden mostrar la fractura a la vez que cualquier alteración intracraneal que debe ser tratada.

El último trabajo de Bressan publicado en 2017 se trata de un meta-análisis y revisión sistemática de más de 6500 niños con fractura craneal y concluye que las fracturas craneales aisladas en niños estables entrañan un riesgo muy bajo de muerte o necesidad de neurocirugía urgente, pero son frecuentemente hospitalizados. Propone que estos pacientes podrían tratarse de manera ambulatoria (131).

No obstante, debe tenerse en cuenta que no siempre están disponibles otras técnicas y actualmente algunos autores continúan recomendando la RX como 
screening en pacientes con TCE, como es el caso de la Asociación Española de Pediatría (AEP) (29).

Quayle sugiere que la lesión intracraneal puede darse con pocos o sutiles signos y síntomas, especialmente en lactantes menores de un año en los que recomienda realizar una RX de cráneo. Igual que otros autores, demuestra que el riesgo relativo de LIC aumenta en la presencia de fractura craneal, aunque su ausencia no descarte LIC (132). Concluye que, si la TAC no está disponible, la RX simple de cráneo puede ser útil en niños con TCE y si se objetiva una fractura craneal debería realizarse una TAC (9).

Por otro lado, Servadei señala que la presencia de fractura craneal podría ser la base para seleccionar aquellos pacientes con lesiones menos graves que se beneficiarán de la TAC. Afirma que en los niños con hematoma intracraneal se encuentra en 1 de cada 157, mientras que la fractura se encuentra en 1 de cada 12500 casos. Cuando se encuentra una fractura, normalmente denota traumatismo significativo con potenciales secuelas graves (133).

Bonadio et al. encontraron que las fracturas complicadas se correlacionaban significativamente con lesión intracraneal. Observaron que la incidencia de hematoma subdural y epidural acompañando la fractura era del $8 \%$ y $10 \%$ respectivamente. Así, concluyeron que los niños con fractura parietal tras TCE tenían un riesgo significativo de anomalía intracraneal (134).

Para Lloyd et al, la RX tiene una 65\% de sensibilidad y un $85 \%$ de VPN para LIC, siendo inferior a la impresión clínica (2). Sin embargo, estas conclusiones fueron cuestionadas por Powel y Hyde. Según sus investigaciones, la odds ratio (OR) era mayor para RX que para la exploración física, por lo que afirman que Lloyd infraestimó el beneficio de la RX generando menos falsos positivos que la exploración neurológica. Teesdale et al. establecieron que un niño con una fractura craneal tiene ochenta veces más riesgo de LIC que uno sin fractura siendo la RX simple de cráneo un predictor valioso de hemorragia intracraneal (135). Sin embargo, al igual que Baker et al. reconocen que la RX de cráneo puede ser útil en fracturas craneales que con frecuencia asocian hemorragia intracraneal, pero que tiene poco valor si existe posibilidad de hacer una TAC craneal de manera urgente.

Por su parte, Reed demostró que se puede abandonar el uso de RX de cráneo en niños de uno a catorce años sin aumento significativo del número de ingresos, dosis 
de radiación o lesiones intracraneales no diagnosticadas. Realizando una TAC en los casos de traumatismo por mecanismo traumático severo, pérdida de consciencia o mareo y puntuación baja en GCS ya que son los indicadores más importantes de LICci en niños (136).

La AEP en sus protocolos de manejo del TCE pediátrico publicados en 2008, recomienda la realización de RX de cráneo en menores de dos años de edad con TCEL que sufren: un mecanismo de alta energía, una colisión con vehículo a alta velocidad, una caída desde más de $50 \mathrm{~cm}$. de altura, una caída sobre una superficie dura, un traumatismo con un objeto romo y pesado, presencia de un cefalohematoma importante, traumatismo no presenciado con posibilidad de mecanismo importante o historia relatada por los padres incierta o indicativa de abuso (29).

En otras guías, como la Canadian Assessment of Tomography for Childhood Head Injury (CATCH) y la Children's Head Injury Algorithm for the Prediction of Important Clinical Events (CHALICE), la radiografía de cráneo se utilizó como una herramienta de diagnóstico para la detección de fracturas de cráneo en una proporción de pacientes entre el 4,7 y el $23,4 \%$, respectivamente, lo que demuestra que la radiografía de cráneo se encuentra todavía en uso en un gran número de pacientes con TCEL, aunque sea menor que en el pasado $(64,9 \%)(11,12)$. Esto es una prueba más de la variabilidad significativa que existe en el manejo de estos pacientes, a pesar de la existencia de guías clínicas y protocolos.

La utilidad potencial del diagnóstico de fractura ósea consistiría en su habilidad para seleccionar a los pacientes con posible lesión encefálica, dado que se ha señalado un aumento del riesgo de lesión intracraneal con la presencia de lesiones óseas (132). Debido a que se ha evidenciado la posibilidad de lesión intracraneal sin la presencia de fractura, y que la mayoría de las fracturas craneales no se asocian a un daño cerebral subyacente, con el estado actual del conocimiento, se desaconseja la utilización sistemática de la radiografía craneal y sólo se admite su uso en algunas situaciones clínicas como es la detección de fracturas craneales $(10,137,138)$.

Las fracturas craneales son difíciles de diagnosticar. A menudo, distinguir fracturas de surcos vasculares o suturas craneales puede ser confuso. En esos casos, una TAC craneal con reconstrucción en 3D resulta inestimable puesto que es más precisa para diagnosticar fracturas craneales. Una imagen linear que atraviesa el hueso parietal y termina en una sutura suele ser una sutura accesoria, sin tratarse de una fractura, sobre todo si es bilateral (139). 


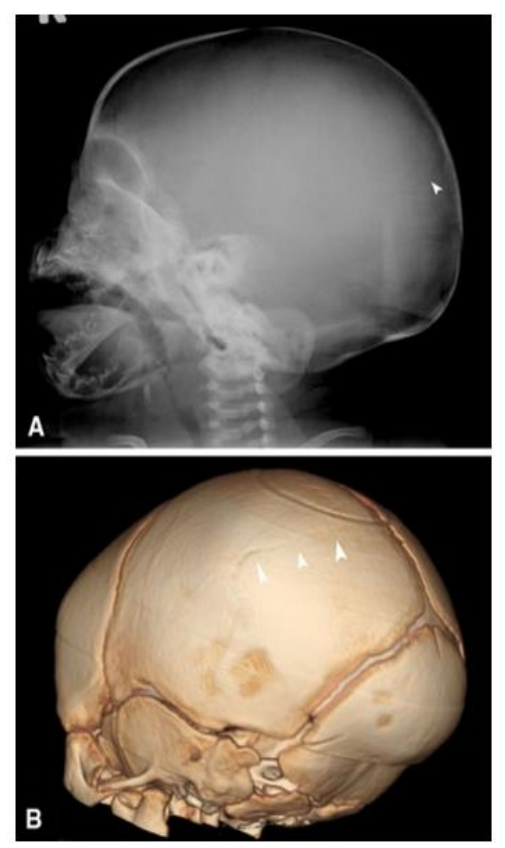

Figura 5. Imágenes de radiografía de cráneo y TAC (140): (A) Rx lateral de cráneo de un lactante de 3 meses que muestra una imagen radiolúcida lineal (flecha) en el hueso parietal. (B) TAC con reconstrucción 3D del mismo paciente donde vemos que la línea radiolúcida (flecha) de la Rx es un surco vascular.

Además, sólo debería realizarse una RX de cráneo si hay disponible un radiólogo pediátrico o neurocirujano pediátrico que sepa interpretarla ya que los pediatras de los SUP tienen poca experiencia en la identificación de fracturas craneales en RX (139).

Según algunos autores, si se detecta fractura craneal en una RX, debe llevarse a cabo una TAC craneal o derivar al paciente a un hospital de tercer nivel, siendo éstas recomendaciones controvertidas $(141,142)$. Pero la ausencia de fractura en la RX de cráneo, no excluye el daño intracraneal, existiendo riesgo de LICci. Un metaanálisis concluyó que la presencia de fractura craneal en la Rx era un predictor de LIC con una OR de 6,1 (95\% CI, 3,4-11,2), pero sin la suficiente sensibilidad (59\%) ni especificidad (88\%) como para recomendar la RX como prueba diagnóstica de LIC en un TCE (143).

Otros estudios concluyen que en menores de dos años con TCEL la observación clínica puede considerarse como una alternativa válida a la realización de RX de cráneo puesto que tienen un riesgo muy bajo de LICci (144). 


\subsubsection{ECOGRAFÍA CRANEAL}

La ecografía es la aplicación diagnóstica de los ultrasonidos en el cuerpo humano.

Es una técnica inocua, requiere personal altamente especializado, y aunque posibilita el diagnóstico de lesiones intracraneales de tamaño mayor y fracturas progresivas, su rendimiento es pobre, por lo que no supone una alternativa a la prueba de referencia en el TCEL, la TAC (145). Tiene su principal limitación en la necesidad de una fontanela craneal abierta y lo suficientemente amplia para posibilitar la exploración.

Sus aplicaciones principales en las enfermedades del SNC son la imagen en escala de grises y Doppler para la evaluación de la permeabilidad vascular y de su flujo y la del vasoespasmo en cuadros de hemorragia subaracnoidea, el cribado de alteraciones intracraneales en neonatos y niños pequeños a través de las fontanelas (104).

Los estudios ecográficos, no suponen prácticamente ningún riesgo para el paciente, no utilizan radiación ionizante y son portátiles. Sin embargo, la calidad de la exploración y, por tanto, la precisión diagnóstica, dependen bastante del operador. La gran dependencia de la ecografía de la presencia de una "ventana acústica" adecuada para realizar el estudio disminuye la utilidad de esta técnica para estudiar el cerebro después del cierre de las fontanelas de los niños. Para un ojo no acostumbrado, las estructuras anatómicas y lesiones patológicas vistas en ecografía no son tan aparentes como en las imágenes de TAC o RM por lo que, en la práctica actual, la TAC craneal es la prueba de imagen gold standard para detectar fracturas craneales y hemorragias intracraneales tras un TCE.

Por un lado, existen varias ventajas en el uso de la ecografía para la detección de fracturas craneales $(146,147)$ :

1. La ecografía craneal puede hacerse rápido y a pie de cama del paciente, lo que facilita la detección de manera precoz de la fractura como marcador de posible LIC y la posibilidad de necesitar consultar con un neurocirujano. 
2. La ecografía a pie de cama puede ser especialmente útil para detectar fracturas craneales en centros sanitarios en los que no existe una TAC disponible, como por ejemplo los centros de salud o consultas. Según los datos de la OMS, se estima que dos tercios de la población mundial no tiene acceso a tecnología de diagnóstico de imagen. Podría ser implantarse un ecógrafo portátil en los lugares con pocos recursos.

3. El hecho de hacer la técnica a pie de cama con los padres presentes durante la prueba, aporta seguridad y confianza en éstos.

4. Tiene la capacidad de disminuir el uso de la TAC y la exposición a radiación en niños.

5. Es una técnica segura que puede realizarse en lactantes sin necesidad de sedación.

6. Puede ser útil como técnica de triaje para situaciones de desastres naturales o accidentes con múltiples víctimas.

7. Permite diagnosticar fracturas mínimas o no desplazadas que pueden no verse en la TAC. Investigaciones recientes han demostrado mayor sensibilidad de la ecografía sobre la RX en ciertos tipos de fracturas, y han visto que se pueden detectar fracturas no desplazadas de $1 \mathrm{~mm}$.

Por otro lado, existen diversas dificultades sobre el uso de la ecografía craneal.

1. Es sabido de que se trata de una técnica dependiente del operador. A la hora de realizar una ecografía transfontanelar, es fundamental tener una buena formación y entrenamiento en la técnica y para ello resulta esencial poseer el conocimiento sobre la anatomía craneal de los niños y fundamentalmente de las suturas craneales ya que una sutura aparece simétrica y regular y llega a una fontanela, mientras que una fractura es mellada y puede estar desplazada.

2. Las fracturas de la base del cráneo no pueden ser identificadas fehacientemente mediante la ecografía. 

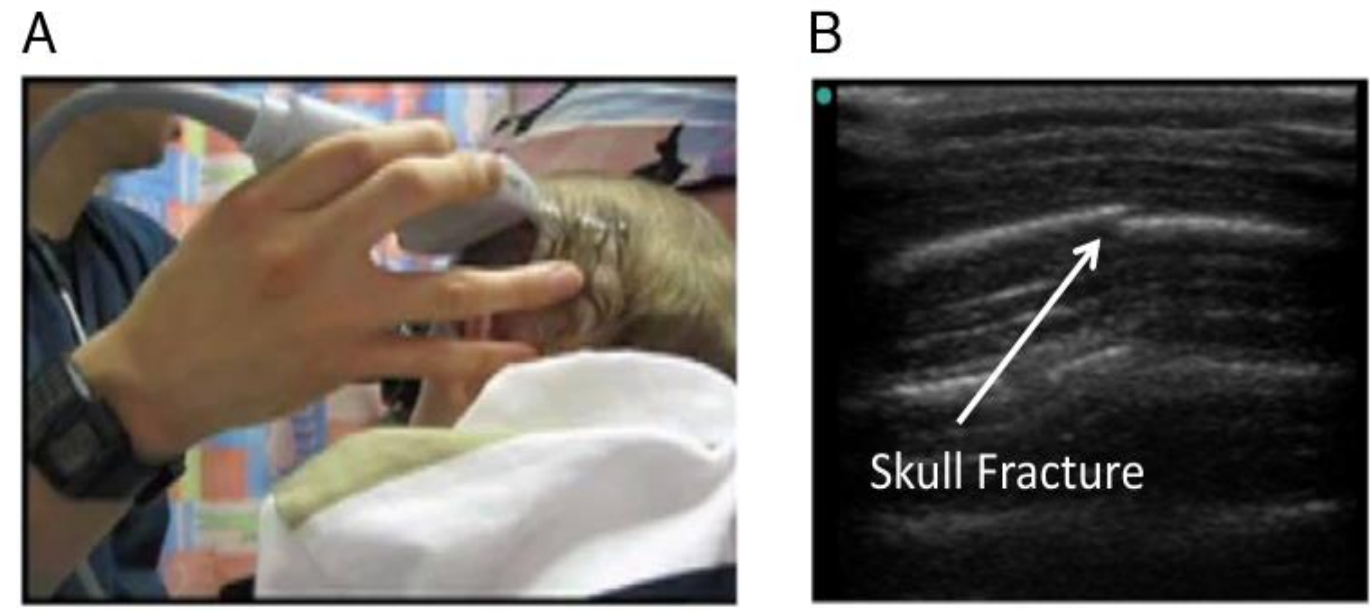

Figura 6. Imágenes de ecografía craneal (146): (A) Transductor lineal del ecógrafo localizado sobre el cráneo. (B) Fractura craneal en ecografía (flecha).

Diversos estudios observacionales preliminares indican que la ecografía a nivel de cama del paciente para detectar fracturas craneales tiene una sensibilidad y especificidad razonables siempre que se realice por facultativos con formación y entrenamiento en dicha técnica (146-149).

Rabiner et al, en una serie de casos de 69 niños con trauma craneal detectaron las fracturas craneales tras TCEL mediante ecografías realizadas por facultativos que habían recibido una hora de formación en la técnica con una sensibilidad del $88 \%$ y una especificidad del 97\%. La prevalencia de fracturas craneales en ese estudio fue del 12\% (146).

Parri demostró que la ecografía era útil para diagnosticar fracturas craneales en niños con TCEL con una especificidad del $95 \%$ y concluyó que se trata de una técnica breve, indolora, sensible para detectar LIC y relativamente sencilla de realizar. Los facultativos que las realizaron en el estudio habían recibido una formación específica breve y consiguieron adquirir los conocimientos necesarios para llevar a cabo la prueba con precisión (147).

Sin embargo, la TAC continúa siendo la prueba diagnóstica de elección porque detecta fracturas craneales y LIC.

La ecografía puede tener un papel como técnica de screening para detectar desgarros durales y otros hallazgos asociados a fracturas craneales crecientes (145). 
No obstante, aún faltan datos prospectivos y más investigación para poder introducir la ecografía craneal en las guías de práctica clínica del TCEL. 


\subsubsection{RESONANCIA MAGNÉTICA}

Es considerada una técnica de imagen relativamente poco invasiva ya que no utiliza radiación ionizante. La señal de resonancia magnética (RM) es derivada de múltiples parámetros incluyendo T1, T2m, densidad de protones, etc. Esto contrasta con la ecografía o la TAC donde la señal es esencialmente uniparamétrica. La RM también ofrece imágenes multiplanares con resolución equivalente en todos los planos (105).

Los estudios de RM, al igual que los de TAC, constan de imágenes tomográficas reconstruidas en un ordenador pero en la RM, al contrario que en la TAC y la RX, la información que se recoge no es la atenuación de un haz de rayos $X$, sino una manifestación gráfica de los datos que se recogen principalmente de los núcleos atómicos de los tejidos orgánicos, especialmente de los núcleos de hidrógeno contenidos en las moléculas de agua y de grasa (104).

A menudo ofrece información más sensible y específica del SNC del paciente pediátrico que la TAC o la ecografía para delinear procesos vasculares y hemorrágicos; puede proporcionar una descripción de estructuras vasculares y anomalías sin necesidad de inyectar contrastes e identificar el estadio de una hemorragia o la formación de coágulos. Permite distinguir entre infartos hemorrágicos y hematomas, así como diferenciar los tipos de malformaciones vasculares y aneurismas y colecciones benignas, como en la hidrocefalia de hematomas subdurales (150).

La imagen se puede ver comprometida por los movimientos del paciente por lo que muy a menudo es necesaria la sedación o anestesia de los niños y en ocasiones también en adultos. Entre las contraindicaciones de la RM se incluyen el ser portador de dispositivos ferromagnéticos y electrónicos como marcapasos o clips de aneurismas (104).

Ve limitada su utilización por el tiempo requerido para una exploración, su elevado coste y un menor rendimiento para reconocer el sangrado agudo intracraneal frente a la TAC. Por este motivo, la RM no es una prueba de uso rutinario en los traumatismos agudos, puede ser útil en ocasiones en pacientes con déficit 
neurológicos no explicados tras el estudio de TAC craneal. Por ejemplo, las hemorragias traumáticas en el tronco del cerebro suelen ser difíciles de ver en los estudios de TAC, pero habitualmente son bastante evidentes en las imágenes de RM. La RM también es útil para demostrar pequeñas lesiones por cizallamiento en el cerebro en el daño axonal difuso y para estudiar el cerebro en pacientes con TCE antiguos (104). También estaría indicada ante la sospecha de lesión medular asociada (que habitualmente se produce en TCE graves) y en los casos de posible lesión medular sin alteraciones óseas no detectables mediante la radiografía o la TC, entidad conocida como SCIWORA (spinal cord injury without radiographic abnormality), que ocurren característicamente en edad pediátrica, y para la detección de colecciones subdurales (poco frecuentes en la infancia y que suelen producirse en adultos al cabo de unos días de un TCE). Es más sensible que la TAC en la detección de la lesión axonal difusa y en fases más avanzadas puede ayudar a sentar mejor el pronóstico del niño (33).

Se está empezando a utilizar la RM como estudio de lesiones agudas tras el TCE y los avances en investigación sugieren que en el futuro podremos beneficiarnos de su uso para identificar lesiones que no se aprecian en la TAC (151). Un estudio retrospectivo observó las ventajas de la RM frente a la TAC en los niños con TCE en cuanto a una mayor precisión diagnóstica en las lesiones intraparenquimatosas evitando además la exposición a radiación, si bien concluyeron que hacen falta estudios en este tipo de pacientes y que su uso debe valorarlo el facultativo que atiende al paciente en cada caso (152). 


\subsubsection{OTRAS}

Se han llevado a cabo trabajos que estudian la utilidad de otras técnicas de imagen para el diagnóstico de las lesiones intracraneales como es la espectroscopia del infrarrojo cercano o near-infrared spectroscopy (NIRS), basada en el análisis de la luz infrarroja recaptada tras incidir sobre las moléculas de hemoglobina del tejido y así determinar su saturación de $\mathrm{O}_{2}$.

Tiene su base en la espectrofotometría y se puede determinar la concentración de una sustancia capaz de absorber energía lumínica (cromatóforo) a partir de la relación de intensidades entre la luz emitida sobre el cromatóforo y la intensidad final que se recupera. En el contexto del paciente con traumatismo grave existen resultados, tanto en trabajos con modelos animales como en investigación clínica sobre el uso de la tecnología NIRS como monitor y objetivo terapéutico, que pueden ayudarnos en la toma de decisiones clínicas aunque todavía no existe un grado de evidencia firme para su uso rutinario en el TCEL (153).

El NIRS es una herramienta no invasiva, portátil y con obtención de la información en tiempo real que tiene un gran potencial como herramienta de valoración clínica de la microcirculación. Tanto los valores basales de saturación periférica de oxígeno $\left(\mathrm{SatO}_{2}\right)$ como los test de isquemia pueden ofrecer la sensibilidad necesaria para detectar alteraciones subclínicas de la perfusión y proporcionar información pronóstica. Robertson et al diseñaron un estudio multicéntrico en el que incluyeron 365 pacientes adultos con TCE a los que se les realizó una TAC y una espectroscopia del infrarrojo cercano. Esta última obtuvo una sensibilidad del $88 \%$ con una especificidad del $90,7 \%$ en las hemorragias intracraneales de mayor tamaño consideradas como LICci y una sensibilidad del $68,7 \%$ en las hemorragias intracraneales de cualquier tamaño y tipo, pero sin diferenciar su localización. Los autores concluyeron que se trata de una técnica que si bien no sustituye a la TAC puede ser de utilidad como ayuda en el cribado de estos pacientes y en los casos en los que no se disponga de una TAC (154).

Estudios posteriores han demostrado la utilidad del NIRS en el TCEL pediátrico como una herramienta útil que podría disminuir la tasa de TAC (155). Salonia et al 
observaron una sensibilidad del 100\% y una especificidad del $80 \%$ en la detección de hemorragias intracraneales mediante el NIRS en niños (156). 


\subsubsection{PRUEBAS DE LABORATORIO}

Puesto que las pruebas de imagen para el diagnóstico de LIC tras un TCE tienen riesgos, se han estudiado modelos pronósticos analíticos que permitan conocer la gravedad del daño cerebral y estimar así las posibles consecuencias del mismo.

Se están investigando biomarcadores de lesión cerebral que puedan expresar con más precisión la extensión y la gravedad de la lesión cerebral traumática (157161). Los biomarcadores son indicadores biológicos cuantificables específicos de un estado fisiológico o patológico. El uso de biomarcadores contribuye al mejor conocimiento de la fisiopatología del daño cerebral, aportando información complementaria esencial para el diagnóstico y pronóstico de estos pacientes (162).

Sin embargo, los marcadores de lesión cerebral se diferencian de otras afecciones, pues el SNC puede presentar múltiples tipos de lesión que, a su vez, pueden afectar a diversas células diana. Además, la existencia de la barrera hematoencefálica (BHE) condiciona las características estructurales de dichos biomarcadores, que deben atravesarla para poder ser liberados al torrente sanguíneo (163).

Hace ya más de veinte años se describió el marcador ideal para el TCE, definiéndolo como aquel que presente alta especificidad y sensibilidad por el tejido cerebral, siendo liberado únicamente tras una lesión irreversible del tejido cerebral y mostrándose en LCR y sangre rápidamente tras el daño. Debe reflejar, además, la extensión y la gravedad de dicha lesión siguiendo un curso temporal conocido. A su vez, las herramientas para el análisis y la detección inmediata deben estar disponibles y ser reproducibles (162).

$\mathrm{Su}$ determinación debe tener relevancia clínica. Cabe resaltar que los biomarcadores son elementos dinámicos con cambios que responden a diferentes estados inflamatorios, fenómenos de necrosis tisular y lesiones por estrés oxidativo. Por tanto, es necesario realizar mediciones seriadas en lugar de determinaciones aisladas para que adquieran significación (157).

Existe cierta controversia en cuanto al tipo de líquido biológico objeto de análisis. La toma de una muestra directa del parénquima cerebral lesionado o en riesgo no es una opción plausible. El resto de las determinaciones dependen de los 
comportamientos de liberación de los biomarcadores, paso a través de membranas (celulares, BHE, etc.), así como el fenómeno de dilución una vez alcanzado el compartimento sistémico (164). Por otro lado, el LCR se encuentra más próximo a la zona lesionada, por lo que las determinaciones a este nivel no se ven condicionadas por la integridad de la BHE. Sin embargo, la toma de muestras de LCR es de difícil acceso y disponibilidad, precisando de maniobras cruentas para su obtención, con frecuencia contraindicadas en sujetos con TCE. Es por ello que la mayoría de los biomarcadores son estudiados en sangre periférica, al tratarse de una técnica sencilla, accesible y reproducible (157).

A continuación describiremos los principales biomarcadores de lesión cerebral, el tejido en el que se originan, el compartimento donde se obtienen las muestras para su determinación y los principales aspectos pronósticos $(157,165)$ :

Proteína tau. Se trata de una proteína estabilizadora del citoesqueleto axonal. La acción de las proteasas inducidas tras el TCE libera fragmentos de proteína tau a suero y al LCR. Estudios en humanos han objetivado que los niveles de c-tau en el LCR aumentan durante las primeras $24 \mathrm{~h}$ tras el TCE grave (157).

Proteína básica de mielina. Es una proteína específica de la mielina liberada a la sangre en situaciones de daño cerebral y enfermedades desmielinizantes. Se han relacionado los niveles séricos con la gravedad y el pronóstico de los TCE (166).

Isoenzima creatincinasa cerebral. Existen tres isoformas de creatincinasa: muscular, cardíaca y específica de tejido cerebral. Tras el TCE grave se produce un pico sérico de creatincinasa de tejido cerebral durante las primeras horas de evolución, que decrece progresivamente, salvo en los sujetos con lesiones potencialmente graves, en los que permanece elevada durante días.

Se trata de un marcador con una sensibilidad y una especificidad reducidas, principal limitante para establecerlo como biomarcador de uso rutinario (163).

Enolasa neuroespecífica (NSE). Se trata de una enzima glucolítica catalizadora. Se han detectado niveles incrementados en el suero de pacientes tras presentar otros fenómenos de lesión cerebral no traumáticos (accidentes isquémicos, hemorragias intracerebrales o maniobras de reanimación cardiopulmonar con hipoxia cerebral secundaria). En estudios se ha señalado la correlación inversa entre la concentración plasmática de NSE y la puntuación en la 
GCS, así como una liberación lineal de la NSE en presencia de hemorragia intracraneal (166).

Hasta la fecha los resultados publicados sobre NSE son contradictorios, dado que algunos trabajos no han encontrado correlación con el pronóstico clínico de los sujetos con TCE grave (167).

Proteína beta amiloide. Participa en procesos de adhesión celular. Existen hallazgos contradictorios en cuanto a la cuantificación de esta proteína en LCR tras daño traumático cerebral, que pueden estar en relación con los distintos métodos de determinación de las muestras de LCR (lumbar, ventricular, etc.) (157).

Proteína ácida fibrilar glial (GFAP). Se trata de una proteína derivada del tejido astrocitario que la hace exclusiva como biomarcador de lesión cerebral en situaciones diversas: daño traumático, eventos isquémicos y ciertos trastornos neurodegenerativos. Se ha relacionado con el mal pronóstico en la fase aguda del TCE grave, las lesiones radiológicas objetivadas en la TAC, la necesidad de neurocirugía urgente, el pronóstico funcional a largo plazo y la mortalidad (158).

Proteína S100 beta. Es el biomarcador de lesión cerebral más estudiado. Es conocida su participación en fenómenos de neurogénesis, astrocitosis, elongación axonal, regulación de actividad enzimática, homeostasis del calcio, interacción con elementos del citoesqueleto y en mecanismos de protección del daño celular oxidativo. Se ha descrito su comportamiento en procesos neurológicos agudos, como en el ictus isquémico y el hemorrágico, así como en otros fenómenos en los que pudiera existir una afectación cerebral secundaria, como sucede durante la cirugía cardíaca y la rotura aneurismática espontánea. En relación con el TCE, se ha documentado la asociación de los niveles séricos de dicha proteína con la gravedad clínica, radiológica y el pronóstico desfavorable $(166,168)$.

Hidrolasa de carboxilo terminal de ubiquitina L1 (UCH-L1). Es una proteína de origen neuronal y está implicada en la eliminación de proteínas degradadas y desnaturalizadas tras fenómenos oxidativos. Algunos estudios han mostrado resultados indicativos de su capacidad para predecir la presencia de lesiones en la TAC, la necesidad de neurocirugía y el pronóstico en pacientes con TCE (169). Es, además, un marcador que puede detectarse en sangre, con elevación de los niveles séricos de forma precoz tras el trauma craneal. 
Dímero D. Utilizado como indicador negativo de forma rutinaria para la evaluación de trombosis venosa profunda o tromboembolismo pulmonar, se propone a su vez, para el TCE. Una característica fisiopatológica común en estos procesos es la activación de la fibrinólisis y es sabido que un relativamente pequeño déficit de fibrinógeno se acompaña de un aumento importante del dímero D. Diversos autores sugieren que se trata de una herramienta con un VPN elevado cuando existe sospecha de LIC y el niño cumple indicaciones de TAC con una GCS de 13 a 15 puntos. En estos casos, niveles bajos de este biomarcador sugieren ausencia de LICci, pudiendo así evitar la realización de TAC craneal (148).

Productos de degradación de la espectrina. La espectrina es una proteína estructural, componente principal del citoesqueleto cortical de los eritrocitos. Diversos autores han demostrado un incremento de productos de degradación de la espectrina en LCR en el contexto de un TCE (170).

Neurofilamentos. Los neurofilamentos ligeros forman parte del citoesqueletoaxonal. Ante una situación de daño axonal, dicha proteína se libera tanto al LCR como al torrente sanguíneo. Son varios los trabajos de investigación que han destacado su papel como biomarcador de daño axonal y discapacidad neurológica en enfermedades neurodegenerativas y neuroinflamatorias (171).

Dado que todos los biomarcadores de lesión cerebral presentan alguna limitación que impide su aplicación de forma universal en el manejo del TCE grave, siguen sin formar parte de la rutina asistencial.

Algunos de ellos, como la NSE y la proteína S100b, han demostrado tener una buena correlación con la gravedad clínica, la extensión del daño cerebral, la respuesta terapéutica y la capacidad de predecir el resultado final. Sin embargo, las limitaciones derivadas de la propia rentabilidad clínica de la proteína o del grado de invasividad para su obtención no han permitido su uso generalizado en dicha patología.

Por otra parte, son necesarios nuevos estudios para comprender el papel que juegan estas proteínas en la fisiología del SNC y en la fisiopatología del TCE, así como dilucidar la utilidad de aquellos biomarcadores que se presumen prometedores en este campo.

Dado que ofrecen una información aislada de algunos de los muchos elementos implicados en la fisiopatología del TCE, es fundamental su análisis de forma 
combinada. De este modo se podría establecer no un biomarcador exclusivo de lesión cerebral, sino un panel de biomarcadores que, en conjunción y considerando las características propias de cada uno, aporte información sobre la gravedad, el potencial beneficio de su modulación y el curso evolutivo de las lesiones tras el TCE (157). 


\subsection{GUÍAS DE PRÁCTICA CLÍNICA}

Las guías de práctica clínica son un conjunto de recomendaciones basadas en una revisión sistemática de la evidencia y en la evaluación de los riesgos y beneficios de las diferentes alternativas, con el objetivo de optimizar la atención sanitaria a los pacientes. No están diseñadas para reemplazar el juicio clínico. Su fundamento principal es que se basan en la evidencia científica existente y proporcionan un apoyo al facultativo clínico en el manejo de las pruebas de neuroimagen en el niño con TCEL (172).

Diversos grupos de investigación han elaborado en los últimos años guías clínicas para ayudar con los problemas que surgen con frecuencia en la evaluación del paciente con TCEL y estandarizar el manejo de estos pacientes. Estas guías son útiles para identificar los diferentes niveles de riesgo en niños con TCEL, logrando una reducción en el número de TAC craneales realizadas (173).

Estudios previos a la elaboración de las distintas guías realizadas en EEUU y Canadá mostraban una gran variabilidad en el uso de pruebas de imagen después de traumatismos craneales en niños, con alguna evidencia de que los SUP tenían menor porcentaje de demanda de pruebas de imagen que los Servicios de Urgencias Generales. En algunos trabajos, hasta el $40 \%$ de los niños se le realizó una TAC siendo más del $90 \%$ de los resultados normales $(3,111,174)$.

De estas guías clínicas, la elaborada con la mayor cohorte de pacientes es la de la PECARN, siendo, además, la única validada tanto para lactantes como para niños por lo que es la guía con un uso más extendido a nivel mundial. Las reglas de PECARN han sido obtenidas y validadas de una larga cohorte pediátrica multicéntrica, (33 785 y 8627 pacientes, respectivamente) incluyendo servicios de urgencias generales y pediátricos. La guía propone una serie de indicadores de bajo riesgo de LICci divididos en dos grupos de edad y su objetivo principal es detectar a los niños con bajo riesgo de LICci que no necesitan neuroimagen $(133,175,176)$.

En conjunto, los estudios de CHALICE y CATCH evalúan la sensibilidad del test para poder identificar de manera correcta los niños con lesión craneal en la TAC. Por contra, el algoritmo de la PECARN predice e identifica los pacientes que no tienen 
lesión intracraneal cuando no están presenten algunos síntomas, consiguiendo así tasas de neuroimagen muy inferiores (177).

A continuación, pasaremos a explicar las guías clínicas para el manejo del TCEL pediátrico de mayor relevancia. 


\subsubsection{Guía de manejo de la PECARN (Pediatric Emergency Care American Research Network)}

Se trata de un estudio de cohortes prospectivo en pacientes menores de dieciocho años en veinticinco SUP en EEUU. Se incluyeron pacientes que acudieron a urgencias por traumatismo craneal en las 24 horas previas con GCS de 14 o 15 puntos (10).

Para la correcta interpretación de sus resultados y recomendaciones, se debe tener en cuenta una serie de definiciones y criterios que se exponen a continuación:

Los criterios de exclusión fueron: TCE trivial o banal, TCE grave, mecanismo traumático leve, comorbilidades (tumores cerebrales, alteraciones neurológicas previas, shunts ventriculares, alteraciones hematológicas...) y trauma penetrante. Además, se excluyeron los pacientes con GSC menor de 14 ya que su riesgo de LICci es superior al 20\%, mayor que el riesgo de radiación por la TAC por lo que su uso en estos casos no es controvertido $(9,12)$. 


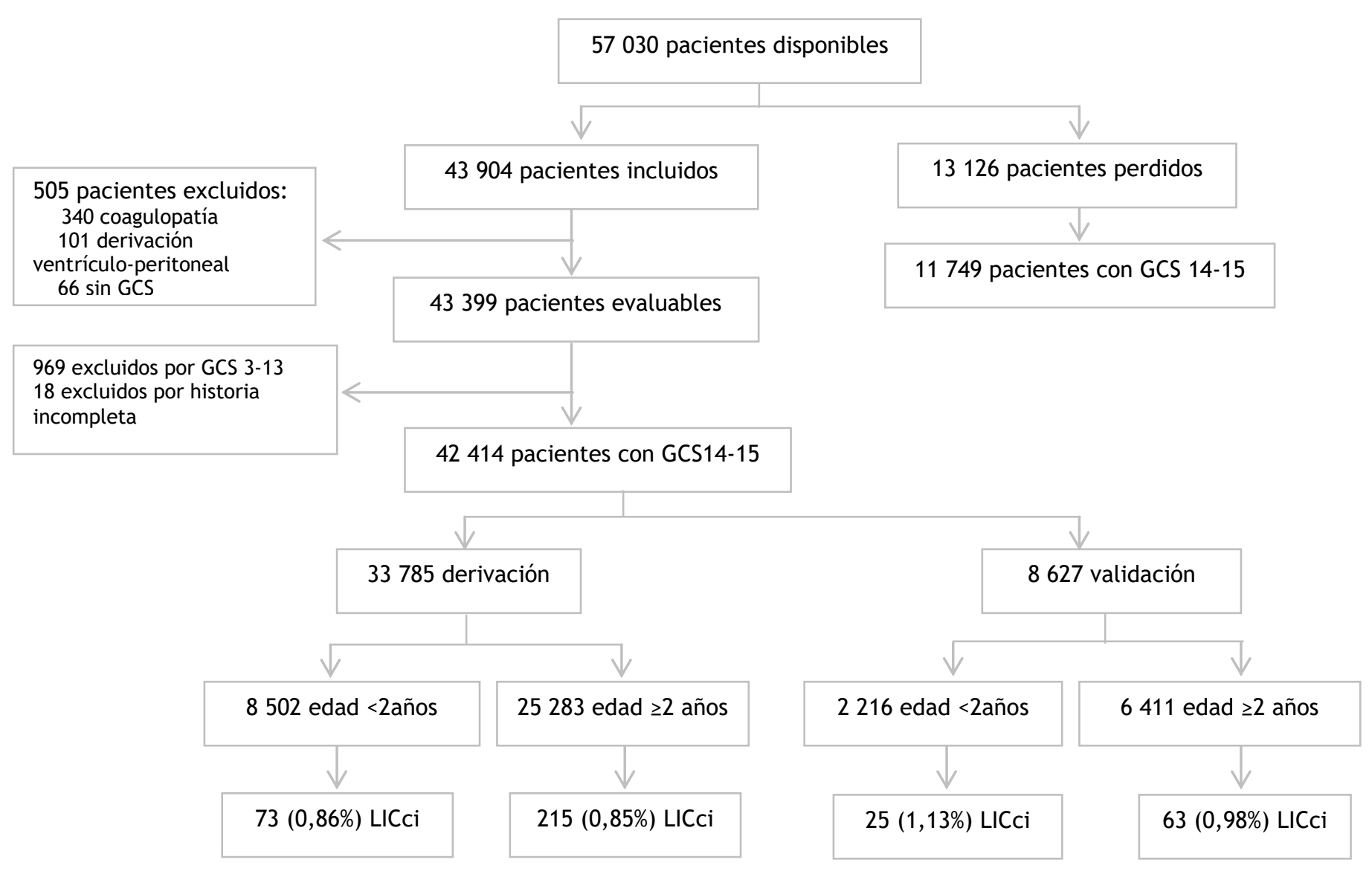

Figura 7. Diagrama de flujo

La PECARN clasificó los mecanismos de producción del traumatismo craneoencefálico en tres categorías:

Severo: accidente de tráfico con salida del vehículo, muerte de otro pasajero, vuelco del coche; peatón o ciclista sin casco atropellado por vehículo motorizado; caídas desde $>1,5$ metros en mayores de dos años y $>$ de $90 \mathrm{~cm}$ en menores de dos años; traumatismo craneal de alto impacto contra un objeto.

Leve: caída desde su propia altura y traumatismo contra un objeto inerte.

Moderado: el resto.

Además, propuso como definición de lesión intracraneal clínicamente importante (LICci), los siguientes supuestos:

- TCE con resultado de muerte del paciente 
- TCE que precise de intervención quirúrgica para:

- monitorización de PIC,

- elevación de fractura craneal deprimida,

- ventriculostomía,

- evacuación de hematoma,

- lobectomía,

- desbridamiento tisular,

- reparación de la duramadre.

- Intubación >24h por TCE (se excluyen intubaciones breves para sedaciones y/o procedimientos)

- Ingreso hospitalario de dos o más noches por síntomas neurológicos persistentes como alteración de la consciencia, vómitos repetidos, cefalea intensa persistente o manejo de convulsiones, en asociación con LIC en la TAC

Se consideraron hallazgos de lesión traumática en la TAC: hemorragia intracraneal, edema cerebral, infarto traumático, daño axonal difuso, lesión por cizalla, trombosis de seno sigmoideo, signos de herniación, diástasis craneal, neumoenféfalo y fractura craneal deprimida.

Se incluyeron 43904 pacientes, de los cuales 10718 eran menores de 2 años. Se realizó TAC craneal a $14969(35,3 \%)$ observando LICci en 376, lo que supone un 0,9\% del total de pacientes. Entre los pacientes con LICci, 60 requirieron neurocirugía. Ingresaron 3821 pacientes, y ningún paciente falleció. De los 38591 que fueron dados de alta, a 96 se les realizó una TAC craneal en la segunda visita.

El gran tamaño muestral de este estudio permitió un análisis estadístico con poder suficiente para poder crear reglas firmes y generalizables. Con el uso del algoritmo propuesto, se disminuyó de de forma eficaz el uso de la TAC craneal en los pacientes pediátricos $(10,178)$.

Se efectuó la validación de reglas de predicción clínica específicas por edad para LICci, ajustado por edad (grupo $<2$ años y grupo $\geq 2$ años): 


\section{VPN para LICci}

$100 \%$

Menores de 2 años

Mayores o igual a 2 años
$99,95 \%$
Sensibilidad

$100 \%$

\section{Propuesta de algoritmo para pacientes con TCEL y GCS 14-15}

\section{Algoritmo A. Pacientes menores de dos años:}

En los pacientes menores de dos años con alteración del nivel de consciencia, GCS de 14 puntos o fractura craneal palpable se recomienda la realización de TAC cerebral ya que estos pacientes presentan un riesgo de LICci del 4,4\%.

Otros signos y síntomas como el cefalohematoma parietal, occipital o temporal, historia de pérdida de consciencia mayor de cinco segundos, mecanismo traumático severo o alteración del comportamiento según los padres, asocian un riesgo de LICci del $0,9 \%$, por lo que resulta prudente optar por una actitud expectante mediante observación en urgencias o bien realizar una TAC craneal.

Esta última decisión dependerá de criterios clínicos (experiencia del facultativo, presencia de uno o varios signos de alarma, empeoramiento clínico en sala de observación, edad inferior a tres meses o preferencias de los padres).

En ausencia de estos signos y síntomas de alarma expuestos, no se recomienda la realización de TAC cerebral ya que el riesgo de LICci es inferior al 0,02\%. 


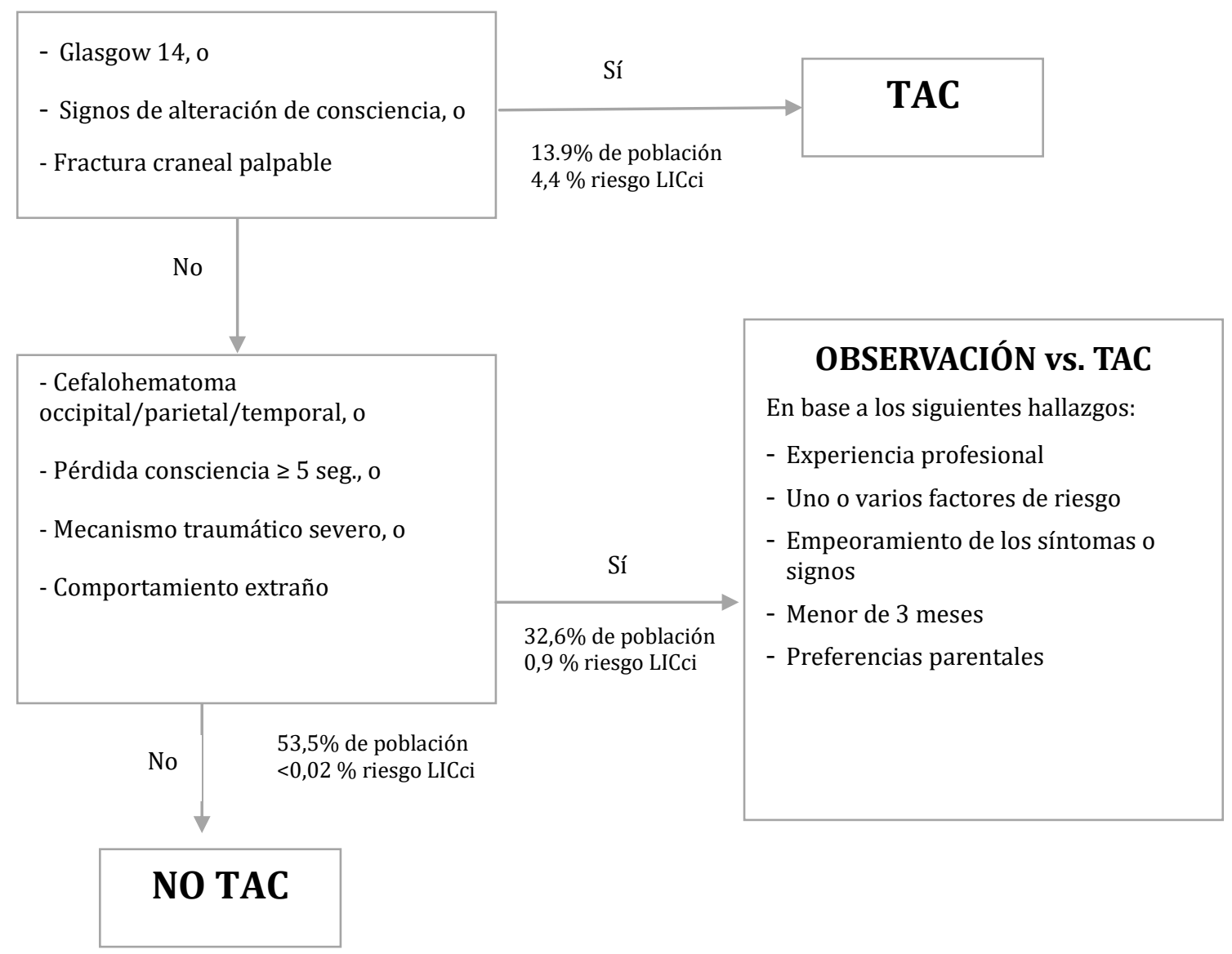

Figura 8. Algoritmo A. Propuesta de algoritmo de TAC en menores de dos años.

\section{Algoritmo B. Pacientes de dos años o más:}

En los pacientes a partir de dos años de edad con puntuación en la GCS de 14, alteración del nivel de consciencia o signos de fractura de la base del cráneo se recomienda la realización de TAC cerebral ya que el riesgo de LICci que presentan estos pacientes es del 4,3\%.

La presencia de otros signos o síntomas, como una historia de pérdida de consciencia, vómitos repetidos, mecanismo traumático severo o cefalea intensa, asocian un riesgo de LICci del $0,9 \%$ por lo que, al igual que en pacientes más pequeños, es recomendable una actitud expectante mediante observación en urgencias o realizar una TAC, en función de los mismos criterios clínicos que en los pacientes menores de dos años (excepto el criterio de edad menor de tres meses). 
La ausencia de estos signos y síntomas de alarma expuestos, supone un riesgo de LICci inferior al $0,05 \%$, por lo que no estaría recomendada la realización de TAC craneal.

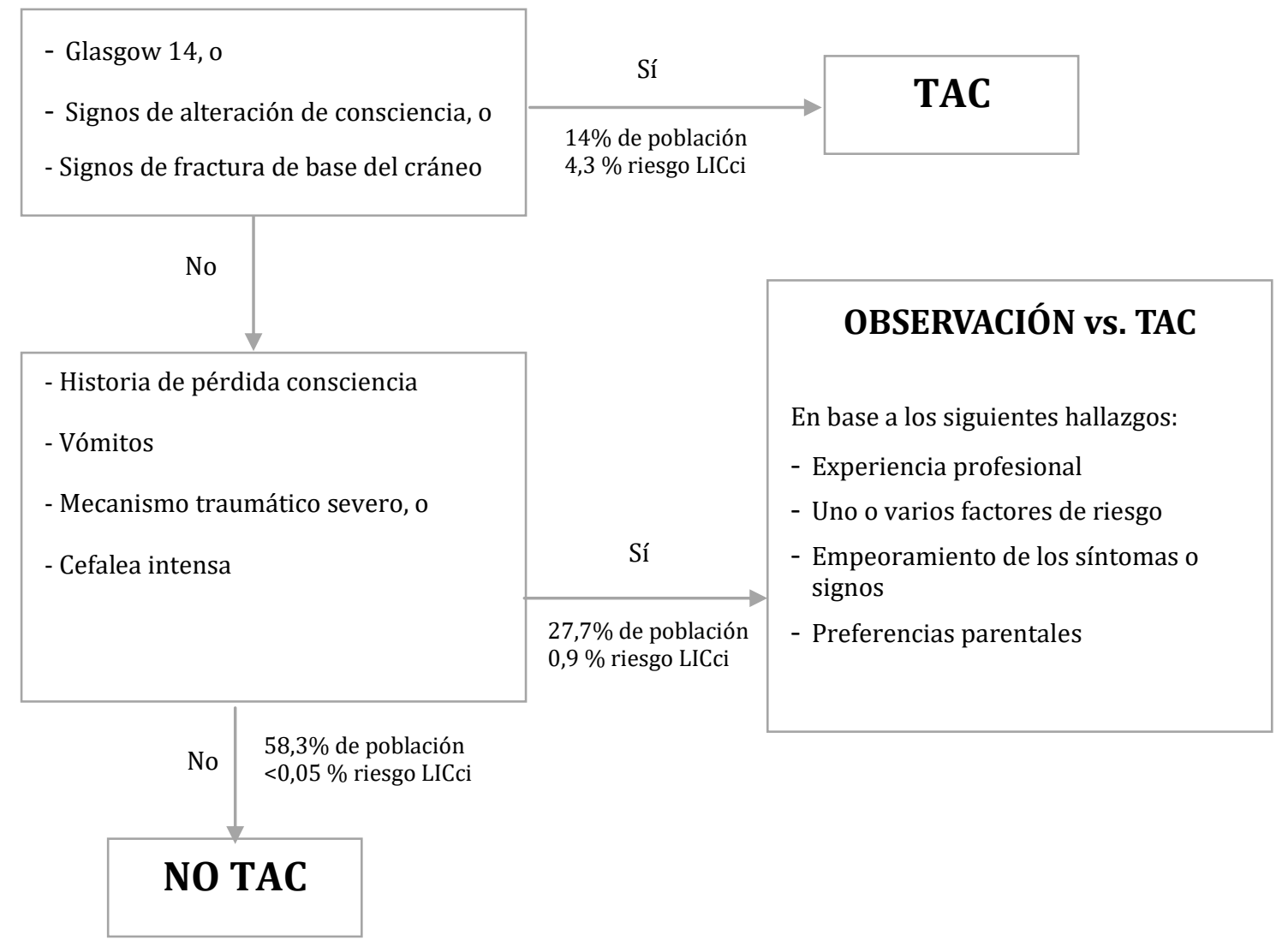

Figura 9. Algoritmo B. Propuesta de algoritmo de TAC en mayores de 2 años.

Mediante estas reglas de predicción clínica, es posible detectar a los pacientes con muy bajo riesgo de LICci en los que podremos evitar el uso de la TAC, que están resumidos en la siguiente tabla: 


\begin{tabular}{|l|l|}
\hline \multirow{2}{*}{$<2$ años } & $\begin{array}{l}\text { Ausencia de pérdida/alteración de consciencia, } \\
\text { comportamiento normal según criterio parental, no } \\
\text { mecanismo traumático severo, no hematoma frontal, no } \\
\text {-evidencia de fractura craneal. }\end{array}$ \\
\hline$\geq 2$ a 18 años & $\begin{array}{l}\text { No alteración del nivel de consciencia, no mecanismo } \\
\text { traumático severo, no cefalea, no signos de fractura de } \\
\text { la base del cráneo. }\end{array}$ \\
\hline
\end{tabular}

Tabla 6. Hallazgos asociados a bajo riesgo de LICci según PECARN

Se ha demostrado cómo la aplicación del algoritmo del manejo del TCEL de la PECARN tiene mejor coste-efectividad que el manejo previo, resultando en menores costes y menos pérdida de calidad de vida ajustada a la edad. Comparado con la estrategia habitual, la estrategia de la PECARN supone un menor uso de TAC craneal, disminuyendo así el riesgo de cáncer inducido por radiación. Según la frecuencia estimada de TCE en niños, el uso de las reglas de PECARN podría prevenir sesenta cánceres inducidos por radiación anualmente en EEUU. Desde un punto de vista económico, su implementación podría reducir los gastos hospitalarios en EEUU aproximadamente 27 millones de dólares anuales (179). Además, la guía PECARN tiene mayor sensibilidad que el juicio clínico para LICci (180).

Bressan et al. concluyeron que la implementación de la guía de PECARN mostró una alta satisfacción por parte de los facultativos que la utilizaron con una elevada adherencia a la guía, identificando el 100\% de LICci en su primera visita al SUP, con un leve ascenso en la tasa de TC craneal del 7\% al 8\% sin significación estadística (181). 


\subsubsection{Guía de manejo CHALICE (Children's Head Injury Algorithm for the prediction of Important Clinical Events study group)}

Es un trabajo publicado en 2006, que consiste en un estudio de cohortes prospectivo en el que participaron diez hospitales de Inglaterra que incluyeron pacientes menores de dieciseis años que acudieron a urgencias con TCE entre febrero del año 2000 y agosto del 2002. Tres hospitales eran infantiles, tres universitarios y cuatro generales (12).

Sus criterios de inclusión fueron amplios, incluyendo a cualquier paciente con historia o signos de traumatismo craneal sin excluir aquellos que podrían haberse categorizado como moderado o grave. El único criterio de exclusión fue el rechazo del consentimiento para participar en el estudio.

Los resultados principales estudiados fueron el fallecimiento por el TCE, la necesidad de neurocirugía o alteraciones manifiestas en la TAC. Como resultados secundarios estudiaron la presencia de fractura craneal y necesidad de ingreso hospitalario.

Para el propósito del estudio, se definió alteración en la TAC como cualquier patología aguda, traumática e intracraneal, informada por el radiólogo incluyendo hematomas de cualquier tamaño, contusión cerebral, edema cerebral difuso y fractura craneal deprimida. Las fracturas simples o no deprimidas aisladas no se consideraron significativas.

Se incluyeron en el estudio 22772 pacientes con una edad media de 5,7 años. Se llevaron a cabo 744 TAC, mostrando 281 de ellos $(1,2 \%)$ alteraciones y $5318 \mathrm{RX}$ de cráneo de las cuales en 259 (4,9\%) se diagnosticaron fracturas craneales. El 6,4\% ingresaron, el $0,6 \%$ requirieron intervención neuroquirúrgica y 15 pacientes fallecieron.

En base a sus resultados, esta guía recomienda la realización de una TAC craneal si aparece alguno de los siguientes criterios: 
1. Historia: pérdida de consciencia $>5$ minutos, historia de amnesia $>5$ minutos (anterógrada o retrógrada), somnolencia excesiva (según criterio del facultativo), más de tres vómitos tras el TCE, sospecha de lesión no accidental, convulsión tras el TCE en un paciente sin antecedentes de epilepsia.

2. Exploración: GCS < 14 (o < 15 en menores de un año), sospecha de lesión craneal penetrante o deprimida, fontanela a tensión, signos de fractura de base de cráneo (otolicuorrea, rinolicuorrea, ojos de mapache, signo de Battle, hemotímpano, lesión facial importante), focalidad neurológica, cefalohematoma, inflamación o laceración $>5 \mathrm{~cm}$. si menor de un año.

3. Mecanismo traumático: accidente de tráfico a alta velocidad como peatón, ciclista u ocupante del vehículo ( $>64 \mathrm{~km} / \mathrm{h}$ ), caída de $>3 \mathrm{~m}$. de altura, lesión contra un objeto a alta velocidad.

Si ninguna de las variables anteriores está presente, se considera que el paciente tiene bajo riesgo de LIC.

Esta guía posee una sensibilidad del 98\% (Intervalo de Confianza (IC) 95\%: 96\%-100\%) y un VPN del 99,97\% (IC 95\%: 99,9\%-100\%) (182).

Crowe et al. sugieren que el uso de la guía CHALICE puede incrementar la tasa de TAC craneal sin mejorar la detección de LICci por lo siguiente: en un estudio retrospectivo de análisis de la aplicación de CHALICE en 1065 niños, el uso de esta guía hubiese incrementado la tasa de TAC del 6,5\% al $10 \%$ con únicamente la detección de siete fracturas craneales o LIC en la evaluación inicial. Si se hubiese llevado a cabo una TAC en estos pacientes, los resultados habrían sido los mismos (182). 


\subsubsection{Guía de manejo CATCH (Canadian Assesment of Tomography for Childhood Head Injury)}

En 2010 se publicó el trabajo llevado a cabo por la CATCH, un estudio de cohortes multicéntrico en el que participaron diez hospitales canadienses $(11,183)$. Se incluyó a los pacientes menores de dieciseis años atendidos en urgencias por TCEL que se definió como: traumatismo en las últimas 24 horas con Glasgow de 13-15 puntos, pérdida de consciencia, amnesia, desorientación, vómitos repetidos o irritabilidad persistente (en menores de dos años).

Se excluyeron los pacientes que presentaban: fractura abierta o deprimida, déficit focal agudo, retraso de desarrollo, sospecha de abuso, embarazadas y los pacientes que reconsultaban por TCE que habían sido atendidos previamente.

Los objetivos del trabajo fueron estudiar la necesidad de intervención neuroquirúrgica y la presencia de lesión intracraneal en la TAC.

De los 3866 pacientes incluidos, con una mediana de edad de 9,2 años, llevaron a cabo 2043 TAC craneales $(52,8 \%)$, de los cuales 154 (4,1\%) presentaban lesión intracraneal. A los pacientes a los que no se les hizo TAC cerebral se les contactó mediante una llamada telefónica a las dos semanas del traumatismo para ver su evolución: si ésta era desfavorable, volvían a ser atendidos en urgencias y se les realizaba la TAC craneal. Veinticuatro pacientes $(0,6 \%)$ requirieron intervención neuroquirúrgica y ningún paciente falleció.

Basándose en sus resultados, crearon una guía de práctica clínica llamada The CATCH rule. Ésta propone cuatro factores de alto riesgo y tres de riesgo intermedio para LIC: 


\section{Variables de alto riesgo: (requieren neurocirugía)}

1. Glasgow $<15$ puntos en las dos horas siguientes al traumatismo

2. Sospecha de fractura craneal abierta o deprimida

3. Empeoramiento de la cefalea

4. Irritabilidad a la exploración

\section{Variables de riesgo medio:}

5. Cualquier signo de fractura de la base del cráneo (hemotímpano, ojos de mapache, otorrea, rinorrea, signo de Battle)

6. Cefalohematoma grande y blando

7. Mecanismo traumático severo (accidente de vehículo a motor, caída de una altura $\geq 91 \mathrm{~cm}$, caída de $>5$ escalones, caída de la bicicleta sin casco)

\section{Tabla 7. The CATCH Rule}

La presencia de una de las cuatro variables de alto riesgo tiene una sensibilidad del 100\% (IC 95\%, 86,2\%-100,0\%) y una especificidad del 70,2\% (IC 95\%, 68,8\%$71,6 \%)$ para identificar a los pacientes con necesidad de neurocirugía.

La presencia de cualquiera de las siete variables, posee una sensibilidad del 98,1\% (IC 95\%, 94,6 \%-99,4\%) con una especificidad del 50,1\% (IC 95\%, 48,5 \% $51,7 \%)$ para identificar LIC en la TAC.

Las limitaciones de la CATCH son que no propone una actuación específica para menores de dos años, tiene una gran variabilidad interobservador en la detección de los diversos signos de riesgo y el alto porcentaje de pacientes perdidos durante su estudio. Además, esta guía resulta en una tasa de TAC craneal del 30-50\%.

Gerdung et al. estiman que el manejo según la $\mathrm{CATCH}$ proporciona indicaciones menos confusas que las que propone la PECARN en cuanto a la indicación de realización de la TAC, con menor riesgo de malinterpretación de las guías (183). 


\subsubsection{Guía de manejo de la AEP (Asociación Española de Pediatría)}

En 2008 la AEP publicó entre sus protocolos terapéuticos (disponibles en http://www.aeped.es/documentos/protocolos-urgencias-pediatricas) el protocolo de manejo del TCE en el paciente pediátrico (29).

Debido a que los lactantes tienen un mayor riesgo de lesión intracraneal (nivel de evidencia B) propone la diferenciación de los pacientes en dos grandes grupos, en función de si son mayores o menores de dos años.

En ambos se determina el riesgo de lesión cerebral (alto, medio y moderado) en función de la historia clínica, la exploración física y el mecanismo accidental. Según el riesgo de lesión intracraneal se establecen la necesidad de pruebas de imagen, los cuidados y el periodo de observación.

\section{MAYORES DE DOS AÑOS}

En mayores de dos años, el nivel de consciencia obtenido en la GCS, unido a la exploración neurológica debe guiar el manejo de pacientes (nivel de evidencia B).

\section{Bajo riesgo de lesión intracraneal}

Estos casos corresponderían a TCE mínimo (GCS de 15), con exploración neurológica normal, sin antecedentes de pérdida de conciencia, con uno o ningún episodio de vómitos. Si existen garantías de observación por adultos durante 48 horas, se puede dar el alta domiciliaria con recomendaciones a los cuidadores sobre los signos de alarma a vigilar. Sólo ante la posibilidad de maltrato estaría indicada la realización de la radiografía de cráneo. En el resto de casos no estaría indicada ninguna prueba de imagen (nivel de evidencia B). La observación en el SUP queda reservada en el caso de no tener garantías de observación por adultos responsables, o 
bien si existen dificultades para buscar ayuda médica en caso de agravamiento, debiendo mantenerlo en el centro sanitario un periodo mínimo de seis horas.

\section{Situación de riesgo intermedio}

Correspondería a TCE leve (GCS de 13 ó 14 de forma mantenida más de dos horas tras sufrir un TCE), o con más de un episodio de vómitos, amnesia postraumática, cefalea intensa, o un mecanismo violento de producción (caídas desde altura superior a 1 metro, accidente de tráfico o bicicleta). En estos casos se recomienda el ingreso en la Unidad de Observación, y/o la realización de la TAC. Ante la persistencia de los síntomas, o el empeoramiento exploratorio ha de realizarse/repetirse la TAC. Si los síntomas han desaparecido y la TAC es normal pueden ser dados de alta y continuar con la observación domiciliaria.

\section{Alto riesgo de lesión intracraneal.}

En este grupo se incluirían los mayores de dos años con un GCS menor de 13 en cualquier momento, focalidad neurológica a la exploración, signos de fractura deprimida, lesión penetrante, fractura basilar y convulsión postraumática (especial atención a la que aparece entre una hora y siete días). En estos casos se debe realizar una TAC sin contraste de forma inmediata (nivel de evidencia B). Los niños encuadrados dentro de este grupo deben de ser trasladados a una UCI pediátrica para su control por un equipo multidisciplinario y por tanto nuestra actuación deberá ir encaminada a mantener la vía aérea, ventilación, circulación y administración de drogas si se requiere, hasta su llegada a dicha unidad.

\section{MENORES DE DOS AÑNOS}

La evidencia demuestra que los criterios para la realización de una TAC en niños menores de dos años con un TCE cerrado han de ser menos estrictos, ya que presentan un mayor riesgo de lesiones cerebrales significativas. 


\section{Grupo de bajo riesgo}

Si el mecanismo ha sido de baja energía (caída desde su altura, o altura menor de $50 \mathrm{~cm}$ ), el paciente está asintomático y la exploración física y neurológica son normales y si existen garantías de observación domiciliaria por adultos responsables durante 48 horas, se puede dar el alta domiciliaria una vez explicadas las normas de vigilancia (nivel de evidencia $B$ ).

\section{Grupo de riesgo intermedio I}

Ante la presencia de signos potenciales de lesión intracerebral, expresado con vómitos en número menor a tres, pérdida de conciencia menor a un minuto, letargia e irritabilidad previas, alteración prolongada del comportamiento o fractura craneal de más de 24 horas de evolución se recomiendan dos alternativas posibles de actuación: la primera, la realización inmediata de la TAC (nivel de evidencia B), o la observación 24-48 horas y si presenta síntomas en ese periodo realizar la TAC (nivel de evidencia C).

\section{Grupo de riesgo Intermedio II}

Si el mecanismo accidental es de alta energía (colisión con vehículo a alta velocidad, caída desde más de $50 \mathrm{~cm}$, impacto sobre superficie dura, con objeto romo o pesado...), sospecha de fractura determinada por la presencia de cefalohematoma $u$ otras lesiones en la superficie craneal, o datos sugerentes de daño intencional, se recomienda la realización de radiografía de cráneo y observación en medio sanitario un mínimo de seis horas. Si existe sospecha de maltrato, se recomienda el ingreso del paciente (nivel de evidencia B).

\section{Grupo de alto riesgo}

Se considera que el paciente presenta alto riesgo de lesión intracraneal si presenta GCS $<15$ en el momento de la exploración, focalidad neurológica, fontanela con aumento de tensión, convulsión postraumática, irritabilidad marcada y persistente, fractura de cráneo de menos de 24 horas de evolución y antecedentes de pérdida de consciencia superior al minuto o vómitos en número superior a dos o persistentes 
durante la observación. En estos casos se debe realizar de forma inmediata una TAC craneal sin contraste (nivel de evidencia B). Ante la presencia de una lesión intracraneal o signos de fractura basilar, el paciente debe ser valorado por Neurocirugía, y trasladar al paciente a un centro con UCI Pediátrica. La actuación en urgencias deberá ir encaminada a la estabilización del paciente, hasta su llegada a dicha unidad.

\section{Malos tratos}

Los lactantes son un grupo altamente susceptible de sufrir daño intencional, por lo que se ha de tener siempre en cuenta esa posibilidad ante TCE sufridos en este grupo de edad cuando se de alguna de las siguientes circunstancias:

- Incongruencia entre las lesiones y la historia clínica.

- Demora no justificable en la asistencia.

- Presencia de lesiones geométricas, en zonas relativamente protegidas o en distinto estadio evolutivo.

- Presencia de otras fracturas o hemorragias retinianas.

- Actitudes extrañas de los padres.

- Conducta poco habitual del lactante (rechazo del contacto físico, irritable con sus padres y tranquilo con el personal sanitario). 


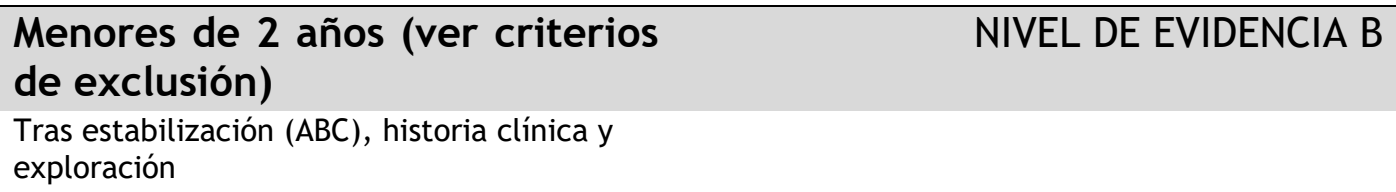

\section{Grupo de Alto riesgo de LIC}

- Disminución de conciencia en el momento de la exploración

- Focalidad neurológica

- Convulsión

Realización de TAC craneal

- Irritabilidad marcada y persistente

- Fractura de cráneo menor de 24 horas de evolución

- Vómitos en número superior a 2 o que persisten más de 24 horas

Si se detecta LIC o fractura de la base del cráneo, consultar con Neurocirugía

- Pérdida de conocimiento superior al minuto

Grupo de Riesgo Intermedio de LIC I (por signos potenciales de LIC)

Alternativas posibles:

- Vómitos en número menor a 3

- Pérdida de consciencia menor a un minuto de duración

Realización de TAC craneal

- Letargia e irritabilidad previas ya resueltas

Observación 24-48 horas

Si persistencia/empeoramiento de síntomas, realizar TAC craneal

- Alteración prolongada del comportamiento

- Fractura craneal de más de 24 horas de evolución

Grupo de Riesgo Intermedio de LIC II (por mecanismo traumático significativo)

- Mecanismo de alta energía

Radiografía de cráneo y

Colisión con vehículo

- Caída desde más de $50 \mathrm{~cm}$

- Impacto con objeto romo y pesado

- Cefalohematoma observación hospitalaria

- Traumatismo no presenciado con posible mecanismo significativo

(4-6 horas mínimo)

Si fractura realizar TAC craneal

Grupo de Bajo riesgo de LIC

- Mecanismo de baja energía

- Asintomático

- Exploración física normal

¿Existen garantías de observación por adultos durante 48 horas?

\section{ALTA DOMICILIARIA}

- En todos los casos vigilar signos sugerentes de maltrato.

Tabla 8. Sumario de recomendaciones de la AEP para el manejo del TCE en menores de dos años. 


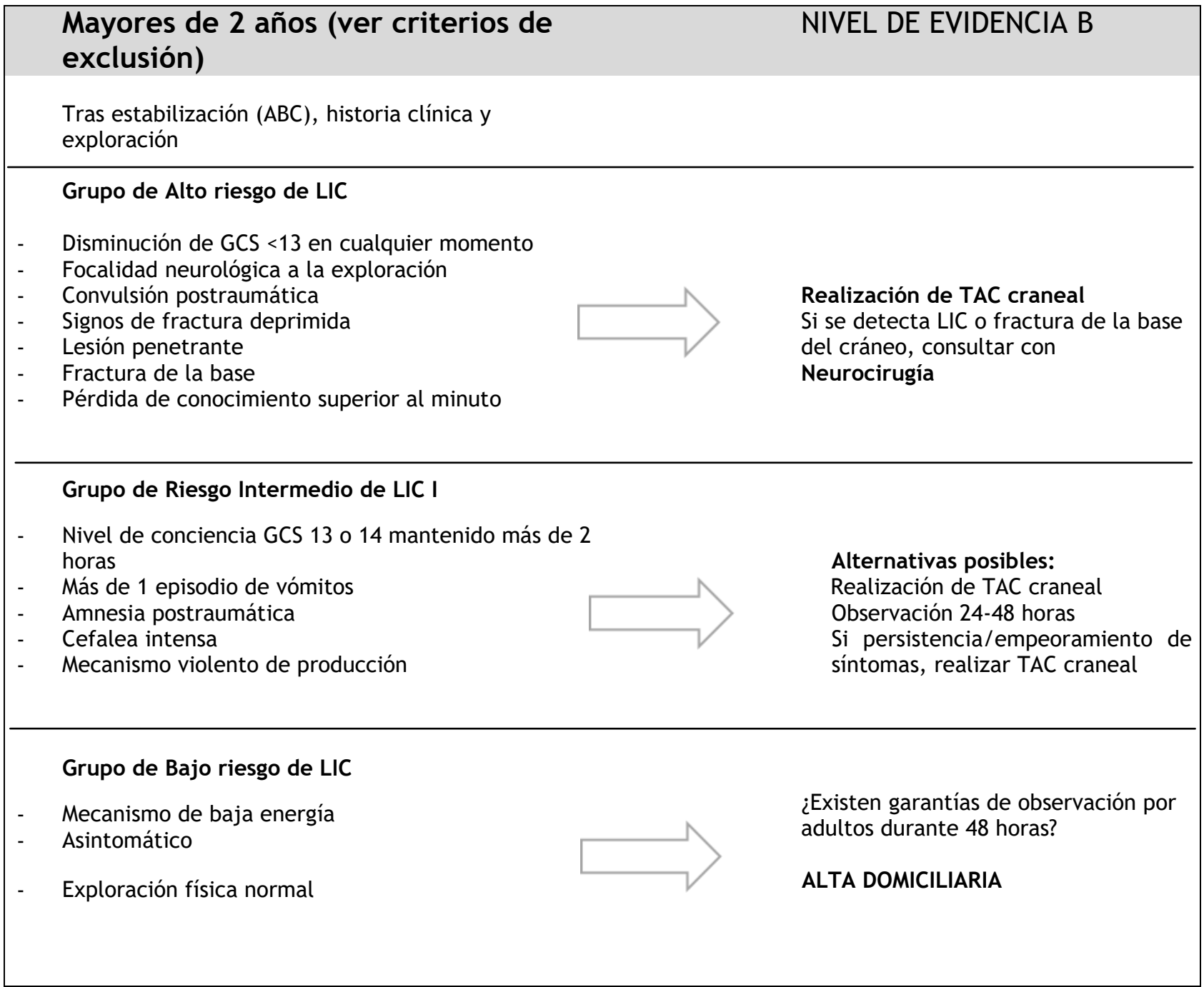

Tabla 9. Sumario de recomendaciones de la AEP para el manejo del TCE en mayores de dos años. 
Indicaciones de radiografía de cráneo (Nivel de evidencia B/C)

Mayores de 2 años:

- Historia incierta o sospecha de maltrato

- Sospecha de cuerpo extraño

- Sospecha de fractura deprimida o herida penetrante

- Ser portador de válvula de derivación intracraneal

Menores de 2 años:

- Hematoma o contusión en cuerpo cabelludo

- Mecanismo de alta energía (por ejemplo vehículos a motor)

- Caída desde más de $50 \mathrm{~cm}$ de altura

- Traumatismo no presenciado con la posibilidad de un mecanismo significativo

Tabla 10. Indicaciones de radiografía de cráneo según Protocolo de la AEP (Nivel de evidencia B/C). 
Indicaciones de TAC craneal (Nivel de evidencia B)

\section{Mayores de 2 años:}

- Cualquier alteración de la GCS en la exploración

- Focalidad neurológica durante la exploración

- Signos de: fractura deprimida, lesión penetrante, fractura de la base

- $\quad$ Pérdida de consciencia superior a un minuto

- Convulsión postraumática

- Amnesia postraumática

- Vómitos persistentes

- $\quad$ Cefalea persistente

- Irritabilidad

Menores de 2 años:

- Cualquier alteración de la GCS modificada para lactantes

- Focalidad neurológica durante la exploración

- Signos de: fractura deprimida, lesión penetrante, fractura de la base

- Pérdida de consciencia superior a un minuto

- Convulsión postraumática

- Amnesia postraumática

- Irritabilidad perdurable

- Fractura de cráneo

- Más de dos episodios de vómitos

Tabla 11. Indicaciones de TAC craneal según Protocolo de la AEP (Nivel de evidencia $B / C$ ) 
Criterios de observación hospitalaria (en función de los recursos asistenciales de cada unidad)

En la Observación de Urgencias (mínimo 6 horas):

- TCE de alta energía

- Pérdida de conciencia previa

- Síntomas persistentes en el momento de la exploración

- Ausencia de síntomas, GCS 13-14 y TC normal

- Fracturas aisladas de cráneo (mayores de 2 años)

Ingreso en planta:

- Sospecha de malos tratos

- Fracturas craneales aisladas en menores de 2 años (con TC normal)

- Persistencia de síntomas más de 6 horas en la unidad de Observación (con TC normal)

- Cualquier situación que impida una adecuada supervisión por adultos responsables las 48 horas posteriores al traumatismo

Traslado a UCIP:

- Cualquier LIC en la TC

- Glasgow < 13 o focalidad neurológica

\section{Criterios de alta:}

- Paciente asintomático, con GCS 15 y ausencia de focalidad neurológica

- Todos los pacientes ingresados en Observación (mínimo 6 horas) en los que hayan desaparecido los síntomas, con GCS de 15 y ausencia de focalidad neurológica

- Existen garantías de observación por adultos durante 48 horas

- Adjuntar siempre la hoja informativa

Tabla 12. Criterios de observación hospitalaria según Protocolo de la AEP (Nivel de evidencia $B / C$ ) 


\subsection{VARIABILIDAD EN EL MANEJO DEL TCEL}

Como se ha expuesto en el apartado anterior, existen múltiples guías de práctica clínica para el manejo del TCEL pediátrico, con sus particularidades específicas y recomendaciones de actuación diferentes. De esta forma, a la hora de atender a los pacientes, los profesionales deciden adherirse a unas $\mathrm{u}$ otras en función de las costumbres del lugar de trabajo, de sus preferencias personales y de los conocimientos que tengan de las mismas. Varios trabajos llevados a cabo para comparar las distintas guías señalan como la guía de mayor cohorte y única validada la de la PECARN $(10,178,184)$.

En un estudio de cohortes prospectivo, en el que se incluyen a pacientes menores de dieciocho años con TCEL, evalúan la precisión diagnóstica de las distintas guías clínicas (PECARN, CATCH, CHALICE) así como la estimación del facultativo en identificar las LICci. Entre los 1009 pacientes incluidos, 21 (2\%; IC 95\% 1\%-3\%) tuvo una LICci. La precisión diagnóstica de las distintas guías para la detección de LICci es variable: sólo la estimación del médico facultativo junto con la PECARN identifican el $100 \%$ de ellas, mientras que CATCH detecta el $91 \%$ y CHALICE el $84 \%$ (184). Babl et al. también demostraron que la sensibilidad de las tres guías en la detección de LICci es notable (176).

Lyttle et al. comparan también las tres mismas guías clínicas y argumentan que éstas son muy diferentes entre sí, ya que estudian resultados diferentes por lo que su comparación era compleja. CHALICE y CATCH detectan qué pacientes se benefician de una TAC mientras que PECARN trata de identificar las TAC que se pueden evitar. Además PECARN es la única con una propuesta de algoritmo distinta para menores de dos años (185).

Por su parte, Holmes et al., comparadas las guías de PECARN y CHALICE y su coste económico según el Sistema Nacional de Salud de Gran Bretaña (NHS), sugieren que CHALICE es la estrategia óptima para evaluar a los niños con TCEL (186). 
El grado de conformidad entre el personal de enfermería y los facultativos médicos para la aplicación de las múltiples guías de TCEL pediátrico es moderado en niños mayores y algo inferior en lactantes (187). Así como la aceptación de los clínicos con las guias de practica clínica es elevada teniendo en cuenta que se debe individualizar cada caso ya que no todos los pacientes pueden ser incluídos en los algoritmos propuestos (108).

El único trabajo que ha estudiado el uso de la guía de manejo de la AEP en el TCEL es el publicado por Velasco et al. en 2014. Se trata de un estudio multicéntrico español en el que participaron cuatro centros hospitalarios, que estudió la adecuación del manejo diagnóstico del TCEL en menores de 24 meses a las guías de práctica clínica PECARN Y AEP. En él se muestra una enorme variabilidad intercentro en la proporción de pacientes en los que se realiza una RX de cráneo, mientras que el uso de la TAC fue similar en los cuatro centros participantes. Concluyó que la concordancia con las guías es baja, siendo superior con la PECARN, siendo en tan solo uno de los centros la adhesión al protocolo de la AEP superior al 50\%. Resulta paradójica la mayor concordancia con las guías internacionales, ya que a priori se supondría que su conocimiento es inferior que el de los protocolos nacionales (173). 
En la siguiente tabla se resumen las indicaciones de manejo (TAC/RX/Observación) en los distintos supuestos clínicos según las distintas guías clínicas expuestas en pacientes con TCEL menores de dos años:

\begin{tabular}{|c|c|c|c|c|}
\hline Variable & AEP & PECARN & CHALICE & CATCH \\
\hline GCS 14 & TAC & TAC & TAC & TAC \\
\hline $\begin{array}{l}\text { Traumatismo con } \\
\text { vehículo a gran } \\
\text { velocidad }\end{array}$ & $\mathrm{RX}$ & TAC/OBS & TAC & TAC \\
\hline Caída de una altura & $\begin{aligned} \mathrm{Si}> & 50 \mathrm{~cm}: \\
& \mathrm{RX}\end{aligned}$ & $\begin{array}{l}\text { Si > } 90 \mathrm{~cm}: \\
\text { TAC/OBS }\end{array}$ & - & - \\
\hline $\begin{array}{l}\text { Caída sobre superficie } \\
\text { dura }\end{array}$ & $\mathrm{RX}$ & - & - & - \\
\hline $\begin{array}{l}\text { Traumatismo objeto } \\
\text { romo y pesado }\end{array}$ & RX & - & - & - \\
\hline Cefalohematoma & $\mathrm{RX}$ & $\begin{array}{c}\text { Si “no frontal": } \\
\text { TAC/OBS }\end{array}$ & $\begin{array}{c}\mathrm{Si}>5 \mathrm{~cm} \text { y }<1: \\
\text { año } \\
\text { TAC }\end{array}$ & $\begin{array}{c}\text { Si grande: } \\
\text { TAC }\end{array}$ \\
\hline $\begin{array}{l}\text { TCE no presenciado } \\
\text { con posible } \\
\text { mecanismo } \\
\text { significativo }\end{array}$ & $\mathrm{RX}$ & - & TAC & - \\
\hline Pérdida consciencia & $\begin{array}{l}\text { Si > } 1 \text { min: } \\
\text { TAC }\end{array}$ & $\begin{array}{l}\mathrm{Si}>5 \text { seg: } \\
\mathrm{TAC} / \mathrm{OBS}\end{array}$ & $\begin{array}{l}\mathrm{Si}>5 \mathrm{~min}: \\
\quad \mathrm{TAC}\end{array}$ & - \\
\hline Vómitos & $\begin{array}{c}\mathrm{Si} \geq 2: \\
\mathrm{TAC}\end{array}$ & - & $\begin{array}{l}\mathrm{Si} \geq 3: \\
\mathrm{TAC}\end{array}$ & - \\
\hline $\begin{array}{c}\text { Alteración } \\
\text { consciencia/comporta } \\
\text { miento anómalo según } \\
\text { padres }\end{array}$ & TAC & TAC & TAC & TAC \\
\hline Convulsión & TAC & - & TAC & - \\
\hline $\begin{array}{c}\text { Fractura vista en Rx } \\
\text { simple/ signos o } \\
\text { síntomas de fractura } \\
\text { base del cráneo } \\
\text { (PECARN) }\end{array}$ & TAC & TAC & TAC & TAC \\
\hline
\end{tabular}

Tabla 13. Diferencias según las distintas guías de práctica clínica en menores de dos años 
En la siguiente tabla se resumen las indicaciones de manejo (TAC/Rx/Observación) en los distintos supuestos clínicos según las distintas guías clínicas expuestas en pacientes con TCEL mayores de dos años:

\begin{tabular}{|c|c|c|c|c|}
\hline Variable & AEP & PECARN & CHALICE & CATCH \\
\hline $\mathrm{GCS} \leq 14$ & TAC & TAC & $\begin{array}{c}\mathrm{Si}<14: \\
\text { TAC }\end{array}$ & TAC \\
\hline $\begin{array}{l}\text { Traumatismo con vehículo a } \\
\text { gran velocidad }\end{array}$ & TAC/OBS & TAC/OBS & TAC & TAC \\
\hline Caída & - & $\begin{array}{c}\mathrm{Si}>150 \mathrm{~cm}: \\
\text { TAC/OBS }\end{array}$ & - & - \\
\hline Pérdida consciencia & $\begin{array}{l}\text { Si > } 1 \text { min: } \\
\quad \text { TAC }\end{array}$ & $\begin{array}{l}\text { Si > } 5 \text { seg: } \\
\text { TAC/OBS }\end{array}$ & $\begin{array}{l}\mathrm{Si}>5 \mathrm{~min}: \\
\quad \mathrm{TAC}\end{array}$ & - \\
\hline Vómitos & $\begin{array}{c}\mathrm{Si} \geq 2: \\
\text { TAC/OBS }\end{array}$ & $\begin{array}{c}\mathrm{Si} \geq 2: \\
\text { TAC/OBS }\end{array}$ & $\begin{array}{l}\mathrm{Si} \geq 3: \\
\mathrm{TAC}\end{array}$ & - \\
\hline $\begin{array}{c}\text { Alteración } \\
\text { consciencia/comportamient } \\
\text { o anómalo según padres }\end{array}$ & TAC & TAC & TAC & TAC \\
\hline Convulsión & TAC & - & TAC & - \\
\hline $\begin{array}{c}\text { Signos de fractura } \\
\text { deprimida/signos o } \\
\text { síntomas de fractura base } \\
\text { del cráneo }\end{array}$ & TAC & TAC & TAC & TAC \\
\hline Cefalea intensa & TAC/OBS & TAC/OBS & - & TAC \\
\hline $\begin{array}{l}\text { Historia incierta o sospecha } \\
\text { maltrato }\end{array}$ & $\mathrm{RX}$ & - & TAC & - \\
\hline $\begin{array}{l}\text { Portador válvula de } \\
\text { derivación intracraneal }\end{array}$ & $\mathrm{RX}$ & - & - & - \\
\hline
\end{tabular}

Tabla 14. Diferencias según las distintas guías de práctica clínica en mayores de dos años 


\section{JUSTIFICACIÓN}




\section{JUSTIFICACIÓN}

El TCE es la primera causa de muerte y discapacidad en los niños a nivel mundial por lo que es indispensable detectar de manera precoz a los niños con LICci tras un TCE que pueden necesitar intervención urgente, fundamentalmente neurocirugía.

El TCEL es un motivo de consulta habitual en Urgencias Pediátricas. En EEUU el TCEL en menores de dieciocho años supone más de 600000 consultas y 60000 ingresos al año. En Europa, estos datos se desconocen.

El TCE pediátrico es uno de los mayores retos para el médico de urgencias y de cuidados intensivos. Si se trata de un niño, la complejidad clínica es aún mayor. Varias son las razones (93):

$1^{\text {a }}$. Las decisiones tomadas en las primeras horas pueden ser cruciales para el pronóstico del paciente, no porque nuestra actuación mejore la lesión cerebral inicial, sino porque evita el empeoramiento de la misma secundaria a un daño cerebral secundario.

$\mathbf{2}^{\mathbf{a}}$. Nuestra actitud terapéutica está basada en la recogida de una información que entraña conocimientos avanzados en monitorización neurológica no fácilmente entendibles.

$3^{\mathbf{a}}$. Muchas de nuestras decisiones se basan en estudios con un nivel de evidencia Clase II en adultos. No obstante, la investigación en niños muy escasa.

4. Los niños requieren atención y cuidados específicos diferentes de los adultos, que deben llevarse a cabo por parte de personal cualificado para ello.

$\mathbf{5}^{\circ}$. Los niños son seres en evolución. Por tanto, evaluar los factores pronósticos de un niño es extremadamente complejo. Lo que para nosotros puede significar una alteración cognitiva o de la conducta, puede ser también el desarrollo psicomotor normal de cada paciente. Por ello investigar sobre el pronóstico a largo o corto plazo de una determinada actitud terapéutica en la fase aguda del TCE no es fácil.

Son pocos los pacientes (4-7\%) con TCEL que presentan una lesión craneal visible en una tomografía axial computerizada (TAC), y sólo 0,5\% tienen una lesión 
intracraneal que requiera intervención urgente. No obstante, los niños con LICci que requieran intervenciones urgentes (especialmente neuroquirúrgicas) deben ser identificados rápidamente.

A pesar de la alta incidencia de TCE, la mortalidad es comparativamente muy baja (6-10 por cada 100000 casos) y pocos pacientes tienen un pronóstico fatal. Así, aunque los médicos de urgencias atiendan muchos pacientes con TCE, es raro ver complicaciones que amenacen la vida del paciente (12).

La TAC craneal es la técnica indicada para el diagnóstico urgente de las lesiones traumáticas intracraneales, aunque algunas lesiones cerebrales pueden no identificarse mediante esta técnica. En los servicios de urgencias de EEUU, alrededor del $50 \%$ de los niños atendidos por TCE se les realiza una TAC.

Desde 1995 se ha duplicado su uso en EEUU. Pese a ello, tan sólo el 10\% de las TAC hechas a pacientes con TCEL muestran hallazgos patológicos. Además, la mayoría de las lesiones que se encuentran en la TAC no precisan cirugía urgente. La mayoría de los pacientes atendidos en los servicios de urgencias con TCEL suelen tener una GCS de 14-15 puntos, y lesiones con GCS 14-15 raras veces requieren neurocirugía.

Por ello, es primordial disminuir el uso de la TAC fundamentalmente debido al riesgo de desarrollar procesos oncológicos a causa de la radiación ionizante (mayor riesgo cuanto menor es la edad del paciente), además de por el tiempo y coste de su realización. Además, la TAC presenta otras desventajas, entre las que se encuentran la necesidad de sedación para su realización, los riesgos asociados al desplazamiento del paciente al escáner, frecuentemente localizado lejos de la supervisión del pediatra de urgencias, y el coste económico adicional.

Por todo ello, tres de los principales grupos de investigación desarrollaron diferentes guías de recomendaciones para intentar ayudar con los dilemas que frecuentemente se presentan en la evaluación de los pacientes con TCEL, estandarizar su manejo y mejorar el cuidado del paciente. Estas reglas pueden utilizarse para identificar diferentes niveles de riesgo en niños con traumatismos craneales aparentemente leves, consiguiendo una reducción en el número de TAC craneales realizados. De todas ellas, la guía clínica de la PECARN es la elaborada con la mayor cohorte de pacientes, y la única validada, tanto en lactantes como en niños mayores. 
Estudios previos realizados en EEUU y Canadá han mostrado una gran variabilidad en el uso de las pruebas de imagen en pacientes con TCEL, con evidencia de una menor proporción de las mismas realizadas en los SUP frente a los Servicios de Urgencias Generales (173).

Hasta este momento no se ha publicado ningún trabajo que evalúe esta variabilidad, así como la epidemiología del TCEL pediátrico en Europa. 
OBJETIVOS 


\section{OBJETIVOS}

Los objetivos del presente trabajo se enumeran a continuación:

\subsection{Objetivo principal}

Investigar la variabilidad en el manejo del TCEL y trivial en los niños atendidos en los Servicios de Urgencias participantes en el estudio.

Se considerarán las Guías Clínicas de PECARN como el estándar de referencia para evaluar cualquier variación en el manejo.

\subsection{Objetivos secundarios}

1. Conocer la prevalencia de TCEL y TCE trivial pediátricos en Europa.

2. Determinar las causas de TCEL y trivial pediátricos en Europa.

3. Analizar las características epidemiológicas de los pacientes afectados de TCEL y trivial en Europa.

4. Estudiar la prevalencia de LICci en el TCEL y trivial pediátricos en Europa.

5. Examinar si existe relación causal entre los tipos de mecanismos traumáticos y los hallazgos en la exploración, así como la presencia de LICci en el TCEL y trivial pediátricos en Europa.

6. Evaluar las pruebas de imagen solicitadas en los TCEL y triviales pediátricos en Europa

7. Investigar la rentabilidad de la radiografía de cráneo a la hora de evaluar la LICci en los pacientes con TCEL y trivial. 
8. Analizar el destino de los pacientes, tanto el porcentaje de pacientes ingresados como los que permanecen en observación para entender si las diferencias pueden ser debidas al diferente manejo de los pacientes o a diferencias entre los diversos SUP. 
MATERIAL Y MÉTODOS 


\section{MATERIAL Y MÉTODOS}

\subsection{Diseño del estudio}

Se trata de un estudio de cohortes retrospectivo multicéntrico, en el que se incluyeron pacientes de dieciocho años o menos que consultaron al SUP por TCE leve o trivial.

Se recogieron datos de los pacientes atendidos entre el 01/01/2012 y el 31/12/2014. Los centros participantes se recogen en la siguiente tabla:

\begin{tabular}{|c|c|c|}
\hline Hospital & Ciudad & País \\
\hline Hospital Universitario Río Hortega & Valladolid & España \\
\hline Hospital Universitario Cruces & Barakaldo & España \\
\hline Hospital Universitario Basurto & Bilbao & España \\
\hline Hospital Universitario de Cabueñes & Gijón & España \\
\hline Hospital de Tarrassa & Tarrasa & España \\
\hline Hospital Universitario Son Espasses & Mallorca & España \\
\hline Hôpital Universitaire Robert Debre & París & Francia \\
\hline Ghent University Hospital & Gante & Bélgica \\
\hline Heim Pal Children's Hospital & Budapest & Hungría \\
\hline Hospital de Santa Maria & Lisboa & Portugal \\
\hline Hacettepe University Hospital & Ankara & Turquía \\
\hline University Hospital of Padova & Padua & Italia \\
\hline Meyer Children's Hospital & Florencia & Italia \\
\hline Erasmus MC Sophia & Rotterdam & Países bajos \\
\hline Temple Sreet Chidren's University Hospital & Dublin & Irlanda \\
\hline
\end{tabular}

Tabla 15. Centros participantes 


\section{Definiciones}

\section{a) Traumatismo craneoencefálico leve}

Definimos TCEL como «historia o signos físicos de traumatismo en cráneo, encéfalo o cuero cabelludo en lactante o niño consciente que responde a estímulos verbales o al tacto con una $C G S \geq 14$ » (17).

\section{b) Traumatismo craneoencefálico trivial}

En el presente estudio, el TCE trivial se define por cumplir AMBOS criterios I y II:

\section{Criterio I:}

Impacto o caída contra un objeto estacionario o contra el suelo desde la posición de sedestación o bipedestación, o bien andando o corriendo.

\section{Criterio II:}

- Ausencia de signos o síntomas de TCE o

- Presencia tan sólo de una abrasión o laceración del cuero cabelludo

\section{Ejemplos de TCE TRIVIAL:}

Niño que se golpea mientras corre con el borde de una mesa y tiene una laceración del cuero cabelludo, sin otros síntomas (cumple criterio I y criterio II).

Niño en sedestación que se cae y golpea su cabeza contra el suelo, sin presentar síntomas ni signos físicos (cumple criterio I y criterio II).

\section{Ejemplos de TCE NO TRIVIAL:}

Caída desde una altura (p.ej. silla, cochecito o cama) en la que el niño se golpea la cabeza, aunque no presente signos ni síntomas (no cumple criterio I).

Cualquier accidente con un vehículo a motor en el que el paciente se golpee la cabeza, aunque no presente síntomas ni signos físicos (no cumple criterio I).

Niño con cefalohematoma tras cualquier tipo de traumatismo (no cumple criterio II).

Niño ( $\geq$ de 2 años) con dolor de cabeza o vómitos tras cualquier tipo de mecanismo (no cumple criterio II). 
Niño de 3 meses de edad que se golpea la cabeza por cualquier mecanismo (no cumple criterio I, puesto que no puede caminar, sentarse, ponerse en pie o correr).

\section{c) Paciente sintomático}

En el presente trabajo se considera un paciente sintomático tras el TCEL cuando presenta uno o más de los siguientes síntomas y signos:

- GCS de 13 en cualquier momento, o GCS de 14 al menos dos horas tras el golpe

- Alteración del sensorio

- Agitación

- Mareo

- Preguntas repetidas o respuesta enlentecida a la comunicación verbal

- Irritabilidad a la exploración

- Comportamiento anómalo a criterio parental

- Dolor de cabeza creciente (en pacientes mayores de dos años)

- Historia de pérdida de conocimiento

- Historia de amnesia

- Tres o más vómitos tras el TCEL (en pacientes mayores de dos años)

- Déficit focal (definido como cualquier déficit, incluyendo motor, sensitivo, de coordinación o reflejos anormales)

- Evidencia de salida de sangre o líquido cefalorraquídeo por oído o nariz

- Signos de fractura de base del cráneo

- Hematoma retroauricular (signo de Battle)

- Hematoma periorbital bilateral (ojos de mapache)

- Hemotímpano

- Otorrea de LCR

- Rinorrea de LCR

- Crepitación de huesos del macizo facial o deformidad grave de los mismos, presencia de hematomas, hinchazón o laceración (en pacientes menores de dos años).

- Cefalohematoma: hinchazón palpable del cuero cabelludo o de la frente. 


\section{d) Lesión intracraneal clínicamente importante (LICci)}

Muchos estudios observacionales fueron diseñados para identificar a los lactantes y niños con mayor riesgo de LIC tras un TCE (188). Definimos el concepto de LICci utilizando los criterios establecidos por las cohortes más grandes estudiadas (10-12) como: presencia de LIC (hematoma epidural, hematoma subdural o contusión cerebral entre otros) en la TAC asociada a uno o más de los siguientes supuestos:

- Fallecimiento por TCE.

- Intervención neuroquirúrgica (monitorización de PIC, elevación de fractura craneal deprimida, ventriculostomía, evacuación de hematoma, lobectomía, desbridamiento tisular, reparación duramadre, otros).

- Intubación > 24 horas por el TCE.

- Ingreso hospitalario > 48 horas por síntomas neurológicos persistentes como alteración consciencia, vómitos repetidos, cefalea intensa persistente o manejo de convulsiones, en asociación con LIC en TAC.

\section{Criterios de inclusión}

Se incluyeron todos los pacientes que sufrieron un traumatismo por encima de las cejas en las 24 horas previas a la visita en el hospital y que cumplían las características de TCEL y trivial y que no presentaban ninguno de los criterios de exclusión.

Se incluyeron los pacientes que fueron atendidos en varias ocasiones por el mismo TCE, así como los pacientes evaluados más una vez por diferentes TCE.

\section{Criterios de exclusión}

- Pacientes con TCE severo:

- Traumatismo penetrante

- Fractura craneal con hundimiento claramente visible

- Fractura craneal abierta

- GCS $\leq 12$ puntos a su llegada al hospital bajo criterio del médico que 
le atendía

- Pacientes a los que se les haya realizado una prueba de imagen fuera del hospital antes de su llegada al hospital

- Déficit neurológico focal agudo

- Trastorno generalizado del desarrollo

- TCE sospechoso de ser secundario a maltrato o a intoxicación

\subsection{Desarrollo del estudio}

En la primera fase del estudio se envió una encuesta vía Google Drive ${ }^{\circledR}$ a todos los centros incluidos, con preguntas acerca de las características del hospital (ver Anexo 9.3) e información acerca de los protocolos o guías clínicas de manejo del TCE usadas en cada hospital.

En la segunda fase del estudio los investigadores revisaron las historias de urgencias de los pacientes atendidos por TCEL en sus SUP entre el 01/01/2012 y el 31/12/2014. Los investigadores de cada centro proporcionaron a los investigadores principales (IP) el número de pacientes atendidos en cada año del estudio, divididos en dos grupos ( $<2$ años $\mathrm{y} \geq 2$ años de edad). Dado que el número de pacientes podría ser excesivamente grande en determinados centros, usando estos datos, se realizó un proceso de aleatorización estratificada por edad $(<2$ y $\geq 2$ años) y año de atención, con proporción de incluidos 1:3. De esta manera se generó un listado de pacientes a revisar por cada centro, que incluía el $25 \%$ de los atendidos en cada año y grupo de edad.

Los investigadores de cada centro rellenaron una hoja de recogida de datos (ver Anexo 9.4) por cada paciente con los siguientes datos:

- Datos generales

- Anamnesis y mecanismo del traumatismo

- Síntomas

- Examen físico

- Pruebas de imagen y destino del paciente

- Necesidad de intervención

Toda esta información se obtuvo de la revisión de la historia clínica del paciente. 
Estos datos fueron introducidos en la base de datos creada por los IP mediante Microsoft Access ${ }^{\circledR}$.

\subsection{Análisis estadístico}

Se utilizó el paquete estadístico para Mac de Stata (Stata Corp, College Station, $\mathrm{TX}^{\circledR}$ ) para todos los cálculos.

Para el objetivo principal del estudio se realizó un análisis descriptivo.

Las variables continuas se expresaron como media y desviación estándar o como mediana y rango intercuartílico, dependiendo de la distribución de la variable. Se usó el test de Shapiro-Wilk para determinar si las variables tenían distribución normal o no.

Las variables categóricas se expresaron en frecuencias absolutas, y sus frecuencias relativas en forma de porcentajes. Las diferencias entre centros se analizaron mediante regresión lineal o logística para variables continuas o categóricas, respectivamente.

Para los objetivos secundarios, la variable resultado fue el porcentaje de pruebas de imagen realizadas en cada centro, diferenciando radiografías, ecografías o TAC. Las diferencias entre centros se estudiaron mediante regresión logística, ajustando por potenciales variables confundidoras o modificadoras del efecto sugeridas en el análisis descriptivo. La proporción de pacientes ingresados en cada centro, así como de pacientes con LICci, se estudiaron también mediante el mismo método.

\subsection{Tamaño muestral}

La variabilidad en el manejo del TCEL entre centros se determinó comparando el porcentaje de pacientes en cada centro a los que se realizan pruebas de imagen, diferenciando entre radiografías, ecografías y TAC; así como el porcentaje de pacientes que permanecen en la unidad de observación y el porcentaje de pacientes ingresados. Se calculó una prevalencia, basada en trabajos anteriores, del 20\% para la 
radiografía simple de cráneo, del 2,9\% para el TAC craneal, del $14 \%$ para la permanencia en la sala de observación, y un $9 \%$ de ingresos $(10,64,173,189)$.

Se asumió para el estudio una significación clínica de la variabilidad en el manejo de $\pm 10 \%$ en la proporción de radiografías simples, $\pm 5 \%$ de estancia en observación, $y \pm 3 \%$ de ingreso, y que la distribución de los pacientes sería similar entre centros. Suponiendo que la mediana de pacientes atendidos en los hospitales pertenecientes a Research in Pediatric Emergency Medicine (REPEM) sería de aproximadamente 40 000 pacientes/año, y que aproximadamente un $3 \%$ de esos pacientes acuden por un TCE, cada hospital tendría unos 1200 pacientes incluibles al año, de los cuales un $25 \%$ sería finalmente incluido. Eso suponía 900 pacientes recogidos en los 3 años del estudio. Con esta muestra el análisis debería ser capaz de detectar diferencias clínicamente significativas con una potencia superior al $85 \%$.

\subsection{Declaración de intereses}

Los autores del estudio declaran no presentar ningún conflicto de intereses.

\subsection{Aprobación institucional}

Este estudio ha sido aprobado por el Comité Ético de Investigación Clínica (CEIC) de Valladolid Oeste (ver Anexo 9.5). 


\section{RESULTADOS}




\section{RESULTADOS}

Los resultados del trabajo los presentaremos en los siguientes apartados:

5.1. Datos generales

5.2. Anamnesis

5.3. Exploración física

5.4. Pruebas complementarias

5.5. Manejo y destino

5.6. Análisis de la variabilidad 


\subsection{Datos generales}

En el presente estudio participaron 15 hospitales, que se encuentran representados en la figura 10.

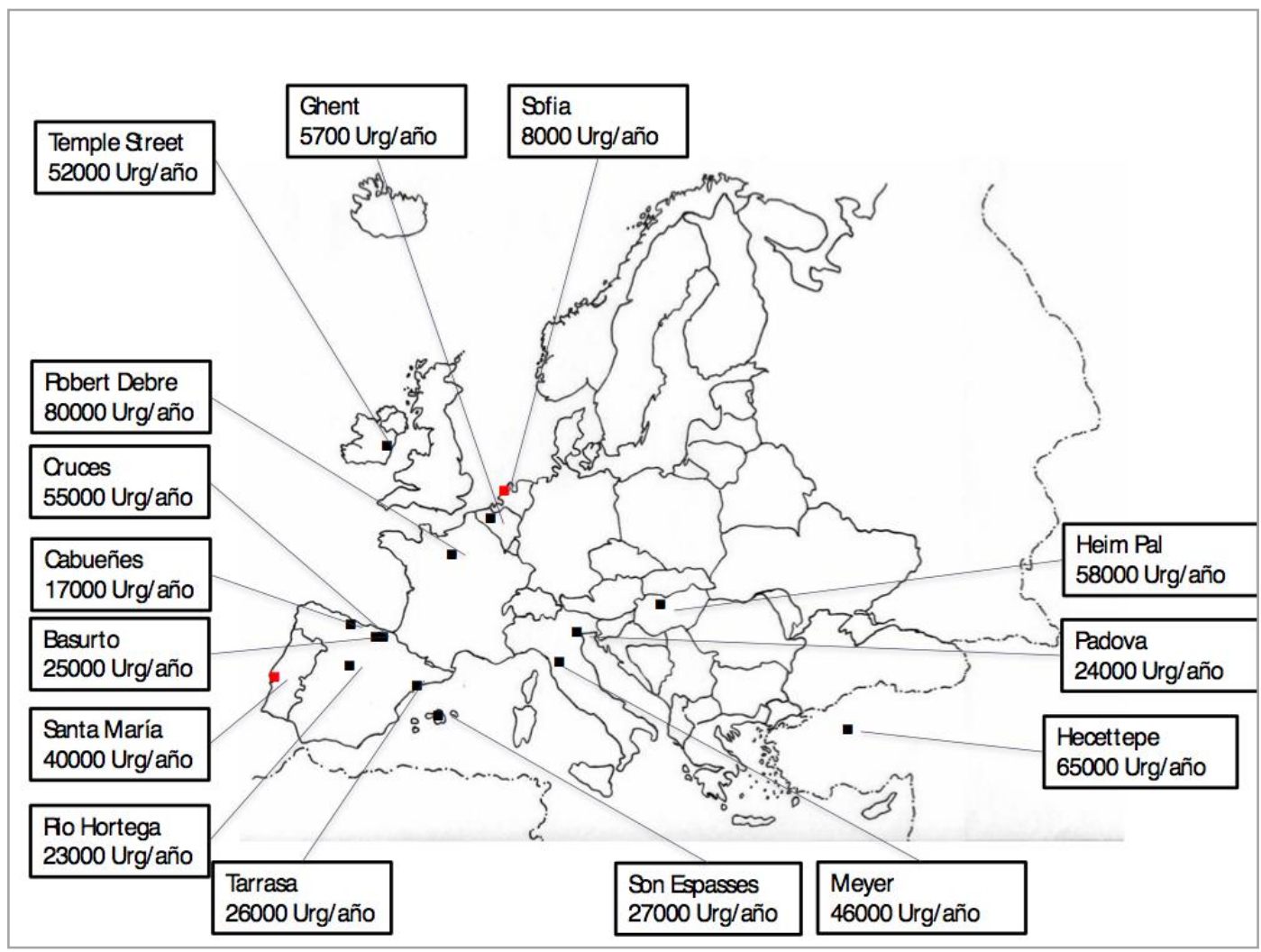

Figura 10. Mapa con los centros participantes y el número de urgencias/año de cada uno 


\begin{tabular}{|c|c|c|c|c|c|c|c|}
\hline & $\mathrm{RH}$ & CR & BA & CA & TA & SE & RD \\
\hline País & España & España & España & España & España & España & Francia \\
\hline $\begin{array}{c}\text { Hospital } \\
\text { pediátrico o } \\
\text { general? }\end{array}$ & General & General & General & General & General & General & Pediátrico \\
\hline $\begin{array}{l}\text { Es un hospital } \\
\text { universitario? }\end{array}$ & Sí & Sí & Sí & No & Sí & Sí & Sí \\
\hline $\begin{array}{c}\text { Pacientes } \\
\text { atendidos/año } \\
\text { (media) }\end{array}$ & 23202 & 54239 & 24330 & 17353 & 26164 & 27662 & 81083 \\
\hline $\begin{array}{c}\text { Edad límite } \\
\text { atención en } \\
\text { urgencias } \\
\text { (años) }\end{array}$ & 14 & 14 & 14 & 14 & 16 & 15 & 18 \\
\hline $\begin{array}{c}\text { Personal de } \\
\text { Urgencias } \\
\text { Pediátricas }\end{array}$ & $\begin{array}{l}\text { Pediatra } \\
\text { SUP }\end{array}$ & $\begin{array}{l}\text { Pediatra } \\
\text { SUP }\end{array}$ & $\begin{array}{l}\text { Pediatra } \\
\text { SUP }\end{array}$ & $\begin{array}{c}\text { Pediatra } \\
\text { SUP }\end{array}$ & & $\begin{array}{c}\text { Pediatra } \\
\text { general }\end{array}$ & Mixto \\
\hline $\begin{array}{l}\text { Quién atiende } \\
\text { los TCE? }\end{array}$ & $\begin{array}{l}\text { Pediatra } \\
\text { SUP }\end{array}$ & $\begin{array}{l}\text { Pediatra } \\
\text { SUP }\end{array}$ & $\begin{array}{l}\text { Pediatra } \\
\text { SUP }\end{array}$ & $\begin{array}{l}\text { Pediatra } \\
\text { SUP }\end{array}$ & $\begin{array}{c}\text { Pediatra } \\
\text { general }\end{array}$ & $\begin{array}{c}\text { Pediatra } \\
\text { general }\end{array}$ & $\begin{array}{l}\text { Médico } \\
\text { urgencias }\end{array}$ \\
\hline $\begin{array}{c}\text { Existe Unidad } \\
\text { de } \\
\text { Neurocirugía? }\end{array}$ & Sí & Sí & Sí & No & No & Sí & No \\
\hline $\begin{array}{c}\text { Existe Unidad } \\
\text { de } \\
\text { Neurocirugía } \\
\text { Infantil? }\end{array}$ & No & No & Sí & No & No & Sí & No \\
\hline $\begin{array}{c}\text { Existe Unidad } \\
\text { de Cuidados } \\
\text { Intensivos? }\end{array}$ & Sí & Sí & Sí & Sí & Sí & Sí & Sí \\
\hline $\begin{array}{c}\text { Existe Unidad } \\
\text { de Cuidados } \\
\text { Intensivos } \\
\text { pediátricos? }\end{array}$ & No & Sí & Sí & No & No & Sí & Sí \\
\hline
\end{tabular}




\begin{tabular}{|c|c|c|c|c|c|c|c|}
\hline GH & HP & SM & HT & PA & MY & ER & TE \\
\hline Bélgica & Hungría & Portugal & Turquía & Italia & Italia & Países Bajos & Irlanda \\
\hline General & Pediátrico & General & Pediátrico & Pediátrico & Pediátrico & General & Pediátrico \\
\hline Sí & Sí & Sí & Sí & Sí & Sí & Sí & No \\
\hline 5730 & 59864 & 39839 & 62026 & 23938 & 42749 & 7862 & 52548 \\
\hline & 18 & 18 & 18 & 14 & 14 & & 16 \\
\hline & $\begin{array}{l}\text { Pediatra } \\
\text { general }\end{array}$ & $\begin{array}{c}\text { Pediatra } \\
\text { general }\end{array}$ & $\begin{array}{l}\text { Pediatra } \\
\text { general }\end{array}$ & Mixto & $\begin{array}{l}\text { Pediatra } \\
\text { SUP }\end{array}$ & & $\begin{array}{l}\text { Pediatra } \\
\text { SUP }\end{array}$ \\
\hline $\begin{array}{c}\text { Pediatra } \\
\text { general }\end{array}$ & $\begin{array}{l}\text { Pediatric } \\
\text { surgeon }\end{array}$ & $\begin{array}{c}\text { Pediatra } \\
\text { general }\end{array}$ & $\begin{array}{c}\text { Pediatra } \\
\text { general }\end{array}$ & $\begin{array}{l}\text { Pediatra } \\
\text { SUP }\end{array}$ & $\begin{array}{c}\text { Pediatra } \\
\text { SUP }\end{array}$ & $\begin{array}{l}\text { Neurólogo } \\
\text { infantil }\end{array}$ & $\begin{array}{c}\text { Pediatra } \\
\text { SUP }\end{array}$ \\
\hline Sí & No & Sí & Sí & Sí & No & Sí & No \\
\hline Sí & Sí & Sí & Sí & Sí & Sí & Sí & Sí \\
\hline Sí & No & Sí & Sí & Sí & No & Sí & No \\
\hline Sí & Sí & Sí & Sí & Sí & Sí & Sí & Sí \\
\hline
\end{tabular}


RH: Hospital Universitario Rio Hortega; CR: Hospital Universitario Cruces; BA: Hospital Universitario Basurto; CA: Hospital Cabueñes; TA: Consorci Sanitari de Tarrassa; SE: Hospital Universitario Son Espasses; RD: Robert Debré Hospital; GH: University Hospital Ghent; HP: Heim Pal Children's Hospital; SM: Santa Maria Hospital; HT: Hacettepe University Medical Faculty; PA: Padova University Hospital; MY: Anna Meyer Children's University Hospital; ER: Erasmus University Hospital; TE: Temple Street Childrens University Hospital.

Tabla 15. Características de los centros participantes. 
Durante el periodo de estudio se atendieron en los hospitales participantes 1649 903 urgencias. En la Figura 9 vemos el diagrama de flujo de los pacientes y el número de pacientes incluidos en cada hospital.
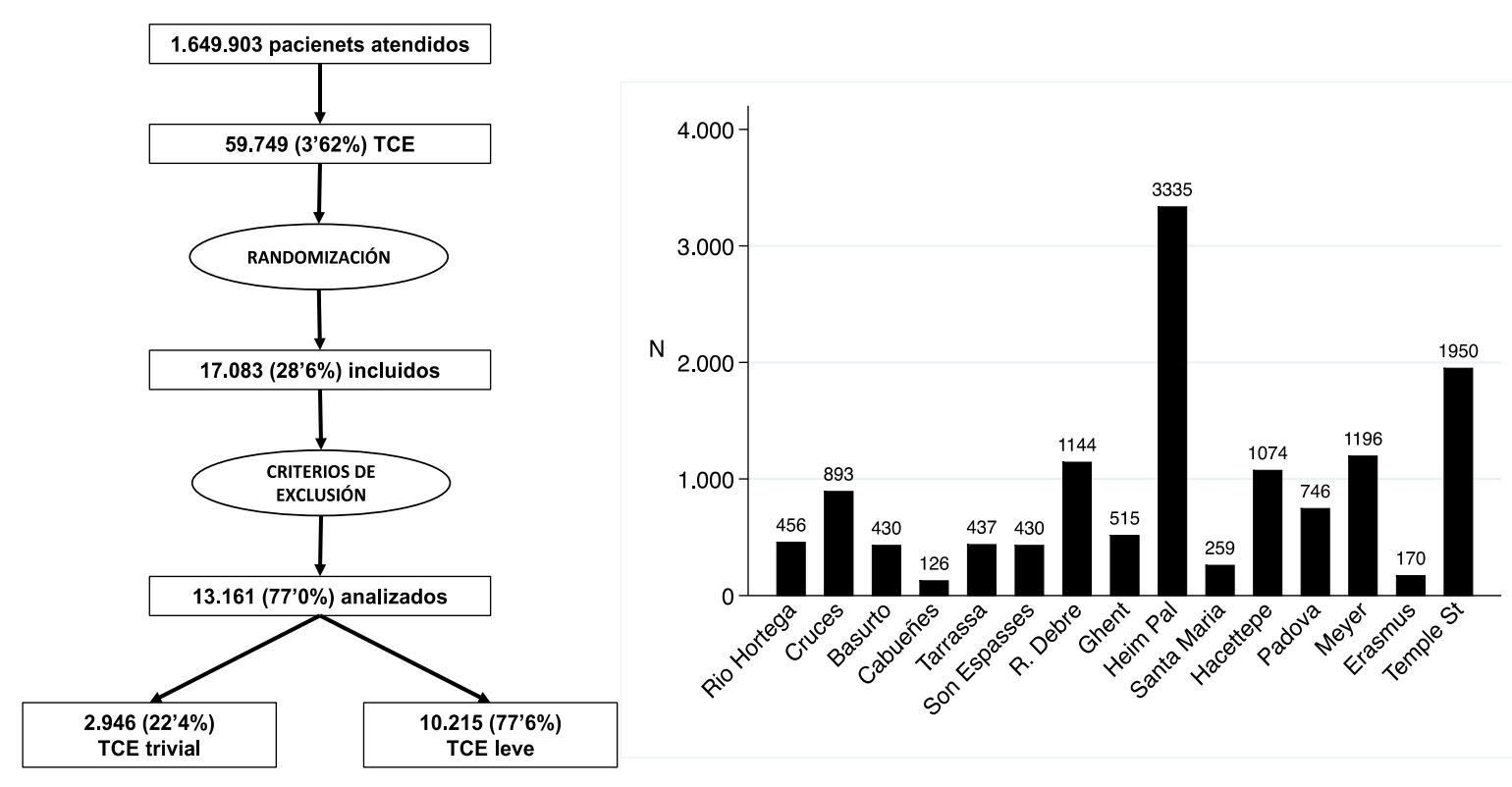

Figura 11. Diagrama de flujo de pacientes y pacientes incluidos por cada hospital

Tras el proceso de aleatorización y la aplicación de los criterios de exclusión, se incluyeron en el estudio 13161 pacientes, de los cuales 10215 (77,6\%) fueron TCE leves, y el resto, $2946(22,4 \%)$ fueron triviales.

Entre los motivos de exclusión en el estudio incluímos: más de 24 horas desde el TCE hasta la atención en el SUP, neuroimagen llevada a cabo en otro centro sanitario, problemas de codificación de las historias clínicas (historias no legibles, diagnósticos erróneos, TCE moderado o grave...), TCE tras intoxicaciones y la presencia de comorbilidad importante (parálisis cerebral infantil, trastornos del desarrollo, púrpura trombótica idiopática,...). 
La media de edad fue de 54,3 meses (DE 51,4) en los pacientes con TCE leve y de 62,8 meses (DE 48,5) en los TCE triviales $(\mathrm{p}<0,01)$. En la figura 12 vemos la distribución de la edad de los pacientes por hospital.

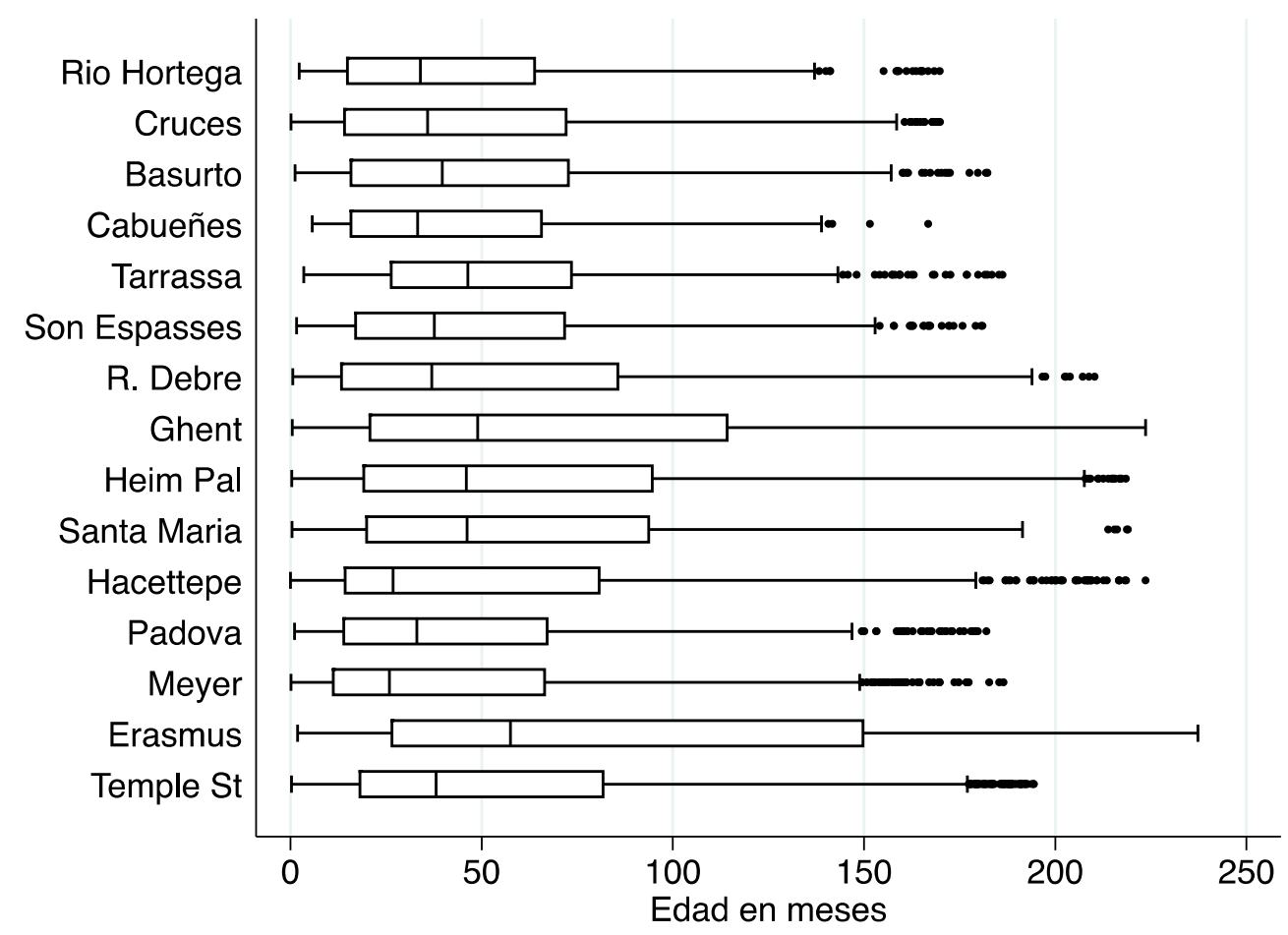

Figura 12. Edad de los pacientes de cada hospital

También hubo diferencias significativas en el sexo de los pacientes, siendo 5954 $(58,4 \%)$ de los TCE leves varones, por $1863(63,4 \%)$ de los triviales $(\mathrm{p}<0,01)$.

Los pacientes fueron atendidos una mediana de 1,37 horas $\left(\mathrm{P}_{25}-\mathrm{P}_{75} 1-3\right)$ tras el traumatismo en los casos de los TCE leves y de 2 horas $\left(\mathrm{P}_{25}-\mathrm{P}_{75}\right.$ 1-3,5) en los triviales. 
De los 13161 pacientes del estudio, 261 (1,98\%) pacientes presentaban comorbilidades. En la tabla 19 vemos la frecuencia de cada una.

\begin{tabular}{|l|c|c|}
\hline \multicolumn{1}{|c|}{ Comorbilidad } & $\begin{array}{c}\text { TCE leve } \\
(\mathbf{n = 1 0} 215)\end{array}$ & $\begin{array}{c}\text { TCE trivial } \\
(\mathbf{n}=2946)\end{array}$ \\
\hline Enfermedad neurológica & $108(1,06 \%)$ & $31(1,05 \%)$ \\
\hline Coagulopatía & $28(0,27 \%)$ & $8(0,27 \%)$ \\
\hline $\begin{array}{l}\text { Derivación ventrículo- } \\
\text { peritoneal }\end{array}$ & $14(0,14 \%)$ & $3(0,1 \%)$ \\
\hline Cardiopatía & $7(0,07 \%)$ & $2(0,07 \%)$ \\
\hline Tumor cerebral & $6(0,06 \%)$ & $3(0,1 \%)$ \\
\hline Osteogénesis imperfecta & $3(0,03 \%)$ & $3(0,1 \%)$ \\
\hline Otros & $43(0,42 \%)$ & $9(0,3 \%)$ \\
\hline
\end{tabular}

Tabla 16. Comorbilidades. 


\subsection{Anamnesis}

En $814(8,0 \%)$ pacientes con TCE leve y $95(3,2 \%)$ pacientes con TCE trivial el traumatismo craneal se asociaba a trauma o lesiones en otras regiones corporales.

Los mecanismos de lesión del traumatismo los dividimos en distintos grupos que están representados en la siguiente tabla: 


\begin{tabular}{|c|c|c|c|}
\hline Mecanismo & $\begin{array}{c}\text { TCE leve } \\
(n=10212)\end{array}$ & $\begin{array}{l}\text { TCE trivial } \\
(\mathrm{n}=2949)\end{array}$ & $\mathbf{p}$ \\
\hline Caída desde una altura & $4529(44,4 \%)$ & $169(5,7 \%)$ & \\
\hline$<90 \mathrm{~cm}$ & $2969(65,6 \%)$ & $166(98,2 \%)$ & \\
\hline $91-152 \mathrm{~cm}$ & $1181(26,1 \%)$ & - & 01 \\
\hline $153-305 \mathrm{~cm}$ & $259(5,7 \%)$ & - & $<0,01$ \\
\hline$>305 \mathrm{~cm}$ & $30(0,7 \%)$ & - & \\
\hline Desconocida & $90(2 \%)$ & $3(1,8 \%)$ & \\
\hline $\begin{array}{l}\text { Caída al suelo desde bipedestación o } \\
\text { corriendo }\end{array}$ & $1680(16,5 \%)$ & $1795(60,9 \%)$ & $<0,01$ \\
\hline $\begin{array}{l}\text { Impacto o caída contra un objeto estacionario } \\
\text { andando o corriendo }\end{array}$ & $832(8,1 \%)$ & $597(20,3 \%)$ & $<0,01$ \\
\hline $\begin{array}{l}\text { Cabeza golpeada con un objeto (no } \\
\text { intencional) }\end{array}$ & $766(7,5 \%)$ & $218(7,4 \%)$ & 0,843 \\
\hline Caída por las escaleras & $544(5,3 \%)$ & $14(0,5 \%)$ & \\
\hline$<6$ escalones & $191(35,8 \%)$ & $12(85,7 \%)$ & \\
\hline 6-15 escalones & $197(35,8 \%)$ & - & $<0,01$ \\
\hline$>15$ escalones & $34(6,2 \%)$ & - & \\
\hline Desconocido & $122(22,7 \%)$ & $2(14,3 \%)$ & \\
\hline Caída o choque con una bicicleta & $436(4,3 \%)$ & $0(0 \%)$ & $<0,01$ \\
\hline Asociada a deporte & $359(3,5 \%)$ & $103(3,5 \%)$ & 0,63 \\
\hline Agresión & $157(1,5 \%)$ & $31(1 \%)$ & 0,03 \\
\hline Accidente con otro vehículo de ruedas & $155(1,5 \%)$ & $0(0 \%)$ & $<0,01$ \\
\hline $\begin{array}{l}\text { Pasajero en un accidente con un vehículo a } \\
\text { motor }\end{array}$ & $149(1,5 \%)$ & $0(0 \%)$ & $<0,01$ \\
\hline Peatón atropellado por un vehículo & $112(1,1 \%)$ & $0(0 \%)$ & $<0,01$ \\
\hline Ciclista atropellado por un vehículo & $39(0,4 \%)$ & $0(0 \%)$ & $<0,01$ \\
\hline Desconocido & $443(4,3 \%)$ & $18(0,6 \%)$ & $<0,01$ \\
\hline Otros & $14(0,1 \%)$ & $1(0,03 \%)$ & 0,144 \\
\hline
\end{tabular}

Tabla 17. Mecanismos de lesión. 
En el siguiente gráfico podemos ver las diferencias en los mecanismos de lesión en las distintas edades.

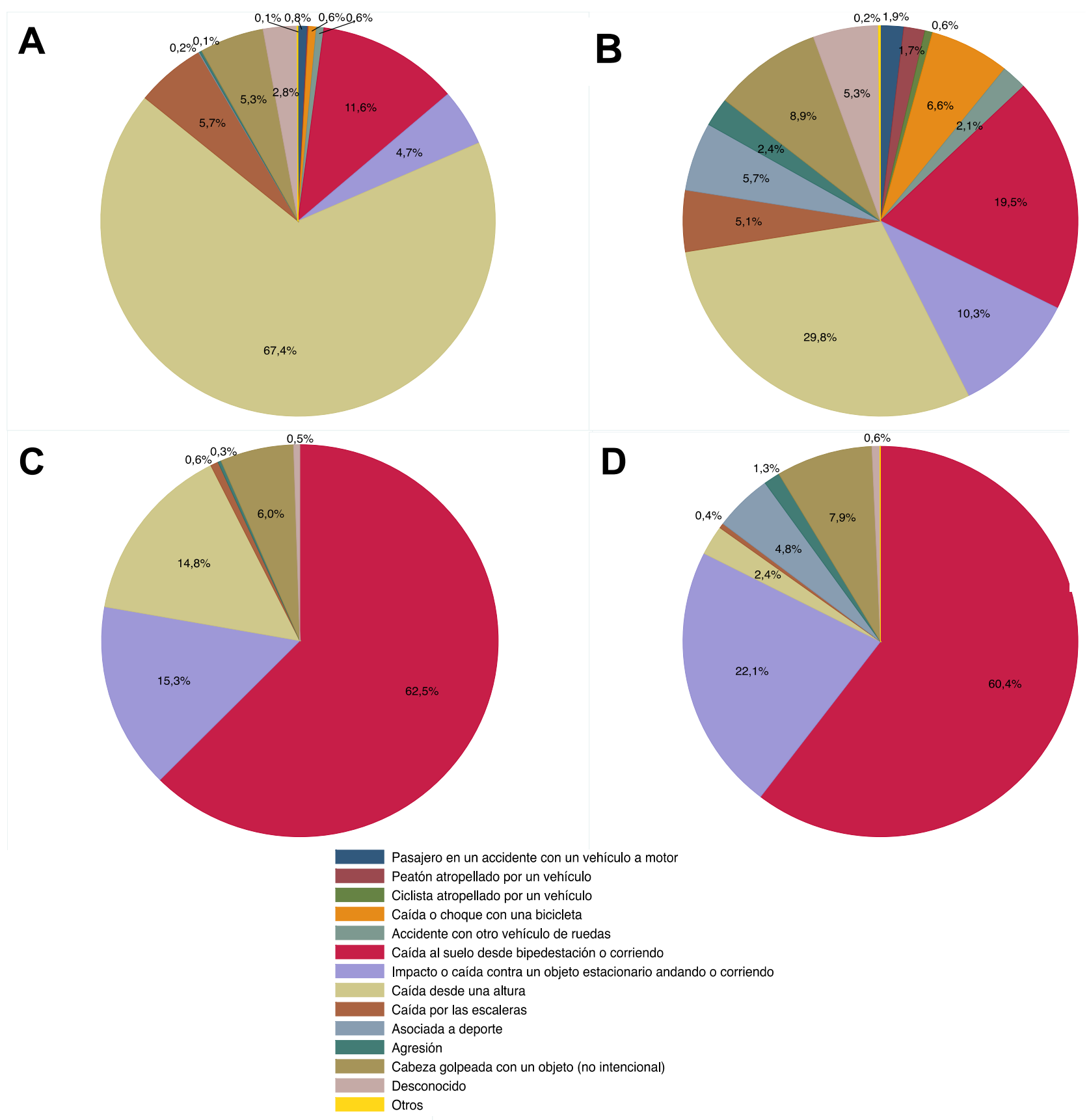

Figura 13. Mecanismos de lesión según la edad y tipo de TCE (A: TCE leve en < 24 meses; B: TCE leve en $\geq 24$ meses; C: TCE trivial en < 24 meses; D: TCE trivial en $\geq 24$ meses). 


\subsection{Exploración física}

De entre los pacientes en los que se recogió la puntuación en la GCS a su llegada a Urgencias, 12815 (98,3\%) presentaban una puntuación de 15 en la escala y $180(1,4 \%)$ de 14 . Dentro de los pacientes con TCE leve hubo una proporción mayor de pacientes con GCS de 14 con respecto a los pacientes con TCE trivial $(1,6 \%$ vs $0,5 \%, \mathrm{p}<0,01)$

La sintomatología referida por los pacientes a su llegada a Urgencias se muestra en la siguiente tabla:

\begin{tabular}{|c|c|c|c|}
\hline Síntomas y signos & $\begin{array}{c}\text { TCE leve } \\
(n=10212)\end{array}$ & $\begin{array}{l}\text { TCE trivial } \\
(n=2949)\end{array}$ & $\mathbf{p}$ \\
\hline Pérdida de conocimiento & $490(4,8 \%)$ & $72(2,4 \%)$ & $<0,01$ \\
\hline Vómitos & $504(4,9 \%)$ & $94(3,2 \%)$ & $<0,01$ \\
\hline $\begin{array}{l}\text { Comportamiento anómalo según los } \\
\text { padres }\end{array}$ & $1114(10,9 \%)$ & $238(8,1 \%)$ & $<0,01$ \\
\hline Convulsión & $69(0,7 \%)$ & $8(0,3 \%)$ & 0,01 \\
\hline Amnesia* & $210(3,4 \%)$ & $39(1,8 \%)$ & $<0,01$ \\
\hline Cefalea* & $861(13,7 \%)$ & $192(8,9 \%)$ & $<0,01$ \\
\hline Mareo* & $433(6,9 \%)$ & $139(6,4 \%)$ & 0,44 \\
\hline
\end{tabular}

*Sólo se incluyen pacientes mayores de 24 meses (6270 TCE leves y 2164 triviales)

Tabla 18. Sintomatología referida a su llegada a Urgencias.

En la siguiente tabla podemos ver la asociación de los distintos mecanismos de producción del traumatismo con la presencia de sintomatología: 


\begin{tabular}{|c|c|c|c|c|c|c|c|}
\hline & $\begin{array}{c}\text { Pérdida de } \\
\text { conocimiento }\end{array}$ & Vómitos & $\begin{array}{c}\text { Comportamiento } \\
\text { anómalo }\end{array}$ & Convulsión & Amnesia* & Cefalea* & Mareo* \\
\hline $\begin{array}{l}\text { Pasajero en } \\
\text { un accidente } \\
\text { con un } \\
\text { vehículo a } \\
\text { motor } \\
(n=149)\end{array}$ & $3(2,0 \%)$ & $3(2,0 \%)$ & $11(7,4 \%)$ & $0(0 \%)$ & $8(6,7 \%)$ & $\begin{array}{c}14 \\
(11,8 \%)\end{array}$ & $\begin{array}{c}2 \\
(1,7 \%)\end{array}$ \\
\hline $\begin{array}{l}\text { Peatón } \\
\text { atropellado } \\
\text { por un } \\
\text { vehículo } \\
(n=112)\end{array}$ & $14(12,5 \%)$ & $4(3,6 \%)$ & $9(8,0 \%)$ & $0(0 \%)$ & 7 (6,5\%) & $9(8,3 \%)$ & $\begin{array}{c}2 \\
(1,9 \%)\end{array}$ \\
\hline $\begin{array}{l}\text { Ciclista } \\
\text { atropellado } \\
\text { por un } \\
\text { vehículo } \\
(n=39)\end{array}$ & $8(20,5 \%)$ & $0(0 \%)$ & $9(23,1 \%)$ & $0(0 \%)$ & $5(12,8 \%)$ & $\begin{array}{c}6 \\
(15,4 \%)\end{array}$ & $\begin{array}{c}4 \\
(10,3 \%)\end{array}$ \\
\hline $\begin{array}{l}\text { Caída o } \\
\text { choque con } \\
\text { una bicicleta } \\
(n=436)\end{array}$ & $34(7,8 \%)$ & $\begin{array}{c}36 \\
(8,3 \%)\end{array}$ & $56(12,8 \%)$ & $2(0,5 \%)$ & $25(6,1 \%)$ & $\begin{array}{c}46 \\
(11,2 \%)\end{array}$ & $\begin{array}{c}17 \\
(4,1 \%)\end{array}$ \\
\hline $\begin{array}{l}\text { Accidente con } \\
\text { otro vehículo } \\
\text { de ruedas } \\
(n=155)\end{array}$ & $16(10,3 \%)$ & $\begin{array}{c}11 \\
(7,1 \%)\end{array}$ & $21(13,6 \%)$ & $2(1,3 \%)$ & $5(3,8 \%)$ & $\begin{array}{c}12 \\
(9,2 \%)\end{array}$ & $\begin{array}{c}7 \\
(5,3 \%)\end{array}$ \\
\hline $\begin{array}{l}\text { Caída al suelo } \\
\text { desde } \\
\text { bipedestación } \\
\text { o corriendo } \\
(n=3475)\end{array}$ & $157(4,5 \%)$ & $\begin{array}{c}177 \\
(5,1 \%)\end{array}$ & $353(10,2 \%)$ & $26(0,8 \%)$ & $67(2,7 \%)$ & $\begin{array}{c}298 \\
(11,8 \%)\end{array}$ & $\begin{array}{c}159 \\
(6,3 \%)\end{array}$ \\
\hline $\begin{array}{l}\text { Impacto o } \\
\text { caída contra } \\
\text { un objeto } \\
\text { estacionario } \\
\text { andando o } \\
\text { corriendo } \\
(n=1429)\end{array}$ & $39(2,7 \%)$ & $\begin{array}{c}65 \\
(4,6 \%)\end{array}$ & $81(5,7 \%)$ & $3(0,2 \%)$ & $17(1,5 \%)$ & $\begin{array}{c}116 \\
(10,3 \%)\end{array}$ & $\begin{array}{c}65 \\
(5,8 \%)\end{array}$ \\
\hline $\begin{array}{l}\text { Caída desde } \\
\text { una altura } \\
(n=4698)\end{array}$ & $179(3,8 \%)$ & $\begin{array}{c}181 \\
(3,9 \%)\end{array}$ & $496(10,6 \%)$ & $30(0,6 \%)$ & $47(2,5 \%)$ & $\begin{array}{c}178 \\
(9,3 \%)\end{array}$ & $\begin{array}{c}66 \\
(3,4 \%)\end{array}$ \\
\hline $\begin{array}{l}\text { Caída por las } \\
\text { escaleras } \\
(n=558)\end{array}$ & $21(3,8)$ & $\begin{array}{c}23 \\
(4,12 \%)\end{array}$ & $66(11,8 \%)$ & $1(0,2 \%)$ & $8(2,5 \%)$ & $\begin{array}{c}26 \\
(8,0 \%)\end{array}$ & $\begin{array}{c}15 \\
(4,6 \%)\end{array}$ \\
\hline
\end{tabular}




\begin{tabular}{|c|c|c|c|c|c|c|c|}
\hline $\begin{array}{l}\text { Asociada a } \\
\text { deporte } \\
(n=462)\end{array}$ & $53(11,5 \%)$ & $\begin{array}{c}28 \\
(6,1 \%)\end{array}$ & $93(20,1 \%)$ & $2(0,4 \%)$ & $39(8,5 \%)$ & $\begin{array}{c}166 \\
(36,2 \%)\end{array}$ & $\begin{array}{c}119 \\
(25,9 \%)\end{array}$ \\
\hline $\begin{array}{l}\text { Agresión } \\
(n=188)\end{array}$ & $8(4,3 \%)$ & $\begin{array}{c}13 \\
(6,9 \%)\end{array}$ & $22(11,7 \%)$ & $0(0 \%)$ & $8(4,5 \%)$ & $\begin{array}{c}40 \\
(22,5 \%)\end{array}$ & $\begin{array}{c}28 \\
(15,7 \%)\end{array}$ \\
\hline $\begin{array}{l}\text { Cabeza } \\
\text { golpeada con } \\
\text { un objeto (no } \\
\text { intencional) } \\
(n=984)\end{array}$ & $20(2,0 \%)$ & $\begin{array}{c}31 \\
(3,2 \%)\end{array}$ & $79(8,0 \%)$ & $6(0,6 \%)$ & $10(1,4 \%)$ & $\begin{array}{c}104 \\
(14,3 \%)\end{array}$ & $\begin{array}{c}70 \\
(9,6 \%)\end{array}$ \\
\hline $\begin{array}{l}\text { Desconocido } \\
(n=461)\end{array}$ & $7(1,5 \%)$ & $\begin{array}{c}25 \\
(5,4 \%)\end{array}$ & $52(11,3 \%)$ & $1(0,2 \%)$ & $3(0,9 \%)$ & $\begin{array}{c}36 \\
(10,3 \%)\end{array}$ & $\begin{array}{c}18 \\
(5,2 \%)\end{array}$ \\
\hline Otros $(n=15)$ & $3(20 \%)$ & $1(6,7 \%)$ & $4(26,7 \%)$ & $4(26,7 \%)$ & $0(0 \%)$ & $\begin{array}{c}2 \\
(16,7 \%)\end{array}$ & $0(0 \%)$ \\
\hline $\begin{array}{l}\text { TOTAL } \\
(n=13161)\end{array}$ & $562(4,3 \%)$ & $\begin{array}{c}598 \\
(4,5 \%)\end{array}$ & $1352(10,3 \%)$ & $77(0,6 \%)$ & $\begin{array}{c}249 \\
(3,0 \%)\end{array}$ & $\begin{array}{c}1053 \\
(12,5 \%)\end{array}$ & $\begin{array}{c}575 \\
(6,8 \%)\end{array}$ \\
\hline
\end{tabular}

*Sólo se incluyen pacientes mayores de 24 meses (8434 pacientes)

Tabla 19. Sintomatología referida a su llegada a Urgencias según el mecanismo de producción del traumatismo.

A la exploración se objetivó un cefalohematoma en 4192 (31,9\%) pacientes. La localización más frecuente fue el hueso frontal $(n=2552,60,9 \%)$, seguida del occipital $(n=826,19,7 \%)$, parietal $(n=589,14,1 \%)$ y temporal $(n=225,5,4 \%)$. No hubo diferencias entre mayores y menores de 24 meses en la prevalencia de cefalohematomas en general, pero sí que los frontales fueron más frecuentes en menores de 24 meses $(68,6 \%$ vs 56,4\%, p<0,01), mientras que la localización occipital fue menos frecuente en los pacientes más jóvenes $(12,1 \%$ vs $24,1 \%$, $\mathrm{p}<0,01)$ 


\subsection{Pruebas complementarias}

Se realizó una Rx de cráneo a 3919 (29,8\%) de los pacientes, encontrándose signos de fractura craneal en $57(1,45 \%)$ de ellas.

A $115(0,88 \%)$ pacientes se les realizó una ecografía. En $102(88,7 \%)$ casos fueron lactantes a los que se realizó una ecografía transfontanelar para descartar LIC, y en los $13(11,3 \%)$ restantes se usó esta técnica para descartar fractura craneal. Se diagnosticaron mediante esta técnica 5 fracturas craneales $(4,35 \%)$, pero ninguna LIC.

En cuanto a la TAC craneal, esta prueba se realizó a 725 (5,5\%) pacientes, siendo patológica en 173 (23,9\%) de los casos. En un paciente esta prueba no fue interpretable. Los hallazgos más frecuentes se muestran en la siguiente tabla:

\begin{tabular}{|l|c|}
\hline \multicolumn{1}{|c|}{ Hallazgo } & N (\%) \\
\hline Fractura craneal & $147(20,3 \%)$ \\
\hline Hematoma epidural & $29(4,0 \%)$ \\
\hline Hematoma subdural & $22(3,0 \%)$ \\
\hline Hemorragia subaracnoidea & $11(1,5 \%)$ \\
\hline Contusión cerebral & $8(1,1 \%)$ \\
\hline Hemorragia cerebral & $8(1,1 \%)$ \\
\hline Edema cerebral & $6(0,8 \%)$ \\
\hline Neumoencéfalo & $3(0,4 \%)$ \\
\hline Desviación de línea media & $3(0,4 \%)$ \\
\hline Hemorragia intraventricular & $1(0,1 \%)$ \\
\hline
\end{tabular}

Tabla 20. Hallazgos encontrados en la TAC craneal (algunos pacientes pueden presentar varios hallazgos). 
A $96(2,45 \%)$ de los pacientes a los que se les realizó una RX se les hizo posteriormente una TAC. Entre ellos estaban 47 de los 57 con signos de fractura en la RX, mientras que los otros 49 tuvieron RX normal. Entre los pacientes con una ecografía craneal, a $5(4,3 \%)$ se les realizó una TAC. Dos de ellos presentaban ecografía con signos de fractura craneal. A cuatro pacientes se les realizó RX, ecografía y TAC craneal. Dos de ellos presentaron lesiones en la TAC (fractura craneal y fractura craneal con hematoma epidural, respectivamente).

En el siguiente gráfico vemos las pruebas de imagen solicitadas en función del tipo de traumatismo:

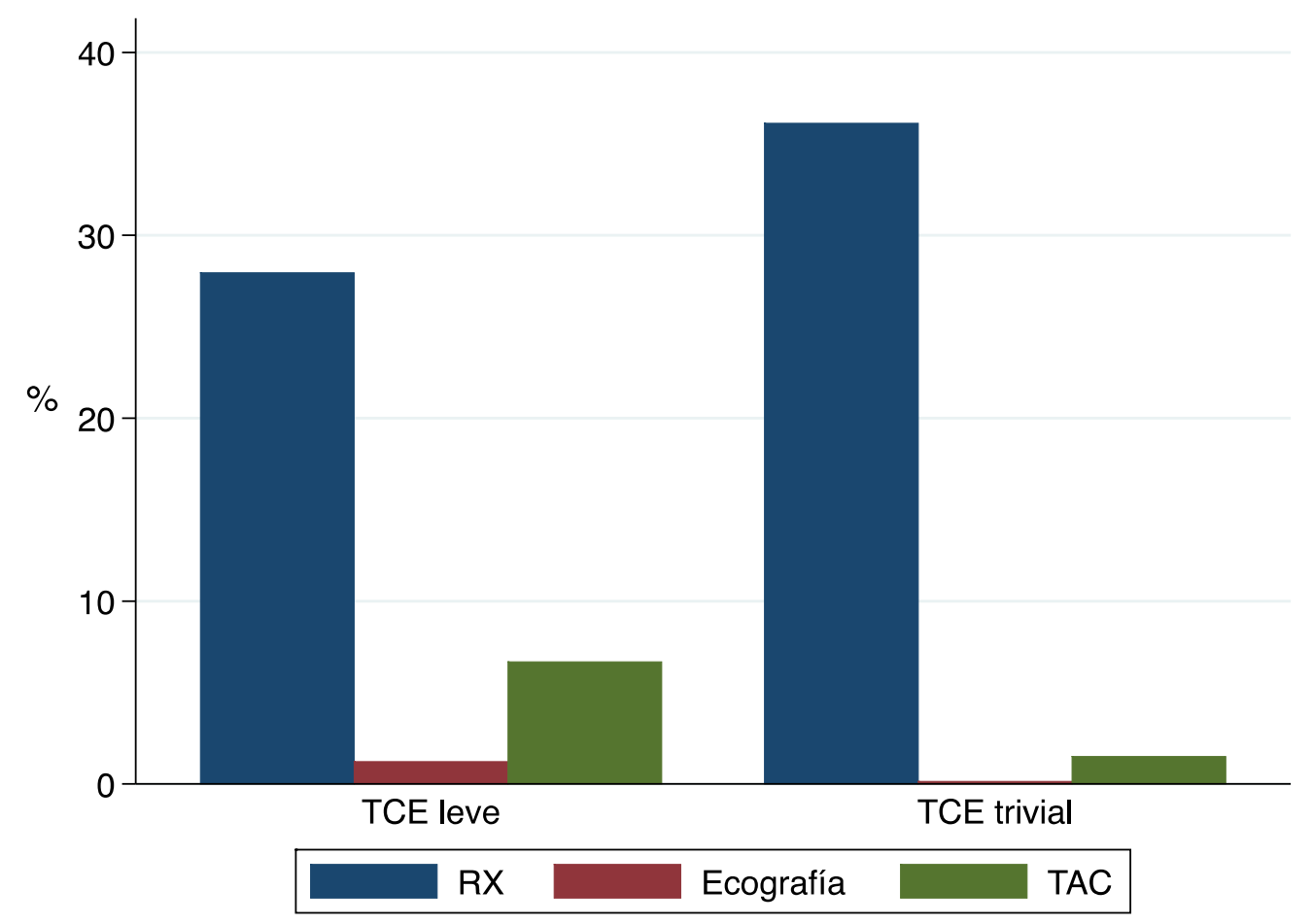

Figura 14. Pruebas de imagen solicitadas en función del tipo de traumatismo 
En la siguiente tabla se muestran las pruebas realizadas en función de la edad de los pacientes y al tipo de traumatismo

\begin{tabular}{|c|c|c|c|c|}
\hline & & $<24$ meses & $\geq 24$ meses & $\mathrm{p}$ \\
\hline \multirow{2}{*}{ RX } & TCE leve & $1095(27,8 \%)$ & $1759(28,1 \%)$ & 0,74 \\
\hline & TCE trivial & $347(44,3 \%)$ & $718(33,2 \%)$ & $<0,01$ \\
\hline \multirow{2}{*}{ Ecografía } & TCE leve & $108(2,7 \%)$ & $4(0,1 \%)$ & $<0,01$ \\
\hline & TCE trivial & $2(0,3 \%)$ & $1(0,1 \%)$ & 0,12 \\
\hline \multirow{2}{*}{ TAC } & TCE leve & 192 (4,9\%) & $490(7,8 \%)$ & $<0,01$ \\
\hline & TCE trivial & $8(1,0 \%)$ & $35(1,6 \%)$ & 0,24 \\
\hline
\end{tabular}

Tabla 21. Pruebas de imagen realizadas en función de la edad y el tipo de TCE. 


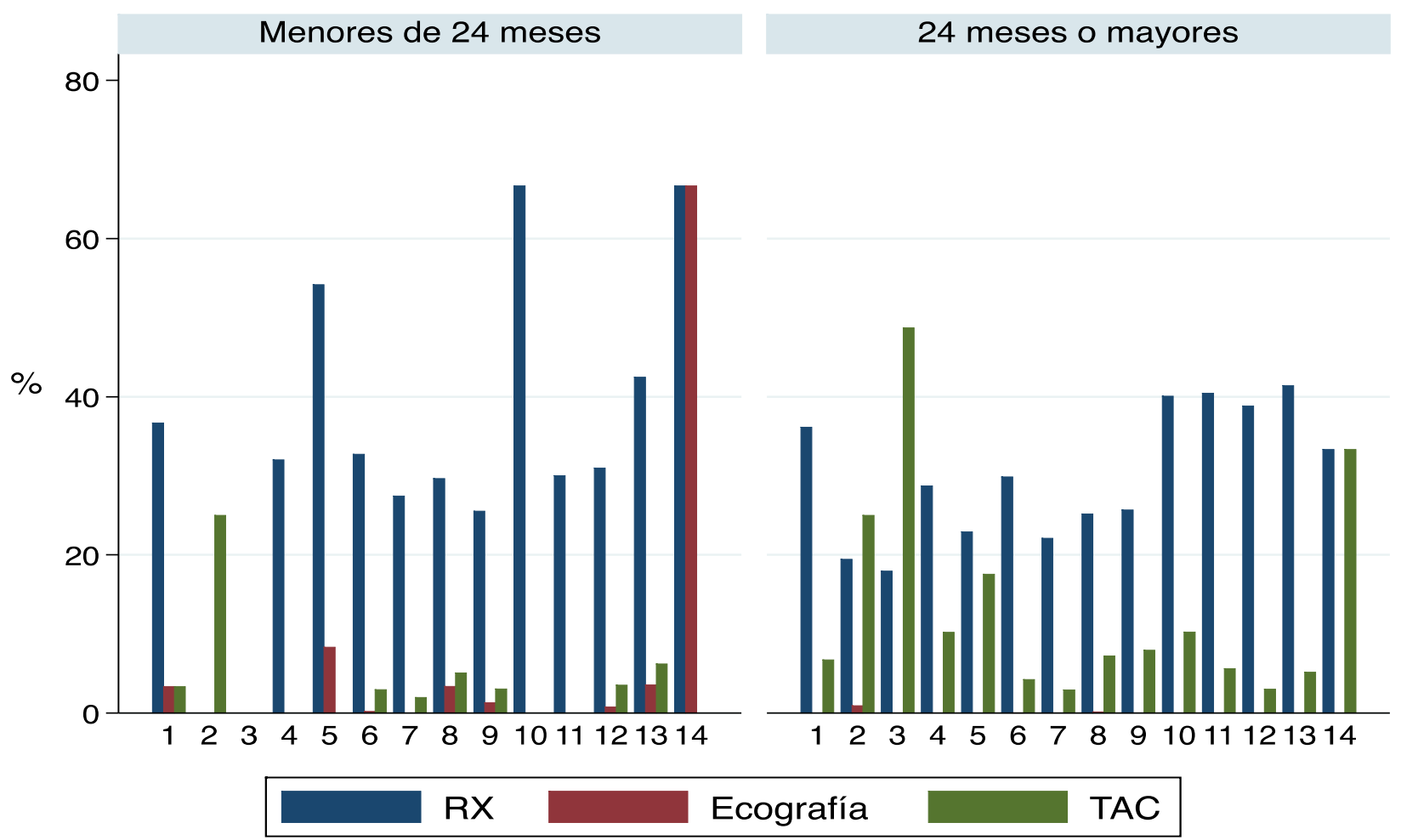

Figura 15. Pruebas de imagen realizadas en función de la edad y el mecanismo de producción del TCE. (NOTA: 1: Pasajero en un accidente con un vehículo a motor; 2: Peatón atropellado por un vehículo; 3: Ciclista atropellado por un vehículo; 4: Caída o choque con una bicicleta; 5: Accidente con otro vehículo de ruedas; 6: Caída al suelo desde bipedestación o corriendo; 7: Impacto o caída contra un objeto estacionario andando o corriendo; 8: Caída desde una altura; 9: Caída por las escaleras; 10: Asociada a deporte; 11: Agresión; 12: Cabeza golpeada con un objeto (no intencional); 13: Desconocido; 14: Otros)

En los menores de 24 meses se realizó una mayor proporción de TAC craneales en los pacientes que consultaron por TCE producido por un mecanismo asociado a algún vehículo con ruedas que en el resto $(14,7 \%$ vs $5,3 \%$, p<0,01). Para el resto de edades y pruebas no hubo diferencias entre los TCE producidos con vehículos y los demás.

Se diagnosticó una LICci a 88 pacientes, lo que da una prevalencia global de 0,67\%. Si estratificamos por el tipo de traumatismo, entre los TCE leves hubo 83 $(0,81 \%)$ pacientes con LICci, por $5(0,17 \%)$ entre los TCE triviales. 
En la Figura 16 vemos la prevalencia de LICci en los TCE leves dependiendo del mecanismo de producción de la lesión. Vemos como en los TCE producidos por mecanismos en los que interviene algún tipo de vehículo, la prevalencia es del 1,8\%, por $0,72 \%$ de los restantes $(\mathrm{p}<0,01)$. En los pacientes que consultan con TCE trivial, destacar que los mecanismos que se asociaron con LICci fueron la caída al suelo desde bipedestación o corriendo $(n=3,0,2 \%)$, el impacto o caída contra un objeto estacionario andando o corriendo $(n=1,0,2 \%)$ y la caída desde una altura menor de $90 \mathrm{~cm} .(\mathrm{n}=1,0,6 \%)$.

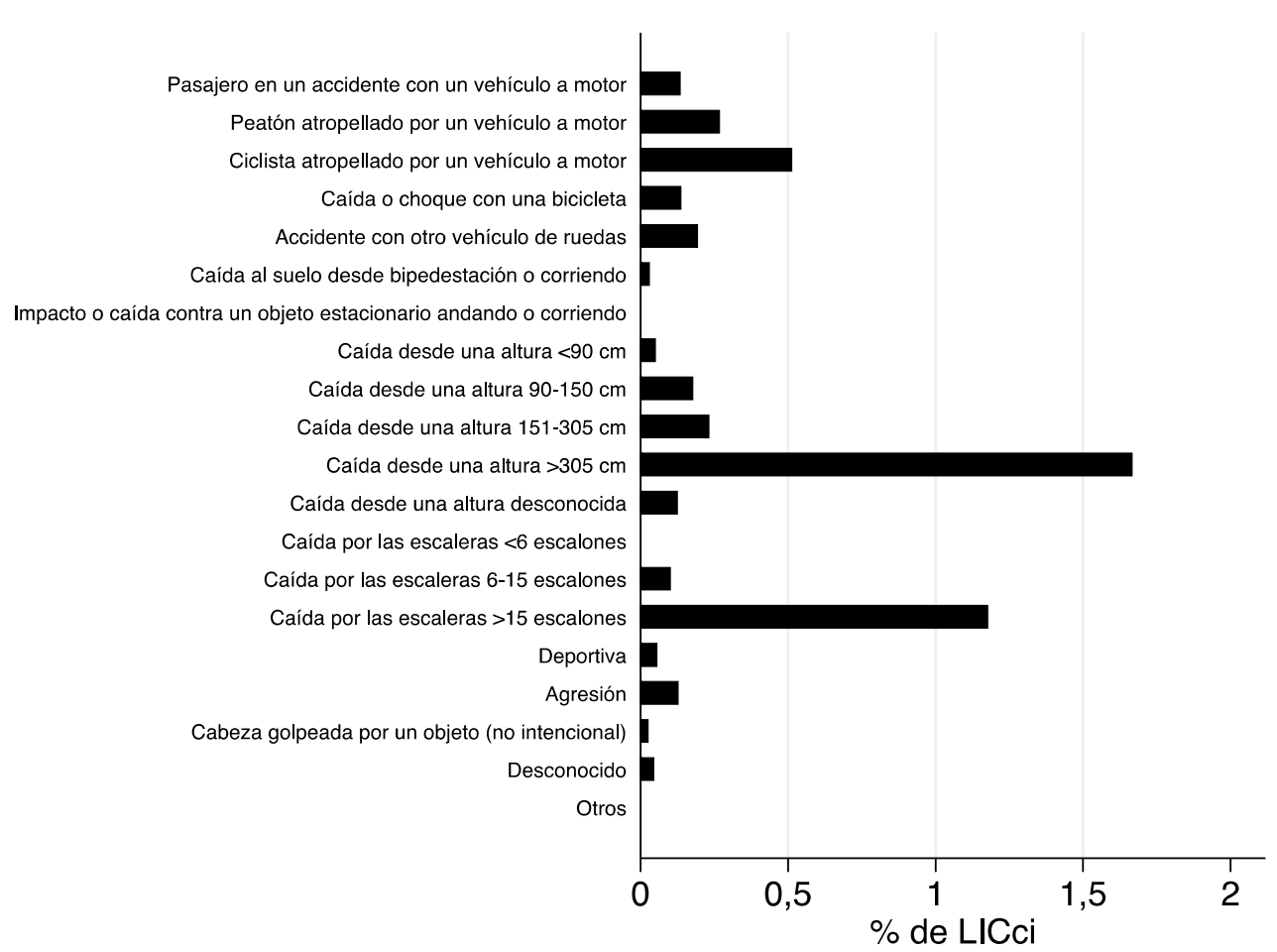

Figura 16. Prevalencia de LICci en los TCE leves en función del mecanismo de producción del traumatismo. 


\begin{tabular}{|c|c|c|c|}
\hline Síntomas y signos & $\begin{array}{c}\text { LICci con } \\
\text { signo/síntoma } \\
\text { ausente }\end{array}$ & $\begin{array}{l}\text { LICci con } \\
\text { signo/síntoma } \\
\text { presente }\end{array}$ & $\mathbf{p}$ \\
\hline Pérdida de conocimiento $(n=562)$ & $65(0,5 \%)$ & $23(4,1 \%)$ & $<0,01$ \\
\hline Vómitos $(n=598)$ & $77(0,6 \%)$ & $11(1,8 \%)$ & $<0,01$ \\
\hline $\begin{array}{l}\text { Comportamiento anómalo según los } \\
\text { padres }(n=1352)\end{array}$ & $60(0,5 \%)$ & $28(2,1 \%)$ & $<0,01$ \\
\hline Convulsión $(n=77)$ & $85(0,7 \%)$ & $3(3,9 \%)$ & $<0,01$ \\
\hline Amnesia* $(n=249)$ & $40(0,5 \%)$ & $7(2,8 \%)$ & $<0,01$ \\
\hline Cefalea* $(n=1053)$ & $37(0,5 \%)$ & $10(1,0 \%)$ & 0,06 \\
\hline Mareo* $^{*}(n=572)$ & $44(0,6 \%)$ & $3(0,5 \%)$ & 0,91 \\
\hline
\end{tabular}

*Sólo se incluyen pacientes mayores de 24 meses (8434 pacientes)

( $n=$ pacientes que referían el síntoma)

Tabla 22. Proporción de Lesión Intracraneal clínicamente importante (LICci) en función de la sintomatología referida a su llegada a Urgencias.

En la tabla 22 observamos la relación entre algunos síntomas y signos con la presencia de LICci. Entre ellos, encontramos asociación significativa en los pacientes que presentaron pérdida de consciencia, vómitos, convulsiones, amnesia (en mayorse de 2 años) y en los que los padres relataban un comportamiento anómalo en el niño. En cambio, los pacientes mayores de 2 años con historia de cefalea o mareo no presentaron mayor riesgo de LICci con significación estadística. 


\subsection{Manejo y destino}

En cuanto al destino de los pacientes, se fueron directamente de alta 9128 $(69,4 \%)$ de los pacientes, mientras que $2884(21,9 \%)$ fueron dados de alta tras un periodo en la sala de observación. La mediana de tiempo de observación fue de 5 horas $\left(\mathrm{P}_{25}-\mathrm{P}_{75} 4-8\right)$. Se ingresó a un total de 1149 (8,73\%) pacientes, 1067 (92,9\%) de ellos en planta, y los $82(7,1 \%)$ restantes en la UCIP. Del total de ingresos, 714 $(66,9 \%)$ se realizaron en el hospital de Heim Pal (Hungría), que no posee sala de observación. El porcentaje de ingresos fue menor en los pacientes menores de 24 meses que en los mayores $(8,1 \%$ vs $9,1 \%, \mathrm{p}=0,048)$, aunque esta diferencia se invierte si se excluyen los pacientes del Heim Pal $(5,1 \%$ vs 4\%, p<0,01). También ingresaron en mayor frecuencia los pacientes que consultaban por TCE leves $(9,5 \%$ vs $6,1 \%, \mathrm{p}<0,01)$. La mediana de días de ingreso fue de 0,08 días $\left(\mathrm{P}_{25}-\mathrm{P}_{75} 0,08-1\right)$. Si excluimos del análisis los pacientes de hospital húngaro la mediana de días de ingreso fue de $1\left(\mathrm{P}_{25}-\mathrm{P}_{75} 0,75-1\right)$.

De entre los pacientes ingresados, $11(0,96 \%)$ precisaron algún tipo de intervención quirúrgica. Las técnicas que se realizaron fueron drenaje del hematoma $(n=9)$, elevación de hundimiento de la fractura $(n=3)$, reparación de la duramadre $(n=1)$, colocación de un monitor de presión intracraneal $(n=1)$ y craneoplastia con colocación de una prótesis metálica $(\mathrm{n}=1)$.

En la tabla 23 vemos el destino de los pacientes en función de las pruebas de imagen realizadas. Llama la atención que, de los pacientes que permanecieron en la sala de observación, aquellos en los que se realizó una TAC y el resultado fue normal tuvieron un tiempo de estancia medio mayor que aquellos en los que no se realizó TAC (10,9 horas vs 6,2 horas, p<0,01) Por otro lado, de entre los 687 pacientes que ingresaron en planta o UCIP con una RX normal, a $24(3,5 \%)$ se les realizó una TAC, que fue patológica en $13(54,2 \%)$ de ellos. 


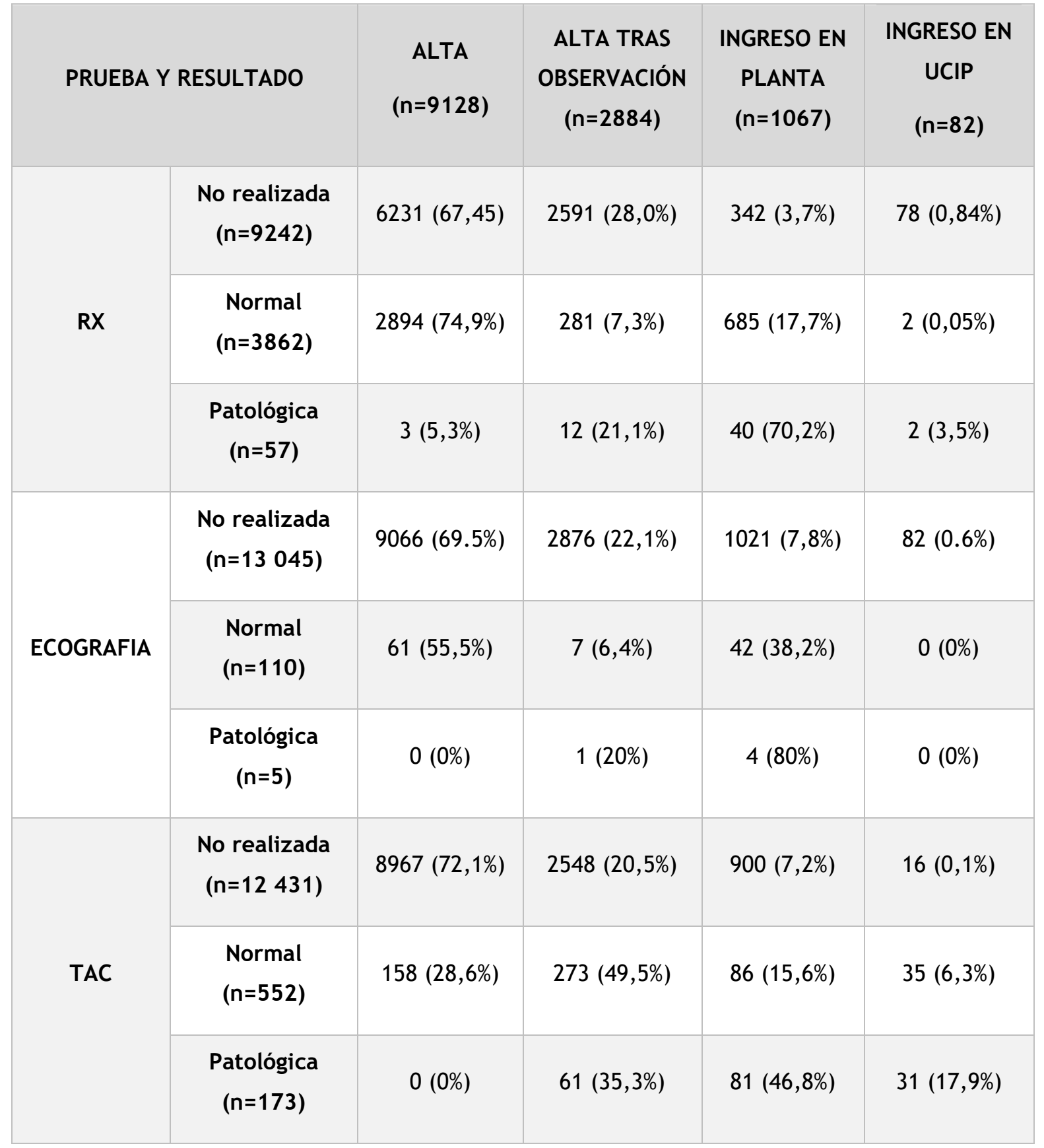

Tabla 23. Destino de los pacientes según las pruebas de imagen realizadas. 
De entre los pacientes que estuvieron en observación, a $10(0,35 \%)$ se les repitió la TAC craneal. Mientras tanto, de entre los ingresados se le repitió a $27(2,4 \%)$

Se atendió de nuevo a $195(1,6 \%)$ pacientes dados de alta. De ellos, a $67(0,34 \%)$ se les realizó alguna prueba de imagen en la segunda visita. En la tabla 26 se muestran las pruebas realizadas y el resultado de las mismas.

\begin{tabular}{|c|c|c|}
\hline & NORMAL & PATOLÓGICA \\
\hline RX & $16(100 \%)$ & $0(0 \%)$ \\
\hline ECOGRAFÍA & $1(100 \%)$ & $0(0 \%)$ \\
\hline TAC & $42(89,4 \%)$ & $5(10,6 \%)$ \\
\hline RMN & $1(100 \%)$ & $0(0 \%)$ \\
\hline
\end{tabular}

Tabla 24. Pruebas de imagen realizadas en segunda visita a Urgencias y sus resultados.

Hubo cinco pacientes en los que se encontró algún hallazgo patológico en la TAC realizada en la segunda visita. Todos fueron TCE leves, que habían permanecido en observación en su primera visita, y a ninguno se le había hecho una TAC. En la tabla 25 se muestran las características de estos pacientes. 


\begin{tabular}{|c|c|c|c|c|c|}
\hline $\begin{array}{c}\text { Edad } \\
\text { (meses) }\end{array}$ & Sexo & Mecanismo de lesión & Síntomas & LIC & Cirugía \\
\hline 55,9 & $\mathrm{~F}$ & Caída $<6$ escalones & $\begin{array}{c}\text { Cefalohematoma parietal } \\
\text { y mareo }\end{array}$ & $\begin{array}{l}\text { Hematoma } \\
\text { epidural }\end{array}$ & Drenaje \\
\hline 113,7 & $\mathrm{~F}$ & $\begin{array}{l}\text { Peatón atropellado } \\
\text { por coche }\end{array}$ & Cefalohematoma parietal & $\begin{array}{l}\text { Hematoma } \\
\text { epidural }\end{array}$ & No \\
\hline 41,1 & $\mathrm{~F}$ & Caída desde >1,5 m. & Cefalohematoma parietal & $\begin{array}{l}\text { Hematoma } \\
\text { subdural }\end{array}$ & No \\
\hline 37,5 & M & Caída de < $90 \mathrm{~cm}$. & Vómitos & $\begin{array}{l}\text { Hematoma } \\
\text { subdural }\end{array}$ & No \\
\hline 41,1 & $\mathrm{~F}$ & Caída de >1,5 m. & $\begin{array}{l}\text { Cefalohematoma parietal } \\
\text { y pérdida de conocimiento }\end{array}$ & $\begin{array}{l}\text { Hematoma } \\
\text { subdural }\end{array}$ & No \\
\hline
\end{tabular}

LIC: lesión intracraneal

Tabla 25. Características de los pacientes diagnosticados de una LIC en una segunda visita al SUP.

Además, hubo otro paciente varón de 63,7 meses que a los 20 minutos de ser dado de alta volvió por cefalea, vómitos y descenso brusco de la GCS a 11. El paciente fue intubado y se realizó una TAC en la que se encontró un hematoma epidural con desviación de la línea media que precisó de drenaje quirúrgico, permaneciendo ingresado siete días. Los seis pacientes presentaban factores de riesgo moderado según las guías de PECARN. Los dos pacientes restantes presentaron tan sólo una fractura craneal. 


\subsection{Análisis de la variabilidad}

En la figura 16 vemos la etiología de los TCE en los diferentes hospitales participantes. Llama la atención que los mecanismos relacionados con vehículos suponen un 27,1\% en el hospital Erasmus (Países Bajos) y un 12,6\% en el de Gante (Bélgica), por el 6,3\% que representan en el resto de hospitales $(\mathrm{p}<0,01)$. Además, los traumatismos relacionados con bicicletas representan el 13,5\% de los atendidos en Países Bajos y el 8,2\% en Bélgica, por un 3,3\% en el resto de países de la muestra $(\mathrm{p}<0,01)$. 


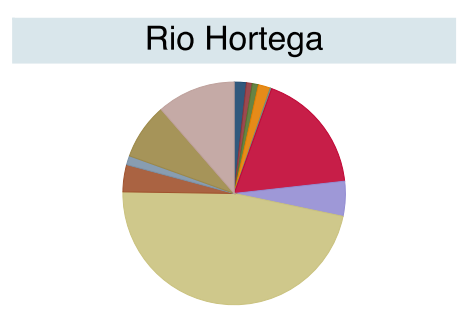

\section{Tarrassa}

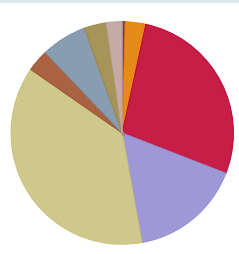

Heim Pal

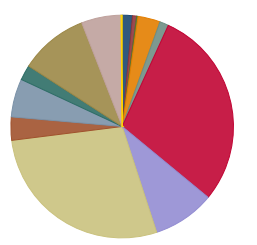

Meyer

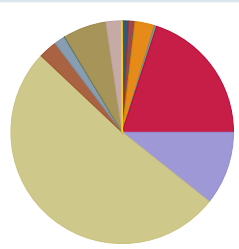

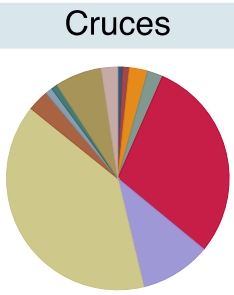

Son Espasses

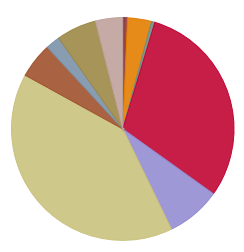

Santa Maria

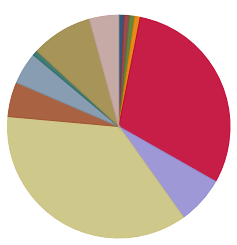

Erasmus

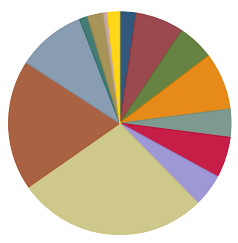

\section{Basurto}

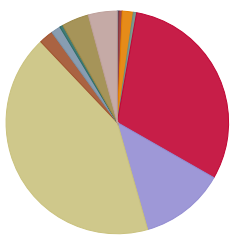

R. Debre

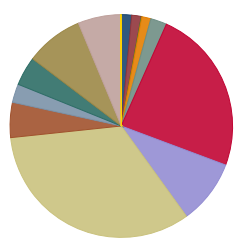

Hacettepe

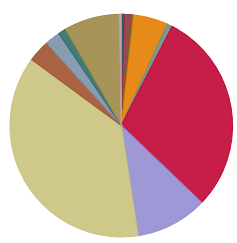

Temple St

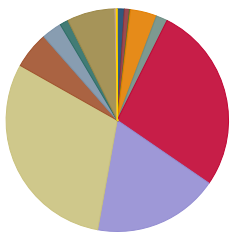

Cabueñes

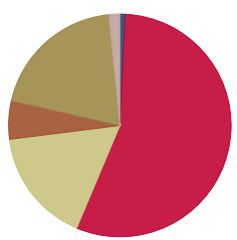

Ghent

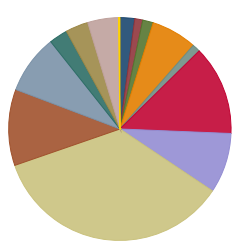

Padova

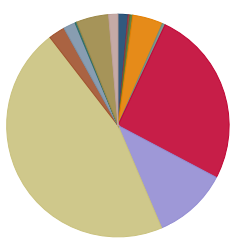

Pasajero en un accidente con un vehículo a motor

Peatón atropellado por un vehículo

Ciclista atropellado por un vehículo

Caída o choque con una bicicleta

Accidente con otro vehículo de ruedas

Caída al suelo desde bipedestación o corriendo

Impacto o caída contra un objeto estacionario andando o corriendo

Caída desde una altura

Caída por las escaleras

Asociada a deporte

Agresión

Cabeza golpeada con un objeto (no intencional)

Desconocido

Otros

Figura 17. Etiología de los TCE en cada hospital participante. 
En las siguientes figuras vemos la proporción de pruebas de imagen realizadas, LICci diagnosticadas y destino de los pacientes en cada hospital participante.
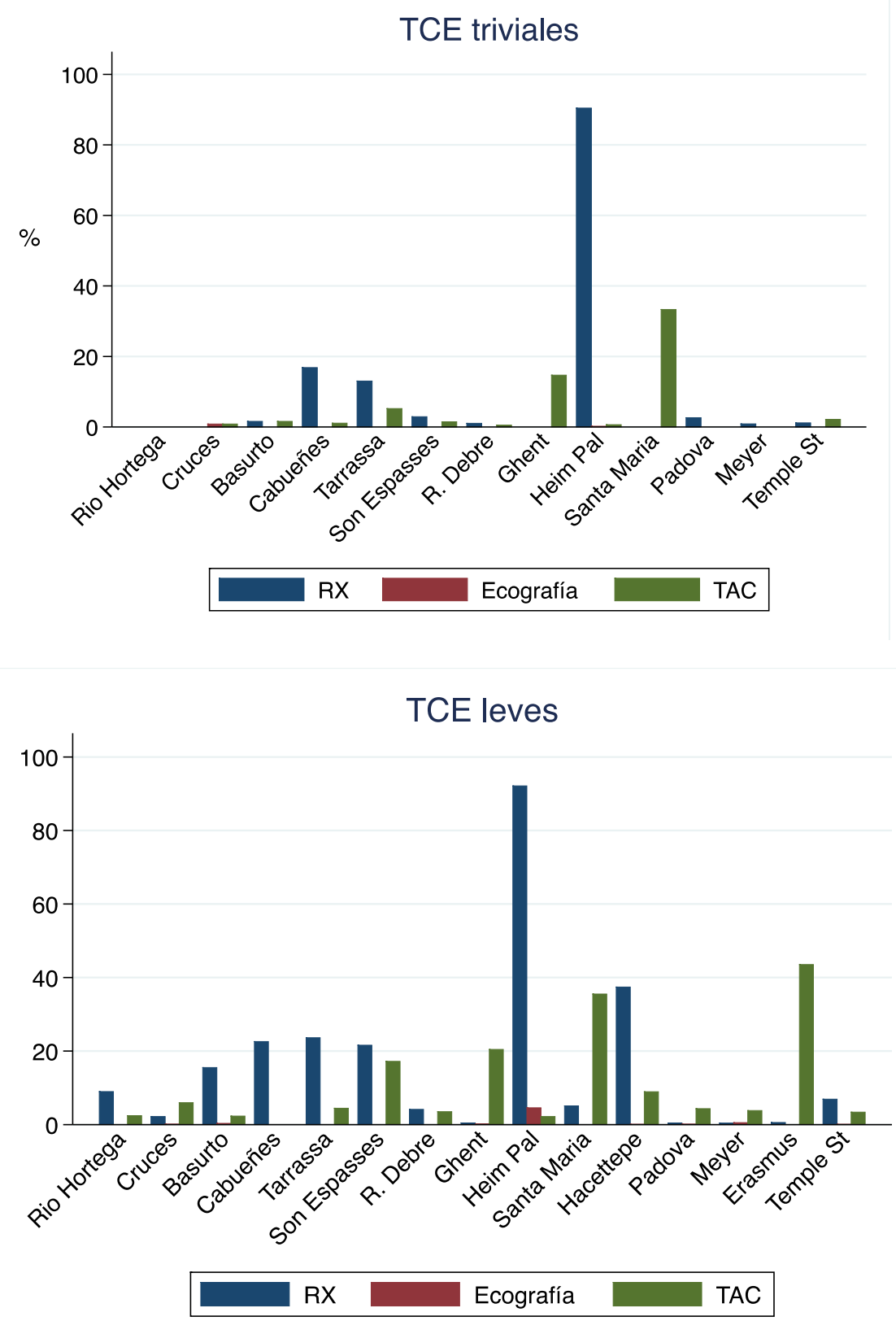

Figura 18. Pruebas de imagen realizadas en cada hospital participante. 


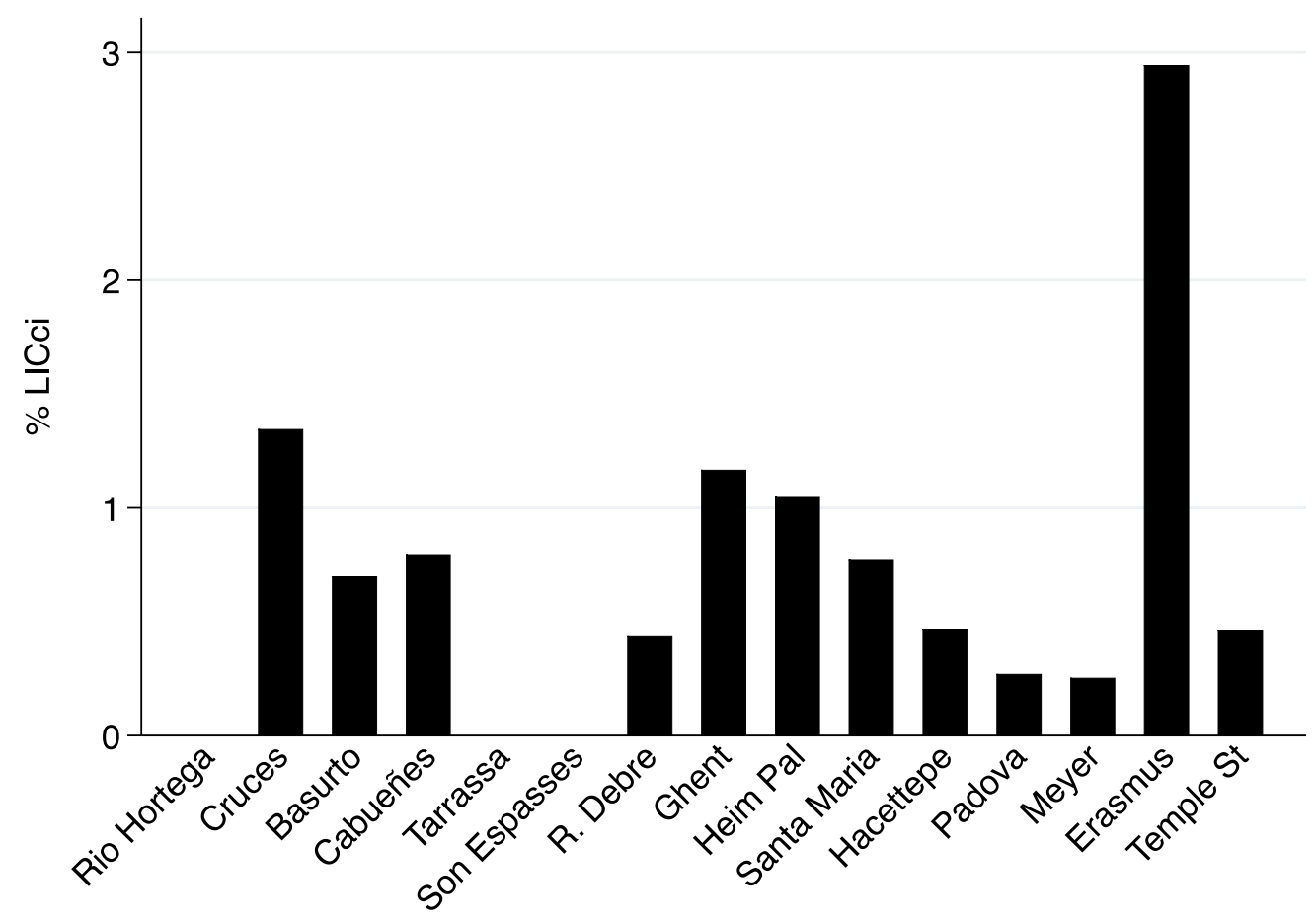

Figura 19. Prevalencia de LICci en cada hospital participante. 


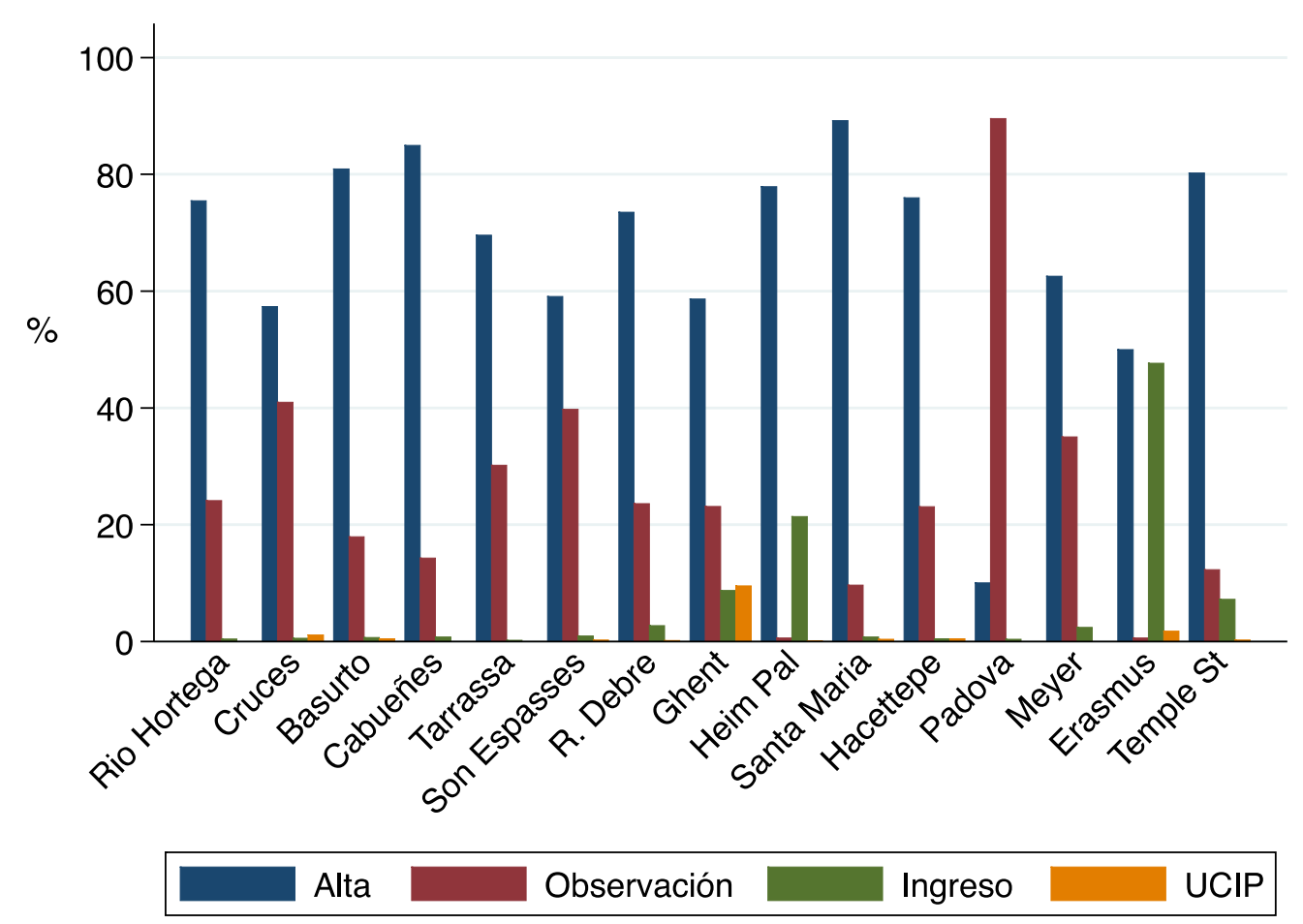

Figura 20. Destino de los pacientes en cada hospital participante. 
DISCUSIÓN 


\section{DISCUSIÓN}

Este trabajo de investigación, además de sus implicaciones clínicas, es un trabajo pionero dentro del campo de las Urgencias de Pediatría en España. Dentro de este entorno de trabajo nunca antes se había desarrollado un estudio reprospectivo multicéntrico a nivel europeo en el seno de una red de investigación.

Sí que se habían desarrollado estudios multicéntricos, fundamentalmente a nivel de EEUU y alguno con participación de hospitales europeos, pero ninguno que abarcase la variabilidad interhospitalaria de entre tantos centros y profesionales que atendemos a los pacientes pediátricos afectos de TCEL. Esta situación contribuía a que, en cada lugar, incluso dentro del mismo país, se atendiera de manera diferente a pacientes con la misma dolencia con la consiguiente realización de pruebas complementarias innecesarias y en ocasiones perjudiciales para ellos. Este trabajo intenta mostrar la ya descrita situación de variabilidad actual y con ello posibilitar la elaboración de protocolos y guías de manejo comunes que aporten un beneficio para nuestros pacientes.

Baste como ejemplo el trabajo de Kupperman, punto de partida e inspiración de todo este proyecto (10). En él, los pacientes de bajo riesgo eran seleccionados por cumplir una serie de criterios clínicos y en función de su presencia o ausencia se calculaba un riesgo de LICci que justificaría la exposición a radiación de la TAC para descartar la LICci frente a la observación clínica. Es decir, el objetivo de su estudio fue seleccionar los pacientes en los que se podía omitir la TAC craneal por su baja probabilidad de LICci. Este planteamiento supuso un cambio en el manejo del TCEL en el que tradicionalmente el objetivo era seleccionar los pacientes a los que realizar pruebas complementarias, y no seleccionar a los que evitárselas. Además, este trabajo no propone el uso de la RX de cráneo, técnica, aún a día de hoy, ampliamente utilizada por mútliples facultativos de distintos centros y países, como hemos podido corroborar.

Según nuestro trabajo la prevalencia de TCE en Europa es del 3,62\%, siendo en su mayoría TCEL $(2,16 \%)$. Esta cifra es superior a la publicada en otras series, aunque como ya se ha comentado los datos sobre prevalencia existentes son escasos y a penas existen registros oficiales sobre prevalencia $(20,25,190)$. La prevalencia de LICci fue del 0,67\%, 
similar a la de otras series, así como si seleccionamos tan sólo los TCEL que fue del $0,81 \%$, parecida a la publicada por Kuppermann $(10,191)$.

Ahora bien, consideramos fundamental tener en cuenta la diferencia entre TCEL y trivial puesto que en algunos centros no se realiza la distinción correctamente y el manejo debe ser diferente.

Son varios los pasos de este proceso diagnóstico y terapéutico donde nuestra investigación incide.

El primero de ellos, siguiendo un orden de relevancia, sería la variabilidad en el manejo de los pacientes pediátricos con TCEL y trivial, tanto en la realización de pruebas complementarias como en el destino de los pacientes tras la valoración clínica. Es importante tener en cuenta que cada país participante tiene unas guías clínicas propias y en algunos de ellos ni siquiera existen. De esta manera, en España existe la guía clínica de la AEP pero observamos cómo muchos de los centros españoles no siguen sus recomendaciones, aspecto que debería plantear la modificación y actualización de sus protocolos (173). Otros países con guías clínicas de manejo elaboradas por sus sociedades nacionales son Italia, Reino Unido, Francia y Holanda (192-194). Hungría y Turquía, en cambio, no tienen protocolos de manejo del TCE, y son en estos centros en los que se realizan, por ejemplo, un mayor porcentaje de radiografías de cráneo. Por este motivo, las guías clínicas más actuales, basándose en estudios previos, recomiendan unificar criterios y hacerlos evidentes para una mejor adherencia a los nuevos protocolos propuestos.

Respecto a los mecanismos de lesión, en general observamos que la etiología de los TCE es similar en casi todos los centros, siendo, al igual que en otras series, las tres principales causas la caída desde una altura, desde la propia altura o el impacto contra un objeto estacionario, con pequeñas variaciones en la proporción de cada una según el centro (20). Sin embargo, los mecanismos relacionados con vehículos que suponen un número más elevado en los Países Bajos y Bélgica, principalmente los accidentes en bicicleta. Según las estadísticas, Holanda es el país con mayor número de bicicletas por habitante a nivel mundial con un $99 \%$ de usuarios y Bélgica ocupa el noveno lugar en el ranking con 48\% (5.200.000 bicicletas para 10.827.519 habitantes). En Holanda el 36\% de la población la utiliza como su modo de transporte habitual, sin embargo, el uso del casco no es obligatorio y según la Unión de Ciclistas de Holanda, uno de cada cuatro accidentes fatales ocurren tras una colisión o atropello con un ciclista y en el año 2016 hubo 185 fallecidos por esta causa (195-197). Estos datos resultan relevantes ya que justifican las diferencias en el manejo de los hospitales de estos países con cifras elevadas 
de TCEL por colisiones o atropellos de bicicletas frente a aquellos donde son prácticamente anecdóticas. Desafortunadamente, en nuestro trabajo no se recogió entre las variables el uso o no de casco, lo que no permite comprobar si la prevalencia de LICci fue mayor en los traumatismos sufridos por ciclistas que no portaban casco.

Nuestra investigación profundiza en otro debate, como es la necesidad de pruebas complementarias. Encontramos variabilidad también entre las pruebas de imagen realizadas.

Varios son los estudios que demuestran que la rentabilidad de la RX en el TCEL es pobre y aunque el bajo valor diagnóstico no justifica su uso, advertimos que la radiografía de cráneo es comúnmente solicitada en un $29,8 \%$ de los pacientes que acuden por un TCEL o trivial a los Servicios de Urgencias $(137,138)$. En nuestra muestra observamos mayor número de RX de cráneo en los TCE triviales en menores de 24 meses respecto a los mayores, lo que sugiere que es una prueba que se selecciona en pacientes de baja sospecha de LICci, pero en los que, por su corta edad, el facultativo que atiende al paciente precisa de alguna prueba complementaria que aumente su certeza diagnóstica, intentando evitar la alta radiación que supondría la TAC. Sin embargo, la literatura más reciente muestra que los pacientes con fractura aislada pueden ser manejados de forma conservadora con seguridad (131). En nuestra muestra tan sólo se hallaron 13 pacientes con una LICci entre las 3919 radiografías realizadas, y de ellas, tan sólo 3 precisaron de manejo quirúrgico. Pero además los 13 pacientes presentaron algún factor de riesgo descrito en las guías de PECARN, lo que hace poco probable que el resultado de la radiografía modificara en la práctica el manejo de estos pacientes.

Respecto a la utilización de la ecografía para el diagnóstico de LICci en los lactantes con TCEL, vemos que su utilización es mínima, con tan sólo un $0,88 \%$ de los pacientes en los que se solicite esta prueba, de los cuales la gran mayoría pertenece al mismo hospital. Las posibles causas de ello pueden ser el desconocimiento de su utilidad y la falta de formación por parte de los facultativos de los SUP. Si bien esta prueba está llamada a sustituir a la radiografía de cráneo como prueba de elección para descartar fracturas simples de cráneo, surge la duda de la rentabilidad de esta prueba en términos de coste-beneficio (147-149). Si bien no tiene los riesgos inherentes a la radiación, el hecho de sobrediagnosticar fracturas simples que, como hemos visto tienen bajo riesgo de complicaciones, podría suponer un aumento en el número de TAC craneales realizados.

En cuanto a la TAC, llama la atención la variablidad en la realización de esta prueba. Los hospitales belga, holandés y portugués son los centros en los que se realizó un 
escáner a un porcentaje mayor de pacientes. En los dos primeros una posible explicación podría ser el mayor porcentaje de pacientes atendidos por traumatismos relacionados con vehículos a motor, de mayor riesgo de LICci $(198,199)$. De hecho, en el global de la muestra se realizó esta prueba con mayor frecuencia a los pacientes con un mecanismo relacionado con un traumatismo por un vehículo, y estos dos centros estuvieron entre los tres con una mayor prevalencia de LICci del estudio. Sin embargo, la epidemiología de los traumatismos en Portugal no difiere de la de los otros centros. Una posible explicación podría ser el hecho de que los TCE son atendidos en el SUP de este hospital por pediatras generales, sin formación específica en Urgencias de Pediatría.

De los 1149 pacientes ingresados, 88 pacientes tenían una LIci y sólo 11 precisaron algún tipo de intervención neuroquirúrgica. Por tanto, es más que factible pensar que realmente el manejo más conservador de estos pacientes con LICci sea una opción.

En cuanto a la clínica, el síntoma que más refieren los padres tras el TCEL es el comportamiento anómalo en un $13 \%$ de los pacientes, con cifras similares a la serie de PECARN. En cambio, sufren cefalea sólo un $8 \%$ de los pacientes con TCEL mayores de dos años a diferencia del $45 \%$ de PECARN.

El porcentaje de cefalohematomas del estudio asciende a un 60,9\% en comparación con otras series que cuentan con un 35-45\%; una probable explicación a este hecho sería la falta de consenso acerca de qué debe ser considerado cefalohematoma, siendo los hospitales con un menor nivel de especialización de su Urgencia Pediátrica aquellos con una mayor tendencia a considerar una lesión de edema como cefalohematoma (61).

Nuestro trabajo permite concluir algo ya sugerido por PECARN, y es que, en los pacientes con pérdida de consciencia, comportamiento anómalo según sus padres y vómitos tienen mayor riesgo de LICci (10). Igualmente, encontramos esta asociación en los pacientes con amnesia y convulsiones. Sin embargo, en nuestro caso al igual que concluyeron algunos trabajos pero a diferencia de PECARN la cefalea en los mayores de dos años no tuvo asociación con la presencia de LICci en la TAC $(59,143)$. Por esto último, al igual que otros autores, proponemos que, según nuestros datos, se podría obviar la presencia de cefalea, sobre todo si se presenta de manera aislada, como factor de riesgo de LICci en la evaluación del niño con TCE.

Existe igualmente, variabilidad en el destino de los pacientes. Observamos una tasa de ingresos global del 8,73\%, aunque esta cifra está artefactada debido al alto porcentaje de ingresos del hospital de Heim Pal (que no dispone de sala de observación). 
Excluyendo estos pacientes, el porcentaje de ingresos en planta o en UCIP fue del 4,4\%, inferior a la publicada en otras series $(10,12)$. Vemos que hay gran variabilidad en cuanto al manejo de los pacientes, ya que hay hospitales con alta tasa de ingreso, como el Erasmus, justificado probablemente por la alta prevalencia de LICci en su población, mientras que la mayoría de hospitales dieron a sus pacientes directamente de alta, excepto en el hospital de Padova, donde la mayoría fueron dados de alta tras un periodo de observación. Los hospitales con mayores tasas de observación son Cruces y Padova, que a su vez tienen tasas ingreso muy bajas.

Otra cuestión a valorar son los costes económicos derivados de la atención al TCE. Algunos autores han publicado los costes sanitarios del TCE pediátrico en EEUU, que alcanzan el billón de dólares anuales (200). En Europa no existen datos precisos que permitan calcular el coste de las pruebas complementarias y los ingresos de los pacientes de nuestro estudio, pero sin duda es algo que se debe tener en cuenta a la hora de tomar una decisión de actuación frente a un TCEL o trivial, siempre priorizando el mayor beneficio para el paciente. La variabilidad del coste del paciente ingresado es consecuencia de diferencias en las prácticas clínicas, la severidad de los pacientes, los factores estructurales, tecnológicos y de la calidad de la atención hospitalaria. Creemos, por todo esto, que nuestra investigación sienta las bases de futuros estudios y guías de práctica clínica donde podamos unificar los criterios para llevar a cabo las mismas pruebas y procedimientos con todos los pacientes.

Por último, un dato que llama poderosamente la atención es que, de 17083 pacientes, fueron excluidos 3922 y entre los motivos de exclusión no encontramos la sospecha de maltrato como causa del TCE en ninguno de ellos. Según un estudio español elaborado por el Ministerio de Sanidad publicado en 2011, el 6,36\% de los responsables de guarderías y colegios detectó algún caso de maltrato en los niños de 0 a 7 años a su cargo en 2006 y el 4,25\% de los menores en edades comprendidas entre los 8 y los 17 años fue maltratado en el ámbito familiar durante 2006 (201). Si bien la frecuencia real del maltrato en la mayoría de los países occidentales es imprecisa, se conoce que está subestimada, tesis que también sugiere nuestro trabajo.

Nuestro estudio presenta varias limitaciones. Por un lado, la principal es que se trata de un estudio retrospectivo, lo que conlleva una pérdida de información debida a la revisión de las historias clínicas incompletas que hemos encontrado. No todas las variables están recogidas en todos los informes de alta. Esta es una limitación habitual en cualquier estudio retrospectivo, que por otra parte es el único tipo de estudio que permite 
analizar el manejo real de los pacientes sin establecer un sesgo de observación. Además, entre los quince hospitales participantes, seis son españoles, lo que puede llevarnos a generalizar conductas a nivel europeo con mayor proporción de participación española por lo que las conclusiones deben ser tomadas con cautela. Sin embargo, creemos que la variabilidad que muestran nuestros resultados refleja de una manera adecuada la situación del manejo del TCEL en nuestro entorno. Por último, en cada centro ha habido uno o dos miembros encargados de la recogida de datos (es decir unas aproximadamente 20 personas en total), lo que puede contribuir a que haya habido variabilidad a la hora de recoger datos de las historias clínicas, pese a que se esta recogida se hizo mediante un formulario estandarizado.

Nuestro trabajo de investigación demuestra que los pacientes son manejados de distinta manera en cuanto a pruebas diagnósticas y actitud terapéutica en función del lugar donde son atendidos.

Quedan, no obstante, importantes cuestiones que responder, como en qué pacientes puede considerarse la ecografía como una prueba diagnóstica útil, cuál es el tiempo de observación seguro para un paciente, si existe cabida para el NIRS en algún supuesto, o si ciertos síntomas y signos que clásicamente hemos considerado de riesgo pueden no tener tanta significación clínica, pero eso será el objeto de futuras investigaciones. 


\section{CONCLUSIONES}




\section{CONCLUSIONES}

a) Existe una gran variabilidad en el manejo del traumatismo craneoncefálico en el paciente pediátrico, tanto en las pruebas diagnósticas como en el manejo terapéutico. Esta variabilidad se presenta entre países, pero también entre centros de un mismo país.

b) El traumatismo craneoncefálico es una causa frecuente de consulta en los servicios de Urgencias de Pediatría europeos, suponiendo una de cada veintisiete pacientes atendidos.

c) Las causas más frecuentes de traumatismo craneoencefálico leve pediátrico en Europa son la caída desde una altura o desde la propia altura, mientras que en los traumatismos craneoncefálico triviales las principales causas son la caída desde la propia altura o el impacto contra un objeto estacionario.

d) Se observa también variabilidad en la etiología de los traumatismos craneoncefálicos, con una mayor prevalencia de los traumatismos asociados a vehículos, principalmente bicicletas, en Bélgica y Holanda.

e) La prevalencia de lesión intracraneal clínicamente importante es baja, inferior al uno por ciento. Los mecanismos más frecuentemente asociados a estas lesiones fueron las caídas de grandes alturas y los ciclistas atropellados por vehículos a motor.

f) Pese a su bajo rendimiento diagnóstico, la radiografía de cráneo sigue siendo una prueba de imagen utilizada frecuentemente, aunque se observa importante 
variabilidad entre centros. También se observan importantes diferencias en el porcentaje de tomografías axiales computerizadas realizadas.

g) La ecografía craneal es una prueba escasamente introducida en el manejo del traumatismo craneoencefálico en Europa.

h) La mayoría de los pacientes valorados por traumatismo craneoncefálico fueron dados de alta directamente. La estancia de los pacientes en sala de observación durante un periodo inferior a 24 horas se asoció con una menor proporción de pacientes ingresados en planta o en las unidades de cuidados intensivos. 


\section{BIBLIOGRAFÍA}




\section{BIBLIOGRAFÍA}

1. Klassen TP, Reed MH, Stiell IG, Nijssen-Jordan C, Tenenbein M, Joubert G, et al. Variation in utilization of computed tomography scanning for the investigation of minor head trauma in children: a Canadian experience. Acad Emerg Med. 2000;7(7):739-44.

2. Lloyd DA, Carty H, Patterson M, Butcher CK, Roe D. Predictive value of skull radiography for intracranial injury in children with blunt head injury. Lancet. 1997 Mar;349(9055):821-4.

3. Blackwell CD, Gorelick M, Holmes JF, Bandyopadhyay S, Kuppermann N. Pediatric Head Trauma: Changes in Use of Computed Tomography in Emergency Departments in the United States Over Time. Ann Emerg Med. 2007;49(3):320-4.

4. Mannix R, Meehan W, Monuteaux MC, Bachur RG. Computed Tomography for Minor Head Injury: variation and trends among major US Pediatric Emergency Departments. J Pediatr. 2013;160(1):136-9.

5. Ministerio de Sanidad SS e I, Dirección General de Salud Pública C e I, Innovación SG de IS e. CIE-10-ES DIAGNÓSTICOS Unidad Técnica de Codificación. 2016.

6. Nathan D. Zasler, Douglas I. Katz, Zafonte RD. Brain Injury Medicine. Second Edi. 2007.

7. Brain Injury Association of America [Internet]. 2011 [cited 2017 Apr 4]. Available from: http://www.biausa.org/announcements/biaa-adopts-new-tbidefinition

8. Lacerda Gallardo AJ, Abreu Pérez D. Traumatic brain injury in paediatrics. Our results. Rev Neurol. 36(2):108-12.

9. Quayle KS, Jaffe DM, Kuppermann N, Kaufman B a, Lee BC, Park TS, et al. Diagnostic testing for acute head injury in children: when are head computed tomography and skull radiographs indicated? Pediatrics. 1997;99(5):E11.

10. Kuppermann N, Holmes JF, Dayan PS, Hoyle JD, Atabaki SM, Holubkov R, et al. 
Identification of children at very low risk of clinically-important brain injuries after head trauma: a prospective cohort study. Lancet. 2009;374(9696):1160-70.

11. Osmond MH, Klassen TP, Wells GA, Correll R, Jarvis A, Joubert G, et al. CATCH: A clinical decision rule for the use of computed tomography in children with minor head injury. Cmaj. 2010;182:341-8.

12. Dunning J, Daly JP, Lomas J-P, Lecky F, Batchelor J, Mackway-Jones K. Derivation of the children's head injury algorithm for the prediction of important clinical events decision rule for head injury in children. Arch Dis Child. 2006;91(11):885-91.

13. Da Dalt L, Marchi AG, Laudizi L, Crichiutti G, Messi G, Pavanello L, et al. Predictors of intracranial injuries in children after blunt head trauma. Eur $\mathbf{J}$ Pediatr. 2006;165(3):142-8.

14. Lee LK, Dayan PS, Gerardi MJ, Borgialli DA, Badawy MK, Callahan JM, et al. Intracranial Hemorrhage after Blunt Head Trauma in Children with Bleeding Disorders. J Pediatr. 2011 Jun;158(6):1003-1008.e2.

15. Nigrovic LE, Lillis K, Atabaki SM, Dayan PS, Hoyle J, Tunik MG, et al. The Prevalence of Traumatic Brain Injuries After Minor Blunt Head Trauma in Children With Ventricular Shunts. Ann Emerg Med. 2013 Apr;61(4):389-93.

16. Dunning J, Daly JP, Malhotra R, Stratford-Smith P, Lomas J-P, Lecky F, et al. The implications of NICE guidelines on the management of children presenting with head injury. Arch Dis Child. 2004 Aug 1;89(8):763-7.

17. Navascués del Río JA, Sotelo Martín J, Cerdá Berrocal J, Barrientos Fernández G, Sánchez Martín R, Romero Rodríguez R, et al. Pediatric trauma registry: analysis of 1200 cases. Cir Pediatr. 1998 Oct;11(4):151-60.

18. Babl FE, Lyttle MD, Bressan S, Borland M, Phillips N, Kochar A, et al. A prospective observational study to assess the diagnostic accuracy of clinical decision rules for children presenting to emergency departments after head injuries (protocol): the Australasian Paediatric Head Injury Rules Study (APHIRST). BMC Pediatr. 2014;14(1):148.

19. Campos MR. Shaken baby syndrome. Cuad Med Forense. 2006;12(43-44):39-45.

20. L Trefan, R Houston, G Pearson, R Edwards, P Hyde IM, RC Parslow AK. Epidemiology of children with head injury: a national overview. BMJ. 
2016;101:527-32.

21. Luerssen TG, Klauber MR, Marshall LF. Outcome from head injury related to patient' age. J Neurosurg. 1988 Mar;68(3):409-16.

22. Rutland-Brown W, Langlois JA, Thomas KE, Xi YL. Incidence of traumatic brain injury in the United States. J Head Trauma Rehabil. 2003;21(6):544-8.

23. M. Faul M, L. Xu M, M. M. Wald M, V. G. Coronado M. Traumatic Brain Injury in the United States: Emergency Department Visits, Hospitalizations and Deaths 2002-2006 (Blue Book) Centers for Disease Control and Prevention National Center for Injury Prevention and Control. 2010.

24. Robert M. Kliegman MD, Bonita F. Stanton MD, Joseph W. St. Geme MD, Nina F. Schor MD P y REBM. Nelson. Tratado de pediatría. 19a Edición. 19th ed. Elsevier España, S.L.; 2013. 2495-2497 p.

25. García García JJ, Manrique Martínez I, Trenchs Sainz de la Maza V, Suárez Suárez A, Martín de la Rosa L, Travería Casanova FJ, et al. Registro de traumatismos craneoencefálicos leves: estudio multicéntrico de la Sociedad Española de Urgencias Pediátricas. An Pediatría. 2009;71(1):31-7.

26. Tagliaferri F, Compagnone C, Korsic M, Servadei F, Kraus J. A systematic review of brain injury epidemiology in Europe. Acta Neurochir (Wien). 2006;148(3):255-68.

27. Benito Fernández J. Traumatismo craneoencefálico en la infancia. Rev Pediatría Atención Primaria. 2007;IX(2):39-47.

28. National Center on Shaken Baby Syndrome [Internet]. 2016 [cited 2016 Oct 1]. Available from: http://www.dontshake.org

29. Manrique Martínez I, Alcalá Minagorre PJ. Manejo del traumatismo craneal pediátrico [Internet]. Protocolos AEP. 2008 [cited 2014 Jun 1]. p. 265-89. Available from: http://www.aeped.es/sites/default/ files/documentos/manejo del traumatismo craneal pediatrico. pdf

30. Burrows P, Trefan L, Houston R, Hughes J, Pearson G, Edwards RJ, et al. Head injury from falls in children younger than 6 years of age.

31. Crowe LM, Catroppa C, Anderson V, Babl FE, Atabaki SM, Holubkov R, et al. Head injuries in children under 3 years. Injury. 2012 Dec 1;43(12):2141-5. 
32. Río JAN, Martín JS, Berrocal JC, Fernández GB, Mialdea RL, Vals CE, et al. Estudio epidemiológico de los accidentes en la infancia: Primer Registro de Trauma Pediátrico. 1997;47:369-72.

33. Cambra FJ PA. Traumatismo craneoencefálico. An Pediatr Cont. 2005;6:327-34.

34. Esparza J, Mintegi S. Guía para padres sobre la prevención de lesiones no intencionadas en la edad infantil [Internet]. Fundación MAPFRE, AEP, editors. 2016. Available from: http://www.aeped.es/sites/default/files/documentos/guiapadres-prevencion-lesiones-no-intencionadas.pdf

35. Francisco Guzmán M. Fisiopatología del trauma craneoencefálico. Colomb Med. 2008;39(3):78-84.

36. Florentino Garduño Hernández. Exploración neurológica de la cabeza en niños recién nacidos. Rev Mex Pediatría. 2004;71(6):292-6.

37. Pascual Gisbert J, Odoles Ibarra R. Pediatría. Tomo VII. Neuropediatría. Editorial Ciencias Médicas; 2012.

38. Koestler J, Keshavarz R, Hennes H, Lee M, Smith D, Al. E, et al. Penetrating head injury in children: a case report and review of the literature. J Emerg Med. 2001 Aug;21(2):145-50.

39. González MA, Benito P, Maria J, Grabulosa S. Secuelas neuropsicológicas de los traumatismos craneoencefálicos. 2004;20(2):303-16.

40. Wegner A A, Wilhelm B J, Darras M E. Traumatismo encefalocraneano: Conceptos fisiológicos y fisiopatológicos para un manejo racional. Rev Chil pediatría. 2003 Jan;74(1):16-30.

41. N. Silva Higuero AGR. Traumatismos craneoencefálicos. Pediatr Integr. 2014;XVIII(4):207-18.

42. Salazar LRM. Trauma craneoencefálico atención inicial y manejo hospitalario. Duazary. 2013;7(1):100-5.

43. Terán IDEL a SC, Manjón-cabeza RMA. Traumatismos craneoencefálicos en el niño. Boletín la Soc Pediatría Astur Cantab Castilla y León. 2000;(40):109-14.

44. Martínez T, Bonifaz O. Traumatismo craneoencefálico en la Unidad de Terapia Intensiva Pediátrica del Hospital Universitario de Puebla. TRAUMA. 2008;11(3):73-85. 
45. Kerr HA. Closed Head Injury. Clin Sports Med. 2013;32(2):273-87.

46. Yus Teruel S, Cidoncha Gallego M. Traumatismo craneoencefálico (TCE). Manual de Medicina Intensiva. $2^{\text {a }}$ edición. Harcourt S. 2000.

47. Sara A Schutzman, MD Patrick D Barnes, MD Michael Mantello, MD R Michael Scott M. Epidural Hematomas in Children. Ann Emerg Med. 1993;22:535-41.

48. Luis Rodríguez García P, Rodríguez García D. Hemorragia subaracnoidea: epidemiología, etiología, fisiopatología y diagnóstico. Rev Cuba Neurol Neurocir. 2011;1(1):59-73.

49. Cardentey-Pereda AL. Hemorragia subaracnoidea. Rev Neurol. 2002;34(10):95466.

50. A. Bárcena-Orbe; C.A. Rodríguez-Arias*; B. Rivero-Martín**; J.M. CañizalGarcía; C. Mestre-Moreiro; J.C. CalvoPérez; A.F. Molina-Foncea y J. CasadoGómez. Revisión del traumatismo craneoencefálico. Recib Neurocir. 2006; 17:495-518.

51. Lee LK, Monroe D, Bachman MC, Glass TF, Mahajan P V, Cooper A, et al. Isolated Loss of Consciousness in Children With Minor Blunt Head Trauma. JAMA Pediatr. 2014;2115(9):837-43.

52. Holmes JF, Palchak MJ, Conklin MJ, Kuppermann N. Do children require hospitalization after immediate posttraumatic seizures? Ann Emerg Med. 2004;43(6):706-10.

53. Huguenard AL, Miller BA, Sarda S, Capasse M, Reisner A, Chern JJ. Mild traumatic brain injury in children is associated with a low risk for posttraumatic seizures. J neurosurg Pediatr. 2016;17:476-82.

54. Holsti M, Kadish HA, Sill BL, Firth SD, Nelson DS. Pediatric closed head injuries treated in an observation unit. Pediatr Emerg Care. 2005;21(10):639-44.

55. Annegers JF, Grabow JD, Groover R V, Laws ER, Elveback LR, Kurland LT. Seizures after head trauma: a population study. Neurology. $1980 \mathrm{Jul} ; 30(7 \mathrm{Pt}$ 1):683-9.

56. Najafi MR, Tabesh H, Hosseini H, Akbari M. Early and late posttraumatic seizures following traumatic brain injury: A five-year follow-up survival study. Adv Biomed Res. 2015;4(82):1-6. 
57. Dayan PS, Holmes JF, Atabaki S, Hoyle J, Tunik MG, Lichenstein R, et al. Association of Traumatic Brain Injuries With Vomiting in Children With Blunt Head Trauma. Ann Emerg Med. 2014;63(6):657-65.

58. Da Dalt L, Andreola B, Facchin P, Gregolin M, Vianello A, Battistella PA. Characteristics of Children with Vomiting after Minor Head Trauma: A CaseControl Study. J Pediatr. 2007;150(3):274-8.

59. Dayan PS, Holmes JF, Hoyle J, Atabaki S, Tunik MG, Lichenstein R, et al. Headache in traumatic brain injuries from blunt head trauma. Pediatrics. 2015;135(3):504-12.

60. Jessica M. Mathieson DO. Derivation of the Children's Head Injury Algorithm for the Prediction of Important Clinical Events Decision Rule for Head Injury in Children. J Emerg Med. 2007;32(3):328-328.

61. Dayan PS, Holmes JF, Schutzman S, Schunk J, Lichenstein R, Foerster LA, et al. Risk of traumatic brain injuries in children younger than 24 months with isolated scalp hematomas. Ann Emerg Med. 2014;64(2):153-62.

62. Burns ECM, Grool AM, Klassen TP, Correll R, Jarvis A, Joubert G, et al. Scalp Hematoma Characteristics Associated With Intracranial Injury in Pediatric Minor Head Injury. Macy ML, editor. Acad Emerg Med. 2016 May;23(5):576-83.

63. Bin SS, Schutzman SA, Greenes DS. Validation of a clinical score to predict skull fracture in head-injured infants. Pediatr Emerg Care. 2010 Sep;26(9):633-9.

64. Greenes DS, Schutzman SA. Clinical Indicators of Intracranial Injury in Headinjured Infants. Pediatrics. 1999;104(4):861-7.

65. Erlichman DB, Blumfield E, Rajpathak S, Weiss A. Association between linear skull fractures and intracranial hemorrhage in children with minor head trauma. Pediatr Radiol. 2010 Aug 9;40(8):1375-9.

66. Duhaime AC, Alario AJ, Lewander WJ, Schut L, Sutton LN, Seidl TS, et al. Head injury in very young children: mechanisms, injury types, and ophthalmologic findings in 100 hospitalized patients younger than 2 years of age. Pediatrics. 1992 Aug;90(2 Pt 1):179-85.

67. Schunk JE, Rodgerson JD, Woodward GA. The utility of head computed tomographic scanning in pediatric patients with normal neurologic examination in the emergency department. Pediatr Emerg Care. 1996 Jun;12(3):160-5. 
68. Greenes DS, Schutzman SA. Clinical significance of scalp abnormalities in asymptomatic head-injured infants. Pediatr Emerg Care. 2001 Apr;17(2):88-92.

69. MCMillan RG. National Clinical Guideline Centre (NICE): Head Injury. National Clinical Guideline Centre Guidelines. 2014.

70. Ferrera PC, Reicho PR. Acute confusional migraine and trauma-triggered migraine. Am J Emerg Med. 1996 May;14(3):276-8.

71. Shaabat A. Confusional migraine in childhood. Pediatr Neurol. 1996;15(1):23-5.

72. Shaffer L, Rich PM, Pohl KRE, Ganesan V. Can mild head injury cause ischaemic stroke? Arch Dis Child. 2003 Mar 1;88(3):267-9.

73. Kieslich M, Fiedler A, Heller C, Kreuz W, Jacobi G. Minor head injury as cause and co-factor in the aetiology of stroke in childhood: a report of eight cases. $\mathrm{J}$ Neurol Neurosurg Psychiatry. 2002 Jul 1;73(1):13-6.

74. Marcin JP, Pollack MM. Triage scoring systems, severity of illness measures, and mortality prediction models in pediatric trauma. Crit Care Med. 2002;30(11 Suppl):S457-67.

75. Medana IM, Esiri MM. Axonal damage: a key predictor of outcome in human CNS diseases. Brain. 2003 Mar;126(Pt 3):515-30.

76. Junqué C. Valoración del daño axonal difuso en los traumatismos cráneoencefálicos. Escritos Psicol. 2008;2(1):54-64.

77. Teasdale G, Jennett B. Assessment of coma and impaired consciousness. Lancet. $1974 \mathrm{Jul} ; 304(7872): 81-4$.

78. Holmes JF, Palchak MJ, MacFarlane T, Kuppermann N. Performance of the Pediatric Glasgow Coma Scale in Children with Blunt Head Trauma. Acad Emerg Med. 2005 Sep 1;12(9):814-9.

79. Galán CREY, Cuervo SM, Torre AC. Manejo inicial del politraumatismo pediátrico (II): Traumatismo craneoencefálico. Boletín Pediatría la Soc Pediatría Astur Cantab Castilla y León. 2008;48:153-9.

80. Teasdale G, Maas A, Lecky F, Rey Manley G, Stocchetti N, Murray G. Personal View The Glasgow Coma Scale at 40 years: standing the test of time. Lacent Neurol. 2014;13:844-54.

81. Moppett IK. Traumatic brain injury: assessment, resuscitation and early 
management. Br J Anaesth. 2007;99:18-31.

82. Thompson DO, Hurtado TR, Liao MM, Byyny RL, Gravitz C, Haukoos JS, et al. Validation of the Simplified Motor Score in the Out-of-Hospital Setting for the Prediction of Outcomes After Traumatic Brain Injury. Ann Emerg Med. 2011 Nov;58(5):417-25.

83. Chou R, Totten AM, Carney N, Dandy S, Fu R, Grusing S, et al. Predictive Utility of the Total Glasgow Coma Scale Versus the Motor Component of the Glasgow Coma Scale for Identification of Patients With Serious Traumatic Injuries. Ann Emerg Med. 2016;1-15.

84. Green SM, Haukoos JS, Schriger DL. How to Measure the Glasgow Coma Scale. Ann Emerg Med. 2016;1-3.

85. Hoffmann F, Schmalhofer M, Lehner M, Zimatschek S, Grote V, Reiter K. Comparison of the AVPU Scale and the Pediatric GCS in Prehospital Setting. Prehospital Emerg Care. 2016 Jul 3;20(4):493-8.

86. Anne Kelly C, Upex A, Bateman DN. Comparison of consciousness level assessment in the poisoned patient using the alert/verbal/painful/unresponsive scale and the glasgow coma scale. Ann Emerg Med. 2004;44(2):108-13.

87. McNarry AF, Goldhill DR. Simple bedside assessment of level of consciousness: comparison of two simple assessment scales with the Glasgow Coma scale. Anaesthesia. 2004 Jan;59(1):34-7.

88. Radvinsky D, Yoon R, Schmitt P, Prestiagiacomo C, Swan K, Liporace F. Evolution and Development of the Advanced Trauma Life Support (ATLS) Protocol: A Historical Perspectiv. Orthopedics. 2012;35(4):305-11.

89. Mohammad A, Branicki F, Abu-Zidan FM. Educational and clinical impact of advanced trauma life support (ATLS) courses: A systematic review. World J Surg. 2014;38(2):322-9.

90. Wiley, Blackwell, editors. Advanced Paediatric Life Support. Sixth edit. 2016.

91. Benito J, Mintegi S, Sánchez J. Urgencias pediátricas. $5^{\text {a }}$ edición. Editorial médica Panamericana; 2013.

92. Zúñiga RV. Triángulo de Evaluación Pediátrica El Triángulo de Evaluación Pediátrica. Pediatr Integr. 2014;XVIII(5):320-3. 
93. Solis Reyes C, López Fajardo P, Rodríguez Carrasco E. Guía clínica del traumatismo craneoencefálico leve y moderado en Pediatría. Can Pediatr. 2010;34(1):31-7.

94. Palchak MJ, Holmes JF, Vance CW, Gelber RE, Schauer BA, Harrison MJ, et al. A decision rule for identifying children at low risk for brain injuries after blunt head trauma. Ann Emerg Med. 2003 Oct;42(4):492-506.

95. Dunning J, Batchelor J, Stratford-Smith P, Teece S, Browne J, Sharpin C, et al. A meta-analysis of variables that predict significant intracranial injury in minor head trauma. Arch Dis Child. 2004;89(7):653-9.

96. Oman JA. Performance of a Decision Rule to Predict Need for Computed Tomography Among Children With Blunt Head Trauma. Pediatrics. 2006 Feb 1;117(2):e238-46.

97. Palchak MJ, Holmes JF, Vance CW, Gelber RE, Schauer BA, Harrison MJ, et al. Does an isolated history of loss of consciousness or amnesia predict brain injuries in children after blunt head trauma? Pediatrics. 2004 Jun;113(6):e507-13.

98. Atabaki SM, Stiell IG, Bazarian JJ, Sadow KE, Vu TT, Camarca MA, et al. A Clinical Decision Rule for Cranial Computed Tomography in Minor Pediatric Head Trauma. Arch Pediatr Adolesc Med. 2008 May 1;162(5):439.

99. Maguire JL, Boutis K, Uleryk EM, Laupacis A, Parkin PC. Should a head-injured child receive a head CT scan? A systematic review of clinical prediction rules. Pediatrics. 2009;124(1):e145-54.

100. Hu C-F, Fan H-C, Chang C-F, Chen S-J. Current Approaches to the Treatment of Head Injury in Children. Pediatr Neonatol. 2013;54(2):73-81.

101. Hamilton M, Mrazik M, Johnson DW. Incidence of delayed intracranial hemorrhage in children after uncomplicated minor head injuries. Pediatrics. 2010;126(1):e33-9.

102. Blackwood BP, Bean JF, Sadecki-Lund C, Helenowski IB, Kabre R, Hunter CJ. Observation for isolated traumatic skull fractures in the pediatric population: unnecessary and costly. J Pediatr Surg. 2016;51:654-8.

103. Fallis A. Guía Práctica Clínica Osakidetza sobre TCE. Vol. 53. 2013. 1689-1699 p.

104. Chen MYM, Thomas L. Pope J, Ott DJ. Radiología básica. Hill M, editor. 2004. 
105. Abdelhalim AN, Alberico RA. Pediatric Neuroimaging. Neurol Clin NA. 2009;27(1):285-301.

106. Griffiths PD, Morrison GD. Computed tomography in children. BMJ. 2004 Oct $23 ; 329(7472): 930-2$.

107. Miglioretti DL, Johnson E, Williams A, Greenlee RT, Weinmann S, Solberg LI, et al. The use of computed tomography in pediatrics and the associated radiation exposure and estimated cancer risk. JAMA Pediatr. 2013;167(8):700-7.

108. Linscott LL, Kessler MM, Kitchin DR, Quayle KS, Hildebolt CF, Mckinstry RC, et al. CT for Pediatric, Acute, Minor Head Trauma: Clinician Conformity to Published Guidelines. Am J Neuroradiol. 2013;34:1252-6.

109. Marin JR, Weaver MD, Barnato AE, Yabes JG, Yealy DM, Roberts MS. Variation in emergency department head computed tomography use for pediatric head trauma. Stevenson M, editor. Acad Emerg Med. 2014 Sep;21(9):987-95.

110. Sorantin E, Wegmann H, Zaupa P, Mentzel H-J, Riccabona M. Computed tomographic scan in head trauma: what is the rational in children? Eur J Pediatr Surg. 2013 Dec 10;23(6):444-53.

111. Brenner DJ, Hall EJ. Computed Tomography - An Increasing Source of Radiation Exposure. N Engl J Med. 2007 Nov 29;357(22):2277-84.

112. Hennelly KE, Mannix R, Nigrovic LE, Lee LK, Thompson KM, Monuteaux MC, et al. Pediatric Traumatic Brain Injury and Radiation Risks: A Clinical Decision Analysis. J Pediatr. 2012;162(2):392-7.

113. Schutzman SA, Greenes DS. Pediatric minor head trauma. Ann Emerg Med. 2001;37(1):65-74.

114. Howe J, Fitzpatrick CM, Lakam DR, Gleisner A, Vane DW. Routine repeat brain computed tomography in all children with mild traumatic brain injury may result in unnecessary radiation exposure. J Trauma Acute Care Surg. 2014 Feb;76(2):292-5-6.

115. Haider AA, Rhee P, Orouji T, Kulvatunyou N, Hassanzadeh T, Tang A, et al. A second look at the utility of serial routine repeat computed tomographic scans in patients with traumatic brain injury. Am J Surg. 2015 Dec;210(6):1088-94.

116. Sifri ZC, Livingston DH, Lavery RF, Homnick AT, Mosenthal AC, Mohr AM, et al. Value of repeat cranial computed axial tomography scanning in patients with 
minimal head injury. Am J Surg. 2004 Mar;187(3):338-42.

117. Hentzen AS, Helmer SD, Nold RJ, Grundmeyer RW, Haan JM. Necessity of repeat head computed tomography after isolated skull fracture in the pediatric population. Am J Surg. 2015 Aug;210(2):322-5.

118. Nigrovic LE, Stack AM, Mannix RC, Lyons TW, Samnaliev M, Bachur RG, et al. Quality Improvement Effort to Reduce Cranial CTs for Children With Minor Blunt Head Trauma. Pediatrics. 2015;136:e227.

119. Brenner DJ, Elliston CD, Hall EJ, E. Berdon W. Estimated Risks of RadiationInduced Fatal Cancer from Pediatric CT. AJR Am J Roentgenol. 2001;176(2):289.

120. Pearce MS, Salotti JA, Little MP, McHugh K, Lee C, Kim KP, et al. Radiation exposure from $\mathrm{CT}$ scans in childhood and subsequent risk of leukaemia and brain tumours: a retrospective cohort study. Lancet. 2012;380(9840):499-505.

121. Stein SC, Hurst RW, Sonnad SS. Meta-analysis of cranial CT scans in children. A mathematical model to predict radiation-induced tumors. Pediatr Neurosurg. 2008;44(6):448-57.

122. Meulepas JM, Ronckers CM, Smets AMJB, Nievelstein RAJ, Jahnen A, Lee C, et al. Leukemia and brain tumors among children after radiation exposure from CT scans: design and methodological opportunities of the Dutch Pediatric CT Study. Eur J Epidemiol. 2014 Apr 19;29(4):293-301.

123. Hall P, Adami H-O, Trichopoulos D, Pedersen NL, Lagiou P, Ekbom A, et al. Effect of low doses of ionising radiation in infancy on cognitive function in adulthood: Swedish population based cohort study. BMJ. 2004 Jan 3;328(7430):19.

124. Sodhi KS, Krishna S, Saxena AK, Sinha A, Khandelwal N, Lee EY. Clinical application of "Justification" and "Optimization" principle of ALARA in pediatric CT imaging: \&quot;How many children can be protected from unnecessary radiation?\&quot;. Eur J Radiol. 2015 Sep;84(9):1752-7.

125. Shah NB, Platt SL. ALARA: is there a cause for alarm? Reducing radiation risks from computed tomography scanning in children. Curr Opin Pediatr. 2008 Jun;20(3):243-7.

126. Boone JM, Geraghty EM, Seibert JA, Wootton-Gorges SL. Dose Reduction in Pediatric CT: A Rational Approach. Radiology. 2003 Aug;228(2):352-60. 
127. Donnelly LF. Reducing Radiation Dose Associated with Pediatric CT by Decreasing Unnecessary Examinations. Am J Roentgenol. 2005 Feb;184(2):6557.

128. Udayasankar UK, Braithwaite K, Arvaniti M, Tudorascu D, Small WC, Little S, et al. Low-dose nonenhanced head CT protocol for follow-up evaluation of children with ventriculoperitoneal shunt: Reduction of radiation and effect on image quality. Am J Neuroradiol. 2008;29(4):802-6.

129. Donnelly LF, Emery KH, Brody AS, Laor T, Gylys-Morin VM, Anton CG, et al. Minimizing Radiation Dose for Pediatric Body Applications of Single-Detector Helical CT. Am J Roentgenol. 2001;176(2):303-6.

130. Goske MJ, Applegate KE, Boylan J, Butler PF, Callahan MJ, Coley BD, Farley S, Frush DP, Hernanz-Schulman M, Jaramillo D, Johnson ND, Kaste SC, Morrison G, Strauss KJ TN. The Image Gently Campaign: Working Together to Change Practice. AJR Am J Roentgenol. 2008;190(2):273.

131. Bressan S, Marchetto L, Lyons TW, Monuteaux MC, Freedman SB, Da Dalt L, et al. A Systematic Review and Meta-Analysis of the Management and Outcomes of Isolated Skull Fractures in Children. Ann Emerg Med. 2017;

132. Muñoz-Sánchez MA, Murillo-Cabezas F, Cayuela-Domínguez A, Rincón-Ferrari MD, Amaya-Villar R, León-Carrión J. Skull fracture, with or without clinical signs, in mTBI is an independent risk marker for neurosurgically relevant intracranial lesion: A cohort study. Brain Inj. 2009 Jan 3;23(1):39-44.

133. Andronikou S, Kilborn T, Patel M, Fieggen AG. Skull fracture as a herald of intracranial abnormality in children with mild head injury: Is there a role for skull radiographs? Australas Radiol. 2003;47(4):381-5.

134. Bonadio WA, Smith DS HS. Clinical indicators of intracranial lesion on computed tomographic scan in children with parietal skull fracture. Am J Dis Child. 1989;143:194-6.

135. Teasdale GM, Murray G, Anderson E, Mendelow D, Macmillan R, Jennett B, et al. Risks of acute traumatic intracranial haematoma in children and adults: implications for managing head injuries. Britsh Med J. 1990;300:363-7.

136. Reed MJ, Browning JG, Wilkinson AG, Beattie T. Can we abolish skull x rays for head injury? Arch Dis Child. 2005;90(8):859-64. 
137. Mulroy MH, Loyd AM, Frush DP, Verla TG, Myers BS, Dale Bass CR. Evaluation of pediatric skull fracture imaging techniques. Forensic Sci Int. 2012;214(1):167-72.

138. Kim YI, Cheong JW, Yoon SH. Clinical comparison of the predictive value of the simple skull X-ray and 3 dimensional computed tomography for skull fractures of children. J Korean Neurosurg Soc. 2012;52(6):528-33.

139. Chung S, Schamban N, Wypij D, Cleveland R, Schutzman SA, Dietrich A, et al. Skull radiograph interpretation of children younger than two years: how good are pediatric emergency physicians? Ann Emerg Med. 2004 Jun;43(6):718-22.

140. Dwek JR. The radiographic approach to child abuse. Clin Orthop Relat Res. 2011;469(3):776-89.

141. Mannix R, Monuteaux MC, Schutzman SA, Meehan III WP, Nigrovic LE, Neuman MI. Isolated Skull Fractures: Trends in Management in US Pediatric Emergency Departments. Ann Emerg Med. 2013;62:327-31.

142. White IK, Pestereva E, Shaikh KA, Fulkerson DH. Transfer of children with isolated linear skull fractures: is it worth the cost? J Neurosurg Pediatr. 2016 May;17(5):602-6.

143. Dunning J, Batchelor J, Stratford-Smith P, Teece S, Browne J, Sharpin C, et al. A meta-analysis of variables that predict significant intracranial injury in minor head trauma. Arch Dis Child. 2004 Jul 1;89(7):653-9.

144. Muñoz-Santanach D, Trenchs Sainz de la Maza V, González Forster E, Luaces Cubells C. Niños con traumatismo craneal leve en urgencias: ¿es necesaria la radiografía de cráneo en pacientes menores de 2 años? Neurocirugia. 2014 Jul $1 ; 25(4): 149-53$.

145. Décarie JC, Mercier C. The role of ultrasonography in imaging of paediatric head trauma. Child's Nerv Syst. 1999 Nov 16;15(11-12):740-2.

146. Rabiner JE, Friedman LM, Khine H, Avner JR, Tsung JW. Accuracy of point-ofcare ultrasound for diagnosis of skull fractures in children. Pediatrics. 2013;131(6):e1757-64.

147. Parri N, Crosby BJ, Glass C, Mannelli F, Sforzi I, Schiavone R, et al. Ability of emergency ultrasonography to detect pediatric skull fractures: A prospective, observational study. J Emerg Med. 2013;44(1):135-41. 
148. Weinberg ER, Tunik MG, Tsung JW. Accuracy of clinician-performed point-ofcare ultrasound for the diagnosis of fractures in children and young adults. Injury. 2010;41(8):862-8.

149. Riera A, Chen L. Ultrasound evaluation of skull fractures in children: a feasibility study. Pediatr Emerg Care. 2012;28(5):420-5.

150. Steinborn M, Schäffeler C, Kabs C, Kraus V, Rüdisser K, Hahn H. CT and MR imaging of primary cerebrovascular complications in pediatric head trauma. Emerg Radiol. 2010 Jul 2;17(4):309-15.

151. Aquino C, Woolen S, Steenburg SD. Magnetic resonance imaging of traumatic brain injury: a pictorial review. Emerg Radiol. 2015 Feb 11;22(1):65-78.

152. Buttram SDW, Garcia-Filion P, Miller J, Youssfi M, Brown SD, Dalton HJ, et al. Computed tomography vs magnetic resonance imaging for identifying acute lesions in pediatric traumatic brain injury. Hosp Pediatr. 2015;5(2):79-84.

153. Borrat Frigola X, Mercadal Mercadal J, Zavala E. Espectroscopia cercana al infrarrojo en la reanimación: medición no invasiva de la perfusión periférica. Rev Esp Anestesiol Reanim. 2010;57(6):364-73.

154. Robertson CS, Zager EL, Narayan RK et al. Clinical evaluation of a portable near-infrared device for detection of traumatic intracranial hematomas. J Neurotrauma. 2010;27:1597-164.

155. Bressan S, Daverio M, Martinolli F, Dona' D, Mario F, Steiner IP, et al. The use of handheld near-infrared device (Infrascanner) for detecting intracranial haemorrhages in children with minor head injury. Childs Nerv Syst. 2013 Nov 14;30(3):477-84.

156. Salonia R, Bell MJ, Kochanek PM, Berger RP. The utility of near infrared spectroscopy in detecting intracranial hemorrhage in children. J Neurotrauma. 2012;29(6):1047-53.

157. E. Gordillo-Escobar, J.J. Egea-Guerrero, A. Rodríguez-Rodríguez FM-C. Utilidad de los biomarcadores en el pronóstico del traumatismo craneoencefálico grave. Med Intensiva. 2016;40(2):105-12.

158. Papa L, Brophy GM, Welch RD, Lewis LM, Braga CF, Tan CN, et al. Time Course and Diagnostic Accuracy of Glial and Neuronal Blood Biomarkers GFAP and UCH-L1 in a Large Cohort of Trauma Patients With and Without Mild 
Traumatic Brain Injury. JAMA Neurol. 2016;73(5):661-73.

159. Jeter CB, Hergenroeder GW, Hylin MJ, Redell JB, Moore AN, Dash PK. Biomarkers for the diagnosis and prognosis of mild traumatic brain injury/concussion. J Neurotrauma. 2013 Apr 15;30(8):657-70.

160. McCarthy MT, Kosofsky BE. Clinical features and biomarkers of concussion and mild traumatic brain injury in pediatric patients. Ann N Y Acad Sci. 2015 May;1345(1):89-98.

161. Swanson CA, Burns JC, Peterson BM. Low Plasma D-Dimer Concentration Predicts the Absence of Traumatic Brain Injury in Children. J Trauma. 2010;68(5):1070-7.

162. Pieter E Vos. Biomarkers of focal and diffuse traumatic brain injury. Crit Care. 2011;15:183.

163. Ingebrigtsen $\mathrm{T}$, Romner B. Biochemical serum markers of traumatic brain injury. $\mathrm{J}$ Trauma. 2002;52(4):798-808.

164. Marchi N, Cavaglia M, Fazio V, Bhudia S, Hallene K, Janigro D. Peripheral markers of blood-brain barrier damage. Clin Chim Acta. 2004;342(1):1-12.

165. Papa L, Ramia MM, Kelly JM, Burks SS, Pawlowicz A, Berger RP. Systematic review of clinical research on biomarkers for pediatric traumatic brain injury. $\mathrm{J}$ Neurotrauma. 2013 Mar 1;30(5):324-38.

166. Berger RP, Beers SR, Richichi R, Wiesman D, Adelson PD. Serum Biomarker Concentrations and Outcome after Pediatric Traumatic Brain Injury. J Neurotrauma. 2007 Dec;24(12):1793-801.

167. Raabe A, Grolms C, Kelle1 M, Èhnert J Do, Sorge O, Seifert V. Correlation of Computed Tomography Findings and Serum Brain Damage Markers Following Severe Head Injury. Acto Neurochir. 1998;140:797-792.

168. Rothoerl, Ralf D. MD; Woertgen, Chris MD; Holzschuh, Matthias MD; Metz, Christoph MD; Brawanski, Alexander MD P. S-100 Serum Levels after Minor and Major Head Injury. J Trauma Inj Infect Crit Care. 1998;45(4):765-7.

169. Linda Papa M, et al. Ubiquitin C-terminal hydrolase is a novel biomarker in humans for severe traumatic brain injury. Crit Care Med. 2010;38:138-44.

170. Mondello S, Robicsek SA, Gabrielli A, Brophy GM, Papa L, Tepas J, et al. aII- 
Spectrin Breakdown Products (SBDPs): Diagnosis and Outcome in Severe Traumatic Brain Injury Patients. J Neurotrauma. 2010;27:1203-13.

171. Gaiottino J, Norgren N, Dobson R, Topping J, Nissim A, Malaspina A, et al. Increased Neurofilament Light Chain Blood Levels in Neurodegenerative Neurological Diseases. PLoS One. 2013;8(9):1-9.

172. Graham R, Mancher M, Wolman DM, Greenfield S, Steinberg E. Clinical Practice Guidelines We Can Trust. National Academy of Sciences. 2011.

173. Velasco R, Arribas M, Valencia C, Zamora N, Fernández SM, Lobeiras A, et al. Adecuación del manejo diagnóstico del traumatismo craneoencefálico leve en menores de 24 meses a las guías de práctica clínica de PECARN y AEP. Anales de Pediatría. 2015;83(3):166-72.

174. Icelle H Aydel MJ, Harles P Reston CA, Revor M Ills TJ, Amuel Uber SL, Rick Laudeau EB, Eter D E B Lieux PM, et al. Indications for computed tomography in patients with minor head injury. N Engl J Med. 2000;343:100-5.

175. Dayan PS, Holmes JF, Atabaki S, Hoyle J, Tunik MG, Lichenstein R, et al. Association of traumatic brain injuries with vomiting in children with blunt head trauma. Ann Emerg Med. 2014;63(6):657-65.

176. Babl FE, Borland ML, Phillips N, Kochar A, Dalton S, McCaskill M, et al. Accuracy of PECARN, CATCH, and CHALICE head injury decision rules in children: a prospective cohort study. Lancet. 2017 Jun 17;389(10087):2393-402.

177. Simma B, Lütschg J, Callahan JM. Mild head injury in pediatrics: algorithms for management in the ED and in young athletes. Am J Emerg Med. 2013;31:1133-8.

178. Schonfeld D, Bressan S, Da Dalt L, Henien MN, Winnett J a, Nigrovic LE. Pediatric Emergency Care Applied Research Network head injury clinical prediction rules are reliable in practice. Arch Dis Child. 2014;99(5):427-31.

179. Nishijima DK, Yang Z, Urbich M, Holmes JF, Zwienenberg-Lee M, Melnikow J, et al. Cost-effectiveness of the PECARN rules in children with minor head trauma. Ann Emerg Med. 2015;65(1):72-80.

180. Atabaki SM, Hoyle JD, Schunk JE, Monroe DJ, Alpern ER, Quayle KS, et al. Comparison of Prediction Rules and Clinician Suspicion for Identifying Children With Clinically Important Brain Injuries After Blunt Head Trauma. Macy ML, editor. Acad Emerg Med. 2016 May;23(5):566-75. 
181. Bressan S, Romanato S, Mion T, Zanconato S, Da Dalt L. Implementation of adapted PECARN decision rule for children with minor head injury in the pediatric emergency department. Acad Emerg Med. 2012;19(7):801-7.

182. Crowe L, Anderson V, Babl FE. Application of the CHALICE clinical prediction rule for intracranial injury in children outside the UK: impact on head CT rate. Arch Dis Child. 2010;95(12):1017-22.

183. Gerdung C, Dowling S, Lang E. Review of the CATCH study: a clinical decision rule for the use of computed tomography in children with minor head injury. CJEM. 2012 Jul;14(4):243-7.

184. S. Easter J, Bakes K, Dhaliwal J, Miller M, Caruso E, S. Haukoos J. Comparison of PECARN, CATCH and CHALICE Rules for Children with minor head injury: a prospective cohort study. Ann Emerg Med. 2014;64(12):145-52.

185. Lyttle MD, Crowe L, Oakley E, Dunning J, Babl FE. Comparing CATCH, CHALICE and PECARN clinical decision rules for paediatric head injuries. Emerg Med J. 2012;29(10):785-94.

186. Holmes MW, Goodacre S, Stevenson MD, Pandor A, Pickering A. The costeffectiveness of diagnostic management strategies for adults with minor head injury. Arch Dis Child. 2012;43(9):1423-31.

187. Nigrovic LE, Schonfeld D, Dayan PS, Fitz BM, Mitchell SR, Kuppermann N. Nurse and Physician Agreement in the Assessment of Minor Blunt Head Trauma. Pediatrics. 2013;132:e689-94.

188. Pickering A, Harnan S, Fitzgerald P, Pandor A, Goodacre S. Clinical decision rules for children with minor head injury: a systematic review. Arch Dis Child. 2011;96(5):414-21.

189. Nigrovic LE, Schunk JE, Foerster A, Cooper A, Miskin M, Atabaki SM, et al. The effect of observation on cranial computed tomography utilization for children after blunt head trauma. Pediatrics. 2011;127(6):1067-73.

190. Hawley C, Wilson J, Hickson C, Mills S, Ekeocha S, Sakr M. Epidemiology of paediatric minor head injury: Comparison of injury characteristics with Indices of Multiple Deprivation. Injury. 2013 Dec 1;44(12):1855-61.

191. Nigrovic LE, Lee LK, Hoyle J, Stanley RM, Gorelick MH, Miskin M, et al. Prevalence of Clinically Important Traumatic Brain Injuries in Children With 
Minor Blunt Head Trauma and Isolated Severe Injury Mechanisms. Arch Pediatr Adolesc Med. 2012;166(4):356-61.

192. Lorton F, Levieux K, Vrignaud B, Hamel O, Jehlé E, Hamel A, et al. Actualisation des recommandations pour la prise en charge du traumatisme crânien léger chez l'enfant. Arch Pédiatrie. 2014;21(7):790-6.

193. De Kruijk JR, Nederkoorn PJ, Reijners En EPJ, Hageman G. Herziene richtlijn "Opvang van patiënten met licht traumatisch hoofd-hersenletsel." NED TIJDSCHR GENEESKD. 2012;156(A4195):1-6.

194. NICE. Head injury: assessment and early management. Clinical guideline. [Internet]. 2017 [cited 2018 Jan 8]. Available from: nice.org.uk/guidance/cg176

195. Elliot Fishman. Cycling as transport. Transp Rev. 2016;36(1):1-8.

196. Fietsersbond D. Fietsersbond onderzoekt: helpt de helm? (The Dutch Cyclists' Union asks: does the helmet help?) (in Dutch). [Internet]. 2013 [cited 2011 Jul 20]. Available from: https://www.fietsersbond.nl/nieuws/fietsersbond-onderzoekthelpt-de-helm/

197. BBC News. Why is cycling so popular in the Netherlands? BBC News [Internet]. 2013 [cited 2017 Nov 28]; Available from: http://www.bbc.com/news/magazine23587916

198. Tunthanathip T, Phuenpathom N. Impact of Road Traffic Injury to Pediatric Traumatic Brain Injury in Southern Thailand. J Neurosci Rural Pract. 2017;8(4):601-8.

199. Wheeler-Martin K, Mooney SJ, Lee DC, Rundle A, DiMaggio C. Pediatric emergency department visits for pedestrian and bicyclist injuries in the US. Inj Epidemiol. 2017;4(1):31.

200. Andrew J. Schneier, Brenda J. Shields, Sarah Grim Hostetler, Huiyun Xiang, Gary A. Smith. Incidence of Pediatric Traumatic Brain Injury and Associated Hospital Resource Utilization in the United States. Pediatrics. 2006 Aug;118(2):483-92.

201. Boletín Oficial del Estado. Maltrato Infantil en la familia en España. Ministerio de Sanidad, Política Social e Igualdad [Internet]. 2011 [cited 2017 Dec 2]. Available from:

http://www.observatoriodelainfancia.msssi.gob.es/productos/pdf/malt2011v4_total _100_acces.pdf 
ANEXOS 


\section{ANEXOS}

\subsection{GLOSARIO DE TÉRMINOS}

AEP: Asociación Española de Pediatría

BHE: barrera hematoencefálica

CATCH: Canadian Assesment of Tomography for Childhood Head Injury

CHALICE: Children's Head injury Algorithm for the prediction of Important Clinical Events

DAD: daño axonal difuso

EEG: electroencefalograma

FC: frecuencia cardiaca

FSC: flujo sanguíneo cerebral

GCS: Glasgow Coma Scale; Escala de Coma de Glasgow

GFAP: proteína ácida fibrilar glial

HTIC: hipertensión intracraneal

LCR: líquido cefalorraquídeo

LIC: lesión intracraneal

LICci: lesión intracraneal clínicamente importante

NIRS: near-infrared spectroscopy

$\mathrm{O}_{2}$ : oxígeno

OMS: Organización Mundial de la Salud

OR: odds ratio

PAM: presión arterial media

$\mathrm{PCO}_{2}$ : presión parcial de dióxido de carbono 
PECARN: Pediatric Emergency Care American Research Network

PI: investigadores principales

PIC: presión intracraneal

PPC: presión de perfusión cerebral

REPEM: Research in Pediatric Emergency Medicine

RM: resonancia magnética

RVC: la resistencia vascular cerebral

Rx: radiografía

$\mathrm{SatO}_{2}$ : saturación arterial de oxígeno

SBS: shaken baby síndrome o síndrome del niño agitado

SNC: sistema nervioso central

SSF: suero salino fisiológico

SEUP: Sociedad Española de Urgencias Pediátricas

SU: servicio de urgencias

SUP: servicio de urgencias pediátrico

TA: tensión arterial

TAC: tomografía axial computerizada

TAS: tensión arterial sistólica

TCDB: Traumatic Coma Data Bank

TCE: traumatismo craneoencefálico

TCEL: traumatismo craneoencefálico leve

TEP: Triángulo de Evaluación Pediátrica

UCH-L: hidrolasa de carboxilo terminal de ubiquitina L1

UCI: unidad de cuidados intensivos

UCIP: unidad de cuidados intensivos pediátricos

VPN: valor predictivo negativo

VPP: valor predictivo positivo 


\subsection{NIVELES DE EVIDENCIA}

Grado A: Existe evidencia satisfactoria, por lo general de nivel 1 (meta-análisis o ensayos clínicos randomizados y controlados) que sustenta la recomendación. Hay buena o muy buena evidencia para recomendarla.

Grado B: Evidencias de nivel 2 (ensayos clínicos bien diseñados y controlados aunque no randomizados). Existe evidencia razonable para recomendarla.

Grado C: Existe pobre evidencia. Hallazgos inconsistentes. Deben ser sometidas a la aprobación del grupo de consenso. Después de analizar las evidencias disponibles con relación a posibles sesgos, el grupo de consenso admite y recomienda la intervención.

Grado D: Existe muy pobre evidencia. Evidencia empírica pobre o no sistemática. Los estudios disponibles no pueden ser utilizados como evidencia, pero el grupo de consenso considera por experiencia que la intervención es favorable y la recomienda.

Clasificación de la evidencia científica según el diseño de estudio (tomado de US Preventive Task Force):

I. Evidencia obtenida a partir de al menos un ensayo aleatorizado y controlado diseñado de forma apropiada.

II. Evidencia obtenida de ensayos controlados bien diseñados, sin randomización. Evidencia obtenida a partir de estudios de cohorte o casocontrol bien diseñados, realizados preferentemente en más de un centro o por un grupo de investigación Evidencia obtenida a partir de múltiples series comparadas en el tiempo con o sin intervención

III. Opiniones basadas en experiencias clínicas, estudios descriptivos o informes de comités de expertos. 


\subsection{ENCUESTA DE INCLUSIÓN EN CADA HOSPITAL}

- Número de pacientes < 2 años de edad atendidos en el SU en 2011, 2012, 2013 y 2014

- Número de pacientes $\geq 2$ años y $\leq$ años de edad atendidos en el SU en 2011, 2012, 2013 y 2014

- ¿Su hospital es un hospital pediátrico o general?

- Pediátrico

- General

- ¿Es un hospital universitario?

- $\mathrm{Si}$

- No

- No lo sé

- ¿Hay un SU mixto (adultos y niños)?

- $\mathrm{Si}$

- No

- No lo sé

- ¿Hay un SU específico de Pediatría?

- $\mathrm{Si}$

- No

- No lo sé

- Si hay un SU pediátrico, ¿hay un equipo específico de personal de Urgencias Pediátricas?

- $\mathrm{Si}$

- No

- No lo sé

- ¿Hay en todo momento al menos 1 pediatra en el SU con especialización en Urgencias Pediátricas?

- $\mathrm{Si}$

- No

- No lo sé 
- ¿Su hospital tiene Servicio de Neurocirugía?

- $\mathrm{Si}$

- No

- No lo sé

- ¿Su hospital tiene Unidad de Cuidados Intensivos Pediátricos?

- $\mathrm{Si}$

- No

- No lo sé

- ¿Quién atiende habitualmente al TCE pediátrico en su hospital?

- Pediatra especialista en Urgencias Pediátricas

- Pediatra General

- Médico de Urgencias (adultos)

- Médico general

- Neurocirujano

- Neurólogo

- Otros (explicar) 


\subsection{HOJA DE RECOGIDA DE DATOS}

Patient code:

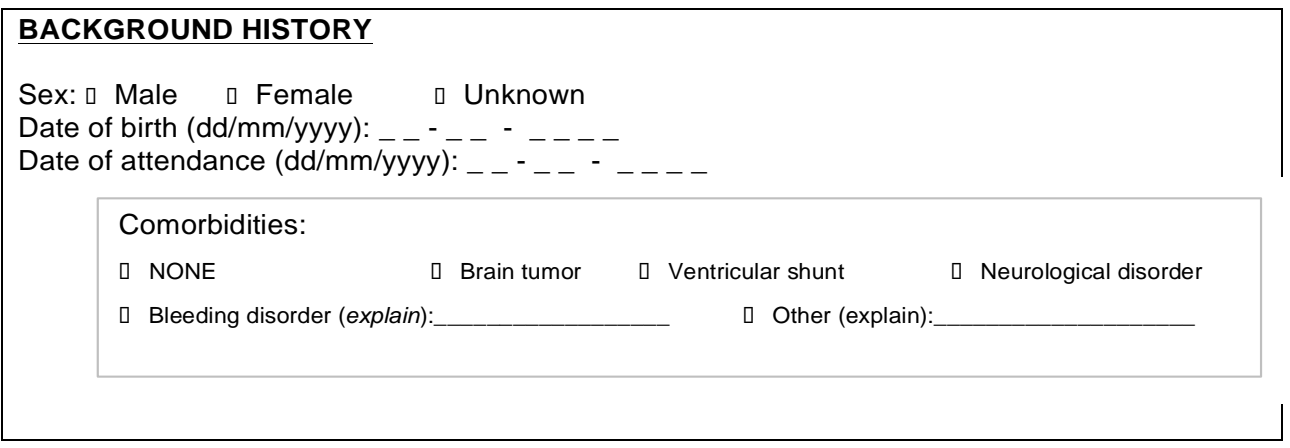

\section{TRAUMA CHARACTERISTICS}

Does it fulfill Trivial Head Trauma Criteria?

$\begin{array}{lllll}\text { Criteria I } & \square \text { Yes } & \text { No } & \text { a Unknown } \\ \text { Criteria II } & \square \text { Yes } & \text { a No } & 0 \text { Unknown }\end{array}$

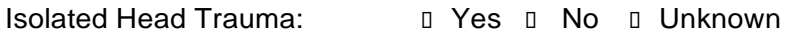

If yes, please describe associated injuries:

Time elapsed since trauma and presentation in ED (hh:mm):

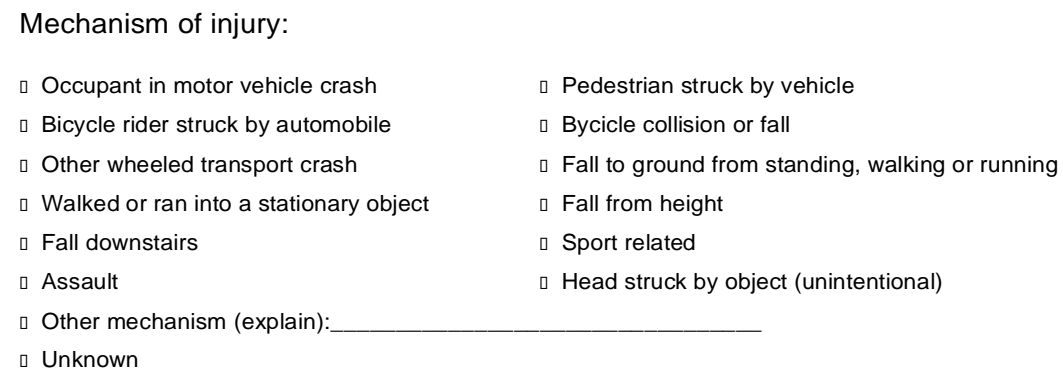

If fall from height:

$$
\begin{aligned}
& \text { u No or } \leq 90 \mathrm{~cm} \text { (or }<3 \text { feet) } \\
& \text { ․ } 91 \mathrm{~cm}-152 \mathrm{~cm}(3-5 \text { feet) } \\
& \text { ( ) } 153 \mathrm{~cm}-305 \mathrm{~cm}(6-10 \mathrm{feet}) \\
& \text { 口 }>305 \mathrm{~cm} \text { (> } 10 \text { feet) }
\end{aligned}
$$

If fall from stairs:

$$
\begin{aligned}
& \text { प } 5 \text { steps or less } \\
& \square \quad 6-15 \text { steps } \\
& \text { प }>15 \text { steps } \\
& \text { प Unknown }
\end{aligned}
$$

\begin{tabular}{|c|c|c|c|c|c|c|}
\hline Loss of conciousness? & . & Yes & $\square$ & No & Q & Unknown \\
\hline Repetitive vomiting? (> 3 vomits) (patients $>2$ years old). & $\ldots$ & Yes & $\square$ & No & Q & Unknow \\
\hline Acting normally according to parent? & $\ldots$ & Yes & $\square$ & No & Q & Unknou \\
\hline Seizure? & . & Yes & 0 & No & ૫ & Unknov \\
\hline Amnesia? (patients $>2$ years old) $\ldots .$. & . & Yes & 0 & No & 0 & Unkno \\
\hline Headache? (patients > 2 years old).. & . & Yes & 0 & No & Q & Unkno \\
\hline Dizziness? & 0 & Yes & 0 & No & 口 & Unkno \\
\hline
\end{tabular}

Struck with a heavy object?: $\quad$ Yes $\square$ No $\quad$ Unknown
Scalp haematoma:
№ $\quad$ Frontal
(1) Parietal
( Temporal
( Occipital 


\section{PATIENT MANAGEMENT}

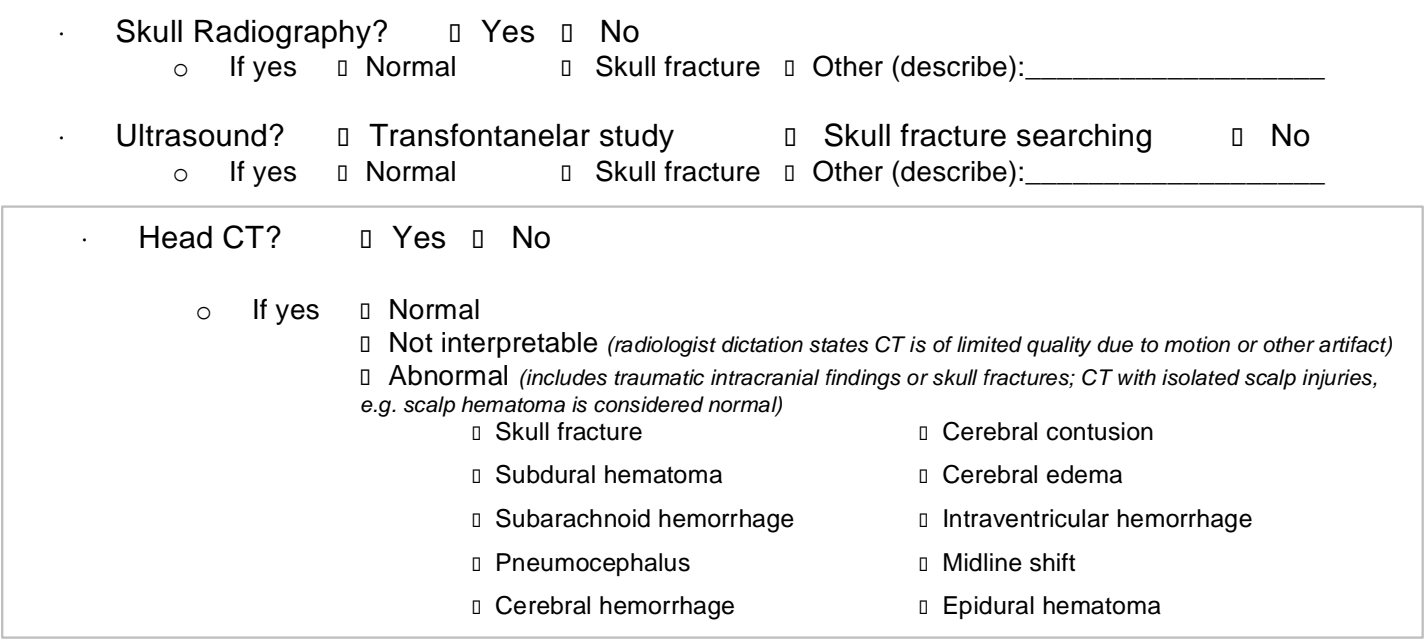

ED Disposition:

$\begin{array}{ll}\text { D Discharged } & \text { Observation unit } \\ \square \text { Admitted into Ward } & \square \text { PICU }\end{array}$

Neurosurgical interventions? $\quad$ Yes $\square$ No

- If yes, check all the apply:
口 Fracture elevation
口 Dura repair for CSF leak
૫ Intracranial Pressure Monitor
口 Hematoma drained

口 Other (explain):

Intubation? (excluding brief intubations for imaging tests) $\quad$ Yes $\square$ No

If admitted into observation unit

- Number of hours:

O During the admission, had a second CT been done? Y Yes $\quad$ No

If admitted into Ward..

- Number of hours:

- During the admission, had a second CT been done? $\quad$ Y $\quad \square \quad$ No

Was the patient attended again in the same ED due to the same MHT? Y Yes $\mathrm{N}$ No

- If yes, did the patient underwent any imaging?

口 Yes 1 No
$\circ$ If yes?
( Skull radiography
प Ultrasound
口 Head CT
- And then? Normal $\square$ Abnormal

\section{OBSERVATIONS:}




\subsection{APROBACIÓN DEL COMITÉ ÉTICO DE INVESTIGACIÓN CLÍNICA}

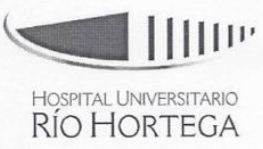

INFORME DEL COMITÉ ÉTICO DE INVESTIGACIÓN CLÍNICA

D. FLORENTINO PINACHO PELAEZ, Secretario del Comité Ético de Investigación Clínica del Hospital Universitario Río Hortega de Valladolid Oeste.

CERTIFICA:

Que este Comité ha conocido la propuesta para que se realice el Estudio Observacional titulado: "Evaluación de la variabilidad en el manejo del traumatismo cráneo encefálico leve en niños en Europa" y considera que:

Se cumplen los requisitos necesarios de idoneidad del protocolo en relación con los objetivos del estudio y están justificados los riesgos y molestias previsibles para el sujeto.

La capacidad del investigador y los medios disponibles son apropiados para llevar a cabo el Estudio.

Y que este Comité acepta que dicho Estudio Observacional sea realizado en el Hospital Universitario del Río-Hortega por el Dr. Roberto Velasco como Investigador Principal.

Lo que firmo en Valladolid, a 19 de Diciembre de 2013

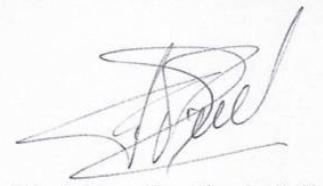

Fdo. D Florentino Pinacho Peláez Secretario CEIC

\section{Sacyl}

HOSPITAL UNIVERSITARIO "RIO HORTEGA COMITÉ ÉTICO DE 